\title{
INFLUÊNCIA DA COBERTURA VEGETAL NA CICLAGEM DE NUTRIENTES VIA SOLUÇÃO DO SOLO NA REGIÃO DE MANAUS - AM
}

\author{
VANIA NEU
}

Dissertação apresentada à Escola Superior de Agricultura “Luiz de Queiroz”, Universidade de São Paulo, para obtenção do título de Mestre em Ecologia de Agroecossistemas.

P I R A C I C A B A

Estado de São Paulo - Brasil

Janeiro - 2005 


\section{INFLUÊNCIA DA COBERTURA VEGETAL NA CICLAGEM DE NUTRIENTES VIA SOLUÇÃO DO SOLO NA REGIÃO DE MANAUS - AM}

\section{VANIA NEU}

Bióloga

Orientador: Prof. Dr. ALEX VLADIMIR KRUSCHE

Dissertação apresentada à Escola Superior de Agricultura “Luiz de Queiroz”, Universidade de São Paulo, para obtenção do título de Mestre em Ecologia de Agroecossistemas.

P I R A C I C A B A

Estado de São Paulo - Brasil

Janeiro - 2005 
Dados Internacionais de Catalogação na Publicação (CIP) DIVISÃO DE BIBLIOTECA E DOCUMENTAÇÃO - ESALQ/USP

Neu, Vania

Influência da cobertura vegetal na ciclagem de nutrientes via solução do solo na região de Manaus - AM / Vania Neu. - - Piracicaba, 2005.

93 p. il.

Dissertação (Mestrado) - - Escola Superior de Agricultura Luiz de Queiroz, 2005.

Bibliografia.

1. Ciclagem de nutrientes 2. Cobertura vegetal 3. Degradação ambiental 4. Ecossistema

5. Fertilidade do solo 6. Física do solo 7. Floresta 8. Química do solo 9. Reflorestamento

I. Título

$\operatorname{CDD} 631.4$

"Permitida a cópia total ou parcial deste documento, desde que citada a fonte - $\mathrm{O}$ autor" 
Aos meus pais Nercio e Iraci, que através da simplicidade, sempre indicaram os melhores caminhos da vida.

E ao meu irmão Vanderlei.

Dedico 


\section{AGRADECIMENTOS}

Aos meus pais, meus orientadores da vida.

Ao Dr. Alex Vladimir Krusche, pela valiosa orientação, apoio, confiança e amizade.

Ao Prof. Dr. Reynaldo Luiz Victoria, pela oportunidade concedida.

Ao Prof. Dr. Marcelo Zacarias Moreira, pelos esclarecimentos e sugestões.

Ao Instituto Nacional de Pesquisas da Amazônia, por todo apoio disponibilizado.

Aos Projetos Jacaranda e LBA, pelo apoio financeiro.

À FAPESP, pela concessão da bolsa de estudo.

Ao Programa de Pós-Graduação em Ecologia de Agroecossistemas (CENA/ESALQ), pela oportunidade.

Ao Dr. João Ferraz, pela orientação e a disponibilização da estrutura laboratorial.

Aos Técnicos do INPA, Pedro Paiva, Anthony Lopes e Manoel Jesus de Souza, pela amizade e importante colaboração na execução das atividades de campo.

Aos Técnicos de Laboratório, Alexandra Montebello, Juliana Santos, Adriane Colombo Liberale, Luiz Silva e Karimi Bentes, pela ajuda nas análises químicas.

Aos pesquisadores Dr. Sávio Ferreira e Dr. Keizo Hirai, pela ajuda e orientação.

Ao amigo Willian Flores, pelas contribuições e orientações.

Ao Dr. Manoel Enrique Guandique, pelas dicas e orientações.

À Dra. Cristiane Tumang Frare, pela amizade e orientação nas análises químicas.

Ao Alailson Santiago, pela ajuda, compreensão e força.

Aos demais Amigos, pelo companheirismo e ajuda. 


\section{SUMÁRIO}

Página

LISTA DE FIGURAS …............................................................................. vii

LISTA DE TABELAS …...................................................................... xii

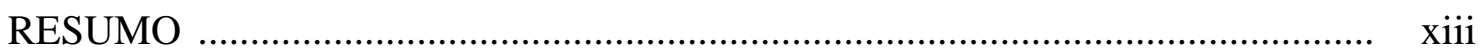

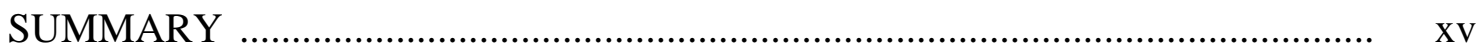

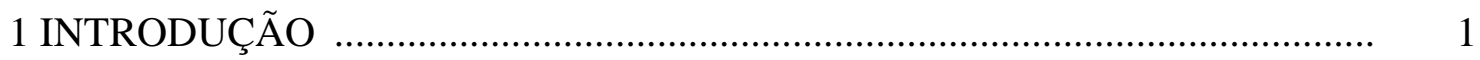

2 REVISÃO DE LITERATURA _.......................................................................

2.1 Caracterização geológica ................................................................................. 3

2.2 Alterações nos ciclos biogeoquímicos em função da conversão de florestas para outras formas de uso e cobertura do solo .............................................................

2.3 Solos e elementos químicos ………………………………………………...

2.4 Matéria orgânica e carbono orgânico dissolvido .................................................. 9

3 MATERIAL E MÉTODOS ........................................................................ 14

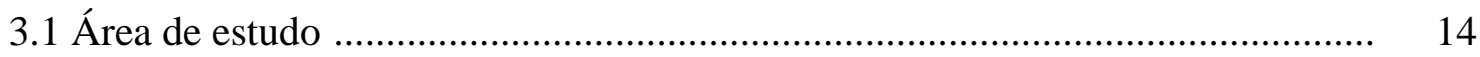

3.1.1 Histórico das áreas e características vegetais ................................................... 18

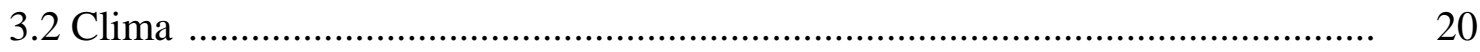

3.3 Métodos de amostragem ........................................................................... 21

3.4 Procedimentos analíticos ............................................................................... 29

3.5 Análise estatística ........................................................................................ 33

4 RESULTADOS E DISCUSSÃO ……………………………………....... 34

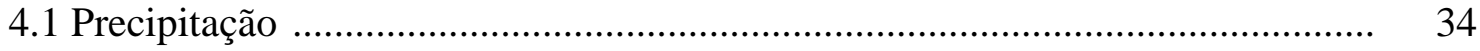

4.2 Caracterização dos solos estudados .................................................................. 35

4.2.1 Caracterização física ...................................................................................... 35

4.2.2 Caracterização química ............................................................................ 37 
4.2.3 Carbono, nitrogênio, $\delta{ }^{13} \mathrm{C}$ e relação C/N no solo ........................................... 41

4.3 Solução do solo ...................................................................................... 45

4.3.1 Carbono orgânico dissolvido .......................................................................... 45

4.3.2 Nitrogênio .............................................................................................. 52

4.3.3 Cátions ................................................................................................... 58

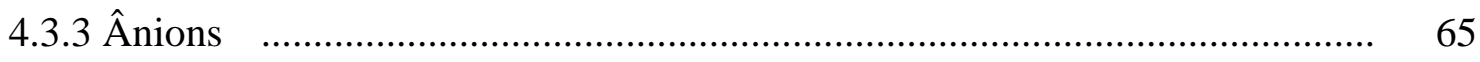

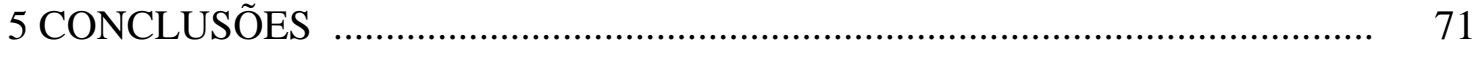

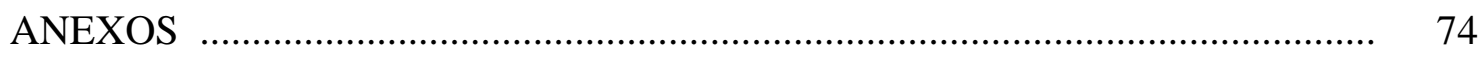

REFERÊNCIAS BIBLIOGRÁFICAS ................................................................ 81 


\section{LISTA DE FIGURAS}

Página

1 Localização geográfica das áreas de estudo na Amazônia Central.

2 Mapa dos municípios de Manaus e Presidente Figueiredo com a localização dos pontos de coleta.

3 Média histórica da temperatura e precipitação (1961-1990), obtidos pela Estação Meteorológica de Manaus.

4 Processo de instalação dos extratores de solução do solo.

5 Extratores de solução de solo para fase inorgânica (A e B); e para fase orgânica (C e D).

6 Desenho esquemático do extrator de tensão utilizado para coleta de solução do solo.

7 Procedimento de amostragem da solução do solo. A a C amostras inorgânicas, preservadas com Thymol (10 mg/100ml); D a F amostras orgânicas, preservadas com HgCl2 (300 $\mu \mathrm{M} \mathrm{Hg).}$

8 Ilustração do procedimento de coleta, filtragem e armazenamento das amostras de solução do solo.

9 Procedimento de coleta da matriz do solo para análise química. Retirada de três amostras simples, a cada profundidade, para formar uma amostra composta. 
10 Pluviômetro com funil captador de água (A); Determinação da massa de água da precipitação em Kg (B) e Balança (C).

11 Equipamentos utilizados para análise da solução do solo. Cromatógrafo Líquido para determinação de cátions e ânions (A); Analisador de Carbono Inorgânico Dissolvido (B); e Analisador de Carbono Orgânico Total (C).

12 Amostras da matriz do solo e equipamentos utilizados para análise química. ... 31

13 Precipitação mensal (2003) e média histórica (1961 - 1990) da região de Manaus.

14 Perfil vertical do gradiente de elevação do relevo na Reserva Florestal (ZF2), no transecto Leste-Oeste, sob floresta primária, com indicação dos pontos amostrais na posição do relevo e o tipo de solo. (adaptado de FERREIRA et al., 2003).

15 Composição granulométrica (\%) dos solos da floresta primária (ZF-2), ao longo do gradiente de elevação.

16 Composição granulométria (\%) das áreas da CAMES (reflorestamento e floresta secundária), e de Presidente Figueiredo (floresta primária e área degradada).

17 Variações dos teores de carbono relacionados com a cobertura vegetal, profundidade e o tipo de solo.

18 Variações dos teores de nitrogênio relacionados com a cobertura vegetal, profundidade e o tipo de solo.

19 Variações da relação $\mathrm{C} / \mathrm{N}$ nos diferentes tipos de solo, cobertura vegetal e profundidades. 
20 Variações do $\delta 13 \mathrm{C}$ \%o nos diferentes tipos de solo, cobertura vegetal e profundidades.

21 Distibuição sazonal das concentrações de COD e a precipitacão durante o período amostral.

22 Concentrações médias de COD e ferro na solução do solo, nos diferentes tipos de solo na floresta primária ZF2.

23 Concentrações médias de COD e alumínio na solução do solo, nos diferentes tipos de solo na floresta primária ZF2.

24 Percentual das frações inorgânicas de nitrogênio na floresta primária e área degradada.

25 Concentrações médias de amônio $[\mu \mathrm{M}]$ e desvio padrão, durante o período chuvoso e seco, na solução do solo, para os diferentes ecossistemas estudados. R= Reflorestamento; FS = Fl. Secundária; DG = A. Degradada com Gramíneas; $\mathrm{AD}=$ Área com maior grau de Degradação; PP = Fl. Primária Platô; PE = Fl. Primária Encosta; PB = Fl. Primária Baixio.

26 Concentrações médias de nitrito $[\mu \mathrm{M}]$ e desvio padrão, durante o período chuvoso e seco, na solução do solo, para os diferentes ecossistemas estudados (Legenda Figura 25).

27 Concentrações médias de nitrato $[\mu \mathrm{M}]$ e desvio padrão, durante o período chuvoso e seco, para os diferentes ecossistemas estudados (Legenda Figura 25).

28 Variações sazonais da precipitação $(\mathrm{mm})$ e concentrações de nitrato $[\mu \mathrm{M}]$ na solução do solo. 
29 Variações sazonais da precipitação $(\mathrm{mm})$ e concentrações de nitrito e amônio $[\mu \mathrm{M}]$ na solução do solo.

30 Diagramas ternários elaborados a partir das concentrações médias dos cátions presentes na solução do solo.

31 - Variações sazonais da precipitação $(\mathrm{mm})$ e concentrações de sódio e potássio $[\mu \mathrm{M}]$ na solução do solo.

32 Concentrações médias e desvio padrão das concentrações de sódio $[\mu \mathrm{M}]$ na solução do solo, durante o período seco e chuvoso. $\mathrm{R}=$ reflorestamento; FS= fl. secundária; DG = degradada com gramíneas; $\mathrm{AD}=$ maior grau de degradação; PP = fl. primária platô; $\mathrm{PE}=$ fl. primária encosta; $\mathrm{PB}=$ fl. primária baixio.

33 Concentrações médias e desvio padrão das concentrações de potássio na solução do solo durante o período chuvoso e seco (Legenda Figura 32).

34 - Variações sazonais da precipitação (mm) e concentrações de magnésio e cálcio[ $\mu \mathrm{M}]$ na solução do solo.

35 Concentrações médias e desvio padrão das concentrações de cálcio na solução do solo durante o período chuvoso e seco (Legenda Figura 32).

36 Concentrações médias e desvio padrão das concentrações de magnésio na solução do solo durante o período chuvoso e seco (Legenda Figura 32).

37 Diagramas ternários elaborados a partir das concentrações médias dos ânions, cloreto, sulfato e bicarbonato, presentes na solução do solo.

38 Concentrações médias e desvio padrão das concentrações de bicarbonato na solução do solo durante o período chuvoso e seco. $\mathrm{R}=$ reflorestamento; FS= fl. secundária; $\mathrm{DG}=$ degradada com gramíneas; $\mathrm{AD}=$ maior grau de 
degradação; $\mathrm{PP}=$ fl. primária platô; $\mathrm{PE}=$ fl. primária encosta; $\mathrm{PB}=$ fl. primária baixio.

39 Concentrações médias e desvio padrão das concentrações de sulfato na solução do solo durante o período chuvoso e seco (Legenda Figura 38). ........... 67

40 Variações sazonais da precipitação (mm) e concentrações de cloreto e

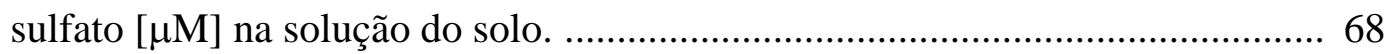

41 Concentrações médias e desvio padrão das concentrações de cloreto na solução do solo durante o período chuvoso e seco(Legenda Figura 38).

42 Concentrações médias e desvio padrão das concentrações de fosfato na solução do solo durante o período chuvoso e seco(Legenda Figura 38). 


\section{LISTA DE TABELAS}

Página

1 Profundidades de coletas (z) da matriz do solo para cada ecossistema estudado.

2 Precipitação total coletada durante o período estudado (2003) e média histórica.

3 Análise química dos solos das áreas de estudo.

4 Concentrações médias e desvio padrão das concentrações de carbono orgânico dissolvido para os perídos seco e chuvoso; pH da solução do solo e teores de ferro e alumínio no solo. 


\title{
INFLUÊNCIA DA COBERTURA VEGETAL NA CICLAGEM DE NUTRIENTES VIA SOLUÇÃO DO SOLO NA REGIÃO DE MANAUS - AM
}

\author{
Autora: VANIA NEU \\ Orientador: Prof. Dr. ALEX VLADIMIR KRUSCHE \\ Co-orientador: Prof. Dr. JOÃO B. FERRAZ
}

\section{RESUMO}

A pesquisa teve como objetivo contribuir para a sustentabilidade das formas de uso dos solos na Amazônia central, avaliando a influência da cobertura vegetal nos teores de nutrientes na solução do solo, ou seja, nos teores de cátions, ânions e carbono orgânico dissolvido (COD). Tomou-se como referência uma floresta primária, para comparação com áreas degradada, de reflorestamento, e de floresta secundária. O estudo foi realizado nos municípios de Manaus e Presidente Figueiredo, AM. Em cada área foram instalados extratores de tensão, nas profundidades de 10, 20, 50, 100 e $150 \mathrm{~cm}$, para as coletas de solução de solo para análise da fase inorgânica, e nas profundidades 20 e $100 \mathrm{~cm}$, para a fase orgânica. A coleta de solo para análise química foi realizada nas mesmas profundidades utilizadas para as coletas de solução do solo da fase inorgânica. As coletas de solução do solo e a quantificação da água da chuva foram realizadas ao longo de um ano hidrológico, seguindo a sazonalidade do clima regional, durante os anos de 2002 e 2003. Após a coleta, filtragem e preservação, as amostras foram encaminhadas ao laboratório para a determinação das concentrações de cátions e ânions por cromatografia líquida (Equipamento Dionex, modelo DX500). As concentrações de COD foram determinadas por combustão, com detecção do $\mathrm{CO}_{2}$ gerado nesta por infra- 
vermelho não-dispersivo (Equipamento Shimadzu, modelo TOC 5000A). A maioria dos solos foi classificada como latossolos, muito ácidos, intemperizados e com baixa disponibilidade de nutrientes. Dos cátions presentes na solução do solo observou-se a predominância sódica-potássica, com grande influência dos aportes atmosféricos. Em relação aos ânions, a predominância foi de bicarbonato e cloreto, com grande contribuição da atividade biológica nas concentrações de bicarbonato em áreas cobertas por vegetação, e do aporte atmosférico nas concentrações de cloreto nas áreas sem cobertura vegetal. A vegetação apresentou forte influência na dinâmica dos íons, principalmente para nitrogênio, fósforo, potássio e magnésio, que apresentam como principal fontes a reciclagem da matéria orgânica e a transprecipitação. Na área degradada ocorreu predominância de cloreto e sódio, elementos que apresentam como principal fonte de entrada a precipitação. Na floresta secundária e no reflorestamento observou-se sinais de recuperação, com níveis mais elevados de nutrientes do que observado na área degradada, com destaque para aumentos significativos de COD e nitrato. Não somente a vegetação afetou a dinâmica dos íons avaliados, mas também a textura do solo, acidez, profundidade e precipitação. Para o carbono orgânico dissolvido observou-se enriquecimento à $100 \mathrm{~cm}$ de profundidade, provavelmente em função dos menores teores de ferro e alumínio em profundidade no solo. Este aumento em profundidade pode estar indicando uma ligação entre os sistemas terrestre e aquático, na qual o primeiro funciona como possível exportador de carbono para o segundo. 


\title{
INFLUENCE OF VEGETATION COVER ON NUTRIENT CYCLING IN SOIL SOLUTION AT THE AREA OF MANAUS - AM
}

\author{
Author: VANIA NEU \\ Adviser: Prof. Dr. ALEX VLADIMIR KRUSCHE \\ Co-Adviser: Prof. Dr. JOÃO B. FERRAZ
}

\section{SUMMARY}

The main objective of this study was to contribute for the sustainability of land use in the central Amazon, evaluating the influence of vegetation cover on nutrient concentrations in soil solution that is, on the amounts of cations, anions and dissolved organic carbon (DOC). Using a primary forest as reference, we compared these concentrations with those in a degraded area, in a reforestation and also in a secondary forest. The study was conducted in the counties of Manaus and Presidente Figueiredo. In each site we collected soil solution using tension lysimeters installed at the depths of 10, 20, 50, 100 and $150 \mathrm{~cm}$ for the inorganic phase and at 20 and $100 \mathrm{~cm}$ for the analysis of the organic phase. The soil itself was also collected at the same depths used for the study of the inorganic phase of soil solution, to determine its structure and chemical composition. Soil solution and precipitation were collected during a hydrological year, following the regional climate seasonality in the years of 2002 and 2003. After sampling, filtering and preserving in the field, soil solution samples were sent to the laboratory for the determination of cation and anion concentrations by liquid chromatography (Dionex, DX500) and DOC concentrations in a total organic carbon 
analyzer (Shimadzu, TOC5000A). Most of the soils were classified as Oxisols, very acid, highly weathered and with low nutrient availability. Sodium and potassium were the most predominant cations in soil solution, due to the influence of the atmospheric inputs. For anions, bicarbonate and chloride were showed the highest concentrations. At the sites covered with vegetation, biological activity played an important role in bicarbonate concentrations, as opposed to the site without vegetation, in which chloride was predominant, due to atmospheric inputs. There was a good correlation between vegetation cover and the dynamics of nitrogen, phosphorus, potassium and magnesium, all of which have as the main source recycling of organic matter recycling and throughfall. At the degraded area, chloride and sodium predominated, due to their main source, which is the precipitation. At the secondary forest and the reforestation there are indicators of the recovery of pristine conditions, whit higher levels of nutrients than those of the degraded area, specially significant increases in DOC and nitrate concentrations. Not only the vegetation influenced the dynamics of these nutrients in soil solution, but also soil texture, acidity, soil depth and precipitation. DOC, for example, showed significant increases in concentrations at $1 \mathrm{~m}$ depths, probably due to the lowest iron and aluminum concentrations at these soil depths. This increase of DOC with depth may indicate an important connection between terrestrial and aquatic ecosystem, with the acting as an exporter of $\mathrm{C}$ to the rivers of the region. 


\section{INTRODUÇÃO}

As alterações dos ecossistemas florestais da Amazônia têm sido constantes nos últimos anos, levando à formação de áreas degradadas. Avaliações da extensão das áreas desmatadas na Amazônia indicam valores da ordem de $608 \times 10^{3} \mathrm{~km}^{2}$ e, para o estado do Amazonas, valores de 31 x $10^{3} \mathrm{~km}^{2}$ (INPE, 2001). Tais áreas caracterizam-se tanto por uma redução da biodiversidade, como por uma redução da qualidade e fertilidade dos solos (Jordan, 1987), especialmente no que diz respeito aos teores de matéria orgânica e nutrientes (Jordan, 1985; Buschbacher, 1987).

A floresta Amazônica é caracterizada por um sistema com várias formações geológicas, formas de relevo, tipos de vegetação e distribuição da flora, sendo, portanto, uma região muito heterogênea. Predominam na Bacia Amazônica na região de Manaus, sedimentos do terciário denominado de “Grupo Barreiras”, sendo constituídos principalmente por minerais resistentes como caulinita, areia quartzosa e oxiidróxidos de ferro e alumínio (BRASIL, 1978; Chauvel, 1881; 1982; Boulet et al., 1984; Telles, 2003).

O crescimento luxuriante da floresta com alta biomassa sobre solos pobres, pode ser explicado pelas características específicas de seus ciclos biogeoquímicos. Segundo Odum (1972), grande parte dos nutrientes está alocado na biomassa e não no solo, e retorna ciclicamente dentro da estrutura orgânica do sistema. Isso mostra que a matéria orgânica é uma importante fonte de nutrientes para as plantas e para a manutenção da sustentabilidade dos ecossistemas naturais ou manejados na Amazônia (Feigl et al., 1995).

O mais importante mecanismo de conservação de nutrientes nesta floresta é o abundante número de raízes e sua distribuição próximo à superfície do solo, 
principalmente nos primeiros $15 \mathrm{~cm}$ de profundidade, onde ocorre rápida transferência dos nutrientes liberados da serapilheira de volta para a biomassa.

Entretanto, pouco se conhece a respeito da dinâmica de nutrientes na solução de solos degradados e reflorestados na Amazônia Central (Schroth et al., 2000; 2001). Os trabalhos existentes limitam-se a dados em sistemas agroflorestais, em áreas de antigas pastagens e florestas primárias adjacentes (Schroth et al., 2000; 2001). Para florestas primárias e florestas manejadas experimentalmente há, ao norte de Manaus, dados sobre os teores de nutrientes na água da precipitação e na solução dos solos (Ferreira, 1999).

Trabalhos que procuram relacionar de modo mais amplo a distribuição de nutrientes na solução de solos também são raros em outras áreas de florestas tropicais chuvosas dos neotrópicos (Poels, 1987). Neste contexto, e levando em consideração a complexa dinâmica da solução do solo e as diversas dúvidas que ainda existem a respeito deste tema, o presente estudo visa avaliar o estado nutricional e a influência da cobertura vegetal nos teores de nutrientes na solução do solo em áreas degradadas, reflorestamentos e florestas primária e secundária, nas regiões de Manaus e Presidente Figueiredo, AM. 


\section{REVISÃO DE LITERATURA}

\subsection{Caracterização Geológica}

Na região de Manaus, na qual encontram-se as áreas CAMES (Cooperativa Agrícola Mista Efigênio Sales) e Reserva Florestal ZF2, ocorrem apenas os sedimentos da Formação Alter do Chão, interpretada como depósitos de ambiente flúvio-lacustre (Caputo et al., 1972; Cunha et al., 1994). Esta formação caracteriza-se por arenitos feldspáticos-cauliníticos grossos, siltitos e argilitos de coloração avermelhada (Daemon, 1975; Cunha et al., 1994; Nogueira et al., 1997). Nesta unidade encontram-se ainda paleossolos desenvolvidos nos arenitos, caracterizados pelo aspecto mosqueado, gretas de contração profundas e abundantes traços de raízes (Nogueira et al., 1999). Baseado em dados palinomórficos, a idade desta formação é atribuída por Daemon (1975) como sendo Mesoalbiano-Turoniano. Para Travassos \& Barbosa Filho (1990), trata-se de um Albiano-Mioceno. Na região de Presidente Figueiredo, ocorrem rochas sedimentares do Paleozóico inferior. A primeira sedimentação da bacia é de idade Siluriana-Devoniana, representada pelo Grupo Trombetas, constituído, da base para o topo, pelas formações Nhamundá, Pitinga e Manacapuru (Cunha et al., 1994).

A Formação Nhamundá (Caputo, 1984), depositada no Siluriano superior (Cunha et al. 1994), consiste em quartzo-arenitos finos a grossos, com estratificações cruzada, plano-paralela, e folhelhos (Carozzi et al., 1973; Cunha et al., 1994; Nogueira et al., 1997; Soares et al., 1998). Esta unidade ocorre geralmente sob a forma de lajedos e blocos freqüentemente fraturados e falhados, apresentando contato brusco com a Formação Pitinga.

A Formação Pitinga consiste em folhelhos e arenitos finos de ambiente marinho plataformal, depositados do Siluriano superior ao Devoniano inferior (Grahn, 1992; 
Cunha et al., 1994). Os sedimentos da Formação Manacapuru, são constituídos por arenitos com estratificações cruzadas, folhelhos escuros e siltitos, ricos em palinomorfos de idade Devoniano inferior (Carozzi et al., 1973; Caputo, 1984; Grahn, 1992).

\subsection{Alterações nos Ciclos Biogeoquímicos em Função da Conversão de Florestas para Outras Formas de Uso e Cobertura do Solo.}

Nas últimas décadas, os processos de conversão de florestas naturais para outras formas de uso e cobertura do solo se intensificaram na Amazônia. Neste processo, a prática mais comun nesta região é a utilização do fogo, na qual, inicialmente, as florestas são cortadas e queimadas para conversão, quase sempre, em pastagens. Posteriormente, o fogo também continua sendo usado periodicamente para eliminação da sucessão secundária. O emprego dessa técnica leva a grandes perdas de nutrientes, principalmente Carbono (C), Nitrogênio (N) e Cálcio (Ca), transformando uma parte dos estoques orgânicos em cinzas (Kauffman, 1998). Para Bigelow (2004), essa prática também faz com que grande quantidade dos nutrientes seja rapidamente perdida pela lixiviação, uma vez que o solo está desprotegido de vegetação.

Kauffman (1995) também salienta que essa técnica de corte e queima da vegetação deixa o carbono vulnerável, e que cerca de 60 a 70\% desse C acumulado na biomassa é perdido nesses processos. Para McGrant (2001), essas perdas ocorrem através de vários mecanismos, desde a combustão durante o fogo, até a decomposição mais rápida da matéria orgânica, resultando em mudanças na química do solo, no microclima local, e também na quantidade e qualidade do carbono reciclado.

No caso do nitrogênio, com a queima, o equilíbrio do sistema é afetado e a parcela estocada na biomassa retorna rapidamente para atmosfera sob forma de $\mathrm{N}_{2}$ ou $\mathrm{N}_{2} \mathrm{O}$, deixando o solo deficiente em compostos nitrogenados (Brinkmann \& Nascimento, 1973). Para Kauffman (1998), as perdas dependem da intensidade do fogo, geralmente atingem taxas de 50 a $90 \%$ do $\mathrm{N}$ estocado na biomassa acima do solo. 
Em relação ao cálcio, observa-se que grande estoque deste elemento está concentrado na biomassa dos troncos, muitas vezes imobilizado na forma de oxalato de cálcio ou fosfato de cálcio (Brinkmann \& Nascimento, 1973; McGrant, 2001). Estudos têm mostrado que a prática repetitiva de corte e retirada dos troncos da floresta, tanto em regiões tropicais como temperadas, pode deixar o ciclo do cálcio mais vulnerável a perdas e disrupções. Isso se deve à prática de remoção dos troncos inteiros da floresta (Spangenberg, 1999; McGrant, 2001).

A queimada provoca ainda efeitos sobre o $\mathrm{pH}$ do solo e a capacidade de troca de cátions (CTC). Quando as cinzas ricas em bases são incorporadas ao solo, os íons $\mathrm{H}^{+}$são dissociados do complexo de troca, ocorrendo aumento do $\mathrm{pH}$, da capacidade de retenção de cátions e da CTC do solo. O aumento do pH do solo também acarreta decréscimo da capacidade de adsorção do fósforo e aumenta sua concentração na forma trocável (Brady \& Weil, 1999). McGrant (2001), relata que há um aumento substancial da concentração de cátions logo após a queina, que permanecem elevados por cerca de uma década, após corte, queima e a conversão para outros sistemas como agricultura e pastagem.

De forma geral, ao passar de poucos anos, observa-se os resultados negativos da conversão de floresta à pastagem, que acarreta drástica perda da diversidade biológica, da biota nativa, declínio no estoque de nutrientes e aumento da compactação do solo (Kauffmann, 1988). A compactação do solo e a degradação física do mesmo, provoca o decréscimo da penetração de raízes no solo, infiltração de água, facilitando perdas de matéria orgânica e de nutrientes, através da erosão (McGrath, 2001).

\subsection{Solos e Elementos Químicos}

Na região de Manaus, segundo Boulet et al. (1984), são observados dois pólos principais de diferenciação pedológica. São eles: (a) um pólo argiloso, que corresponde aos Latossolos, que dominam os elementos da paisagem na Amazônia Central (IPEAN, 1969;) e; (b) um pólo arenoso, sob o qual encontram-se os Espodossols formados por 
espessas camadas de areia branca e profunda, de textura mais grosseira (Ranzini, 1980; boulet et al., 1984). Ligando estes dois pólos Boulet et al. (1984) também identificaram superfícies intermediárias formadas por Argissolos.

Nessa região, a transição desses solos ocorre de forma gradual ao longo das toposequências. Os Latossolos estão associados predominantemente aos platôs, enquanto os Argissolos às encostas, e os Espodossols aos baixios. No entanto, nos teores de argila é observado grande contraste ao longo destas toposequências, sendo encontrado nos Latossolos teores de 80 a 90\%, enquanto nos Espodossols esses teores não ultrapassam 5\% (Bravard \& Righi, 1988).

Quanto à textura do solo, observa-se também que os Latossolos argilosos apresentam correlação possitiva entre o teor de argila e as concentração dos nutrientes nitrogênio, potássio, cálcio e magnésio, ao contrário ocorre nos Espodossols (Laurance, 1999; McGrant, 2001). Isto decorre das propriedades físicas dos solos arenosos, que apresentam grande permeabilidade e aeração, que favorecem os processos de rápida degradação da matéria orgânica, mineralização e perdas dos nutrientes pela baixa capacidade de adsorção dos elementos à matriz do solo (Brinkmann, 1983).

Para Bravard \& Righi (1988), o decréscimo do conteúdo de argila e, conseqüentemente, o aumento de quartzo em solos localizados em áreas de baixio são devidos aos intensos processos de hidrólise, eluviação e erosão seletiva da fração argila, que são mais intensos durante o período chuvoso. Segundo Santos \& Camargo (1999), com a perda de nutrientes através desses processos, aumenta a liberação de alumínio $\left(\mathrm{Al}^{+3}\right)$ para solução do solo e diminuição do $\mathrm{pH}$, resultando em solos fortemente ácidos e com baixa saturação de bases (Bravard \& Righi ,1988).

Hedin (2003) relata que a intensa produção de ácidos orgânicos nos ecossistemas Amazônicos também favorece o aumento da acidez da solução do solo ( $\mathrm{pH}<5,0$ ), elevação das concentrações de alumínio, e uma redução na disponibilidade de fósforo, potássio, cálcio e magnésio. Estudos realizados por Laurance (1999); Brinkmann \& Nascimento (1973), na região de Manaus, relatam a baixa disponibilidade de fósforo, elemento que aparece em menores concentrações nos solos que apresentam pH entre 3,4 
a 4,5. A forma predominante de fósforo no solo, é a inorgânica, que se liga com alta energia à fração mineral (Novais \& Smyth, 1999).

A deficiência de fósforo disponível no solo também está fortemente relacionada com a cobertura vegetal. Segundo Kauffman (1998), em florestas primárias, 65\% do estoque deste elemento está na biomassa acima do solo. Quando ocorre a conversão de floresta primária à pastagem, este estoque cai para 9\%. O ânion fosfato é o mais afetado quando ocorre a remoção da cobertura vegetal de uma área, devido à origem do mesmo ser basicamente de componentes terrestres, derivados de partículas biológicas, como exudado de raízes e reciclagem da serrapilheira (Berner \& Berner, 1987; Stallard \& Edmond, 1981). Em estudo realizado na região de Manaus Luizão (1989), observou que, através da reciclagem de serrapilheira sobre Latossolos, ocorre a entrada anual de $3 \mathrm{Kg} / \mathrm{ha}$ de fosfato.

De forma geral, para muitos solos da Amazônia os cátions solúveis estão exauridas (Stallard \& Edmond, 1981). O cálcio e o magnésio trocável em solos de floresta primária são observados em concentrações extremamente baixas. Segundo Marrs (1991), a disponibilidade do cálcio no solo é um fator limitante da produtividade e da ciclagem de outros nutrientes, bem como a taxa de mineralização do nitrogênio em florestas de terra firme na Amazônia.

As principais fontes de cálcio solúvel em áreas de floresta na região de Manaus, se originam da decomposição da serrapilheira e da transprecipitação (Brinkmann \& Nascimento, 1973). Cerca de 99\% do cálcio estocado na biomassa acima do solo retorna via reciclagem de serrapilheira que ocorre principalmente durante a estação úmida (Campo et al., 2000), sendo equivalente a uma entrada de $37 \mathrm{Kg} / \mathrm{ha}$ de cálcio (Luizão, 1989). No entanto, em áreas desmatadas e queimadas, as concentrações de cálcio são mantidas por um curto período de tempo, derivado da lixiviação de material remanescente dos processos de corte e queima, que vão sendo perdidos após alguns meses de queima (Brinkmann \& Nascimento, 1973; Kauffman et al., 1995). Por meio de crescimento secundário relativamente denso, os níveis de concentração de cálcio tendem 
a aumentar no solo, devido à contribuição da decomposição da serrapilheira como fonte principal (Brinkmann \& Nascimento, 1973).

O magnésio também apresenta grande contribuição biológica. Luizão (1989), em trabalho realizado na região de Manaus, observou que a principal fonte de magnésio no solo é derivada da reciclagem de serrapilheira, correspondendo a uma entrada anual de 14 Kg/ha de magnésio. Campo et al.,(2000) e FilosO et al.(1999) observaram que, além da reciclagem de serrapilheira, ocorrem entradas significativas de magnésio via transprecipitação.

O potássio apresenta como fonte de maior importância a transprecipitação (Likens \& Bormann, 1977; Berner \& Berner, 1987; Filoso et al., 1999; Campo et al., 2000; Grimaldi et al.2004) e, com participação menos significativa, os exudados de raízes em sistemas cobertos por vegetação (Stallard \& Edmond, 1981). Segundo Luizão (1989), ocorre entrada significativa deste elemento, via ciclagem de serrapilheira em floresta primária de Manaus, valores que correspondem a 15Kg/ha de potássio por ano. Já em áreas desmatadas e queimadas, as cinzas são uma fonte de potássio por poucos anos. Após 6 anos a diponibilidade decresce, devido à grande mobilidade deste elemento, que é perdido rapidamente via solução do solo (Kauffman et al., 1998; Grimaldi et al., 2004).

Quanto ao nitrogênio, observa-se que na região Amazônica existe a tendência natural dos ecossistemas de perder nitrogênio via solução do solo, devido ao intenso mecanismo de lixiviação, drenagem, e os rápidos mecanismos de decomposição (Santos et al., 1975). Em florestas nas quais a disponibilidade de nitrogênio é alta, mudanças sazonais de umidade no solo levam a fluxos de maiores perdas de $\mathrm{N}_{2} \mathrm{O}$ durante a estação chuvosa, enquanto na estação seca, os maiores fluxos são de NO (GARCIA-MONTIEL et al.,2001).

A entrada de nitrogênio ao ecossistema pode ocorrer de várias formas, através da água da chuva, transprecipitação, fixação por leguminosas e subprodutos do metabolismo dos microorganismos (Santos et al., 1975). Mas, a principal fonte deste 
elemento está relacionada à introdução via resíduos orgânicos, sendo, portanto, fortemente afetada com a retirada da cobertura vegetal (Berner \& Berner, 1987).

O ânion nitrato pode retornar ao solo por duas vias, através da nitrificação ou da mineralização. A taxa de mineralização do nitrogênio é correlacionada positivamente com a concentração de matéria orgânica e argila (Smethurst, 2000). Solos de textura fina e altas concentrações de carbono apresentam altas taxas de mineralização líquida de nitrogênio em florestas nativas (Neill et al.,1997; Silver et al., 2000).

Para os processos de nitrificação, as bactérias transformadoras da matéria orgânica são de extrema importância. Neste processo, ocorre inicialmente a liberação de aminas, que são transformadas em amônia gasosa por organismos heterotróficos. A amônia gasosa pode ser perdida parcialmente para a atmosfera, ou transformada em carbonato de amônia, que se apresenta na solução do solo nas formas de amônio e carbonato. O amônio pode ser absorvido pelas plantas, ficar adsorvido ao solo, ou pode continuar a sequência da nitrificação, sendo transformado à nitrito pelas bactérias Nitrossomonas. Neste processo, ocorre a liberação de $\mathrm{H}^{+}$para o meio, sendo esta a fase acidificante do processo de decomposição da matéria orgânica. O nitrito formado é tóxico para as plantas, porém, devido à sua instabilidade, pode sofrer processos de oxiredução, transformando-se rapidamente em nitrato na presença de oxigênio, fração na qual as plantas também absorvem o nitrogênio. No entanto esta fração é facilmente lixiviada do solo, podendo migrar à grandes profundidades (Luchese et al., 2001).

\subsection{Matéria Orgânica e Carbono Orgânico Dissolvido}

Bruening (1996), em trabalhos realizados nas Ilhas da Malásia e Indonésia, uma região Tropical Montanhosa, observou que uma densa massa de raízes, misturada com folhas caídas e húmus, é encontrada na superfície de quase todos os tipos de solos. Os nutrientes da matéria orgânica (MO) morta são eficientemente reciclados e as perdas para a hidrosfera são muito pequenas. A proporção de biomassa de raízes, no total de 
biomassa viva das árvores, é geralmente inversamente proporcional ao decréscimo da fertilidade do solo. Quanto mais pobre o solo, maior a biomassa de raízes, devido à necessidade de otimização do sistema radicular em relação à exploração de nutrientes (Bruening, 1996; Junk, 1997; Silver, 2000). Na Amazônia Central, onde não existe período prolongado de seca, a densidade de raízes finas e sua distribuição no solo concentram-se na camada de húmus do perfil do solo, mostrando ser um importante mecanismo de conservação de nutrientes (Junk, 1997).

Luchese et al. (2001), demonstraram que o pH é um fator que apresenta grande influência sobre a composição química do solo. O carbono orgânico apresenta aumento acentuado com a diminuição do $\mathrm{pH}$ da solução do solo, o qual previne a rápida decomposição da matéria orgânica pelas bactérias. Em pH baixo, os fungos são os principais microorganismos decompositores da MO (Thurman, 1985).

O solo é um importante reservatório de carbono orgânico, compreendendo aproximadamente 2/3 do carbono estocado no ambiente terrestre (Schimel, 1994). Segundo Nepstad et al. (1994), inventários de carbono no solo raramente incluem análises abaixo de $1 \mathrm{~m}$ de profundidade, e o carbono presente em solos profundos é, muitas vezes, ignorado. Nepstad et al. (1994), avaliaram a importância da distribuição de raízes no ciclo do carbono e, através de estimativas do estoque, observaram perdas de carbono. Essa perda é coincidente com a pequena massa de raízes finas e aparente redução da entrada de carbono na superfície do solo em áreas de pastagem degradada. O solo inventariado abaixo de $1 \mathrm{~m}$ de profundidade, apresentou estoques de carbono maiores que aqueles no perfil acima de $1 \mathrm{~m}$. Através dos dados isotópicos foi demonstrado a presença significativa de carbono recente nesta porção do solo.

Quanto às principais adições de carbono ao solo, Duxbury et al. (1989) dividiram o mesmo em compartimentos A e B, sendo que A é formado pela biomassa vegetal viva e B pelos resíduos vegetais, raízes e exudados. A magnitude do compartimento B é diretamente dependente do A. O compartimento B é muito dinâmico; cerca de 80\% do material deste compartimento é liberado, na forma de $\mathrm{CO}_{2}$, pela ação de 
microorganismos, em curto período de tempo (3 a 4 meses), e apenas 20\% torna-se parte dos compostos orgânicos mais estáveis (Cerri, 1986).

Na solução do solo, o carbono orgânico dissolvido é originário da matéria orgânica superficial, ou de material orgânico fossilizado presente no material geológico, e encontra-se em concentrações relativamente baixas. Isso se deve à adsorção do COD à matriz sólida ou aos processos de oxidação, que transformam a MO em dióxido de carbono $\left(\mathrm{CO}_{2}\right)$. Entretanto, quando a solução do solo encontra-se em anaerobiose, o material orgânico pode ser convertido à metano, ou ser perdido na forma de carbono orgânico volátil (Thurman, 1985).

Muitos estudos têm mostrado que o estoque e a ciclagem de carbono estão relacionados com fatores ainda não bem conhecidos como o clima, textura do solo, o tipo de vegetação (SchimeL, 1995), geologia e uso do solo (Nelson, 1993). A textura do solo, ou conteúdo de argila, tende a variar em escala local ao longo da topografia, sendo elemento chave do estoque de carbono do solo e influenciando na disponibilidade e retenção de nutrientes, particularmente em solos altamente intemperizados (Silver et al., 2000; Nelson et al., 1993). Existem grandes diferenças nas concentrações da matéria orgânica dissolvida em águas do solo, principalmente devido às diferenças na textura e na química do solo (McClain et al., 1997). Segundo McDowell, (1984), e McKnight et al. (1992), solos que apresentam teores elevados de óxidos de ferro e alumínio removem carbono orgânico dissolvido da solução do solo. Isso deocorre das reações de adsorção e coprecipitação que acontecem entre estes metais, e o material orgânico presente no solo.

Em estudos realizados na Amazônia brasileira, foram observadas correlações entre a concentração de material orgânico dissolvido nos rios e o tipo de solo da bacia (Sioli, 1984). Portanto, a textura do solo é um dos parâmetros chave da biogeoquímica terrestre, a qual geralmente mostra o aumento da matéria orgânica do solo com aumento do conteúdo de argila em escala regional e global (Nelson et al., 1993; Parton et al., 1993; Schimel, 1994)

A alta concentração de material orgânico dissolvido nos rios de água preta devese ao alto nível de componentes secundários derivados de plantas (Janzen, 1974). Na 
região Amazônica perto de Manaus, a fração de substâncias húmicas presente nas águas pretas são derivadas primariamente da água do solo que drena Espodossols rasos (Leenheer, 1980). A baixa adsorção da matéria orgânica por este tipo de solo, devido ao baixo teor de argila, taxas de decomposição mais lentas, e acúmulo de serapilheira na superfície, são uma fonte contínua de substâncias húmicas solúveis para a solução do solo (janzen, 1974; leenheer, 1980). Nos Latosolos, devido à efetiva adsorção e proteção física da matéria orgânica do solo pelos minerais de argila, com maoir área superficial específica, além de taxas relativamente mais rápidas de decomposição, as águas que drenam os mesmos apresentam baixas concentrações de material orgânico (Leenheer, 1980; Christensen, 1992; McClain et al., 1997). Assim, os solos argilosos podem facilmente formar depósitos de carbono passivo, com ciclagem mais lenta.

Segundo Thurman, (1985); McClain et al. (1997); Batjes et al. (1999); Kalbitz et al. (2001), Fiedler \& Kalbitz (2003), o carbono orgânico dissolvido na solução do solo decresce em profundidade, tanto em Espodossols como em Latossolos, tendo sua percentagem máxima acima de 1m. Dawson (1981), avaliando o COD na água intersticial de solos em Florestas de Washington, encontrou que a concentração de COD também decresce com a profundidade. O mesmo também foi observado por Meyer \& Tate (1983), que quantificaram o COD na água intersticial dos solos de florestas da Carolina do Norte (EUA). Dawson (1981) e Meyer \& Tate (1983) concluiram que a remoção de COD em profundidade é devido à processos de adsorção, processos químicos, e biológicos no solo e na solução do solo.

McClain et al. (1997), em estudo realizado nas proximidades de Manaus, observou que há diferenças significativas entre as concentrações de COD na solução do solo e na água rio. Isso se deve principalmente a textura e a química do solo. O mesmo comparou, ainda, as concentrações de COD na solução dos solos arenosos, os Espodosolos (baixio), e a água dos igarapé que se originam neste tipo de solo. Observaram que não há diferenças significativas entre a concentração de COD na solução de solo dos Espodosolos e na água dos igarapés. Através deste trabalho, 
puderam comprovar a perda de matéria orgânica via solução do solo, principalmente pelos Espodossolos arenosos.

Também foram estimadas por McClain et al. (1997), as perdas de COD para as florestas sobre platôs (Latossolos), que representaram apenas uma pequena porção do total de carbono orgânico anualmente reciclado no sistema ( $0,2 \%)$, ao passo que, nas terras de campina (Espodossolos), as perdas através da solução do solo foram estimadas em 8\% do carbono anualmente reciclado. Estes resultados estão de acordo com afirmações anteriores de Thurman (1985), de que a água do solo pode ser um grande contribuidor para a descarga dos rios e o maior fornecedor de COD para os mesmos. 


\section{MATERIAL E MÉTODOS}

\section{1 Área de Estudo}

A pesquisa foi desenvolvida na região Amazônica, nos municípios de Manaus e Presidente Figueiredo. Foram selecionados quatro diferentes ecossistemas: área degradada (AD); floresta primária (FP); floresta secundária (FS); e reflorestamento (R), conforme as Figuras 1 e 2.

Os locais de coleta foram distribuídos da seguinte forma:

\section{Experimento 1:}

Na Cooperativa Agrícola Mista Efigênio Sales (CAMES), município de Manaus, AM-010, km 41, sobre platô (Latossolo Amarelo), o experimento compreende uma floresta secundária (FS) de aproximadamente 20 anos, após uso agrícola e abandono (02 48' 42.5”'S, 59॰56'18.5” W), e uma área degradada e reflorestada (DR) com Swetenia macrophylla com 3 anos de idade (02 48' 42.3”S, 59 56 ' 16.5 ” W).

\section{Experimento 2:}

Na Estação Experimental de Silvicultura Tropical do Instituto Nacional de Pesquisas da Amazônia ZF-2, cerca de 50 km ao norte de Manaus, BR-174 (Manaus-Boa Vista), a área amostral compreende uma floresta primária (FP), em transecto leste-oeste que acompanha uma toposequência, platô (02 36' 35.1”S, $60^{\circ} 10^{\prime} 58.5^{\prime}$ W), encosta e baixio ( $02^{\circ} 36^{\prime} 44.9^{\prime}$ 'S, $60^{\circ} 11^{\prime} 46.9^{\prime}$ W). Para o

presente estudo o platô foi considerado como área mais alta, o qual está associado à solos muito argilosos (Latossolos Amarelos), as áreas de encosta apresentam solos argilosos (Argissolos) e o baixio, caracteriza-se por solos arenosos (Espodosolos). 


\section{Experimento 3:}

No município de Presidente Figueiredo, cerca de 100 km ao norte de Manaus, a área amostral compreende uma área degradada (AD) na Fazenda Santa Cláudia (0201’31.0”S, 60 01’23.6”), BR-174, km 108, uma área de floresta primária (FP), e uma área degradada com gramíneas (ADG) na Serraria Teixeira (01 56' 20.0” S, 60 01’47.6”W), BR-174 Km 120. Estas áreas estão localizadas regiões platô. 


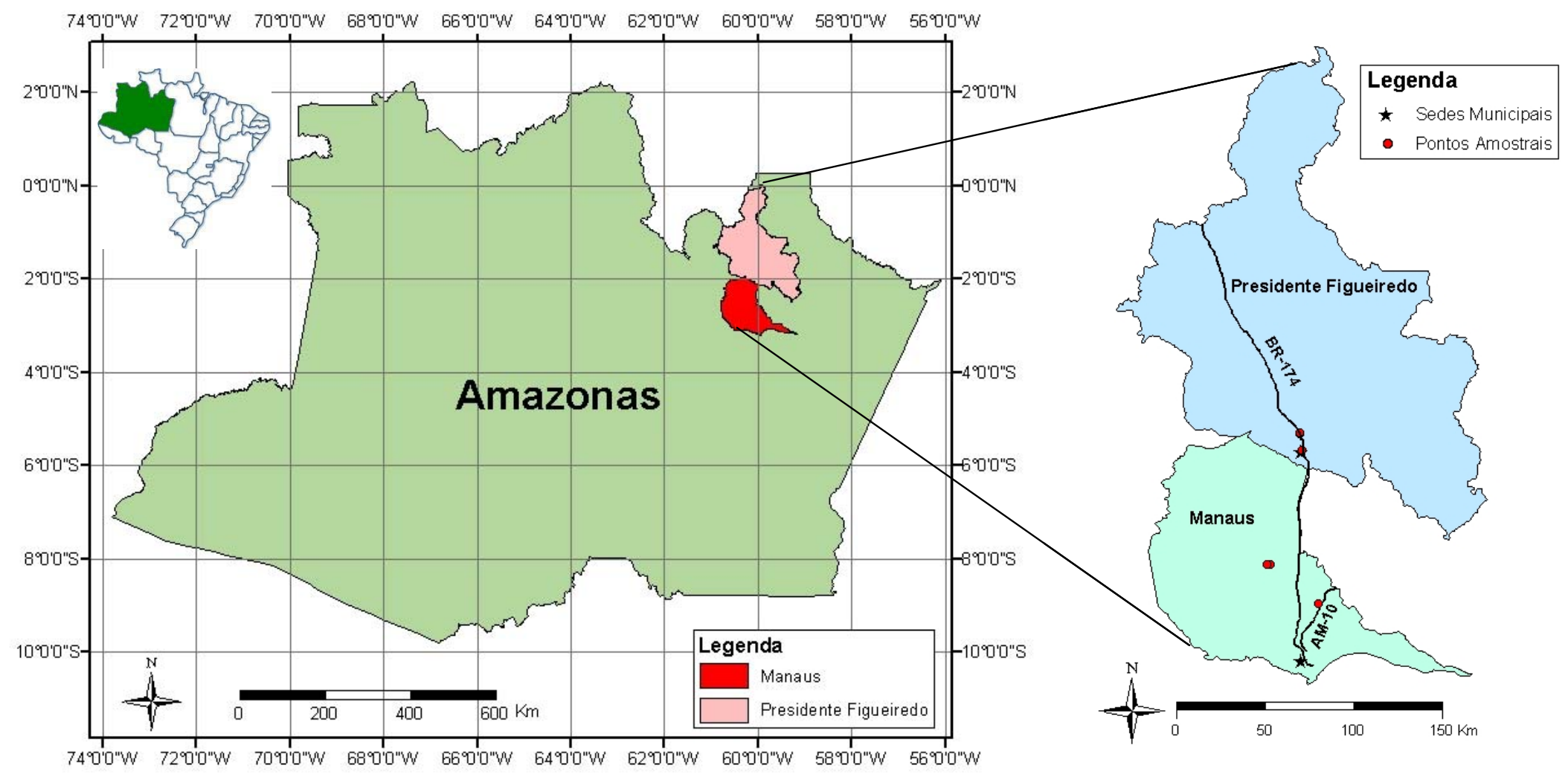

Figura 1 - Localização geográfica das áreas de estudo na Amazônia Central 


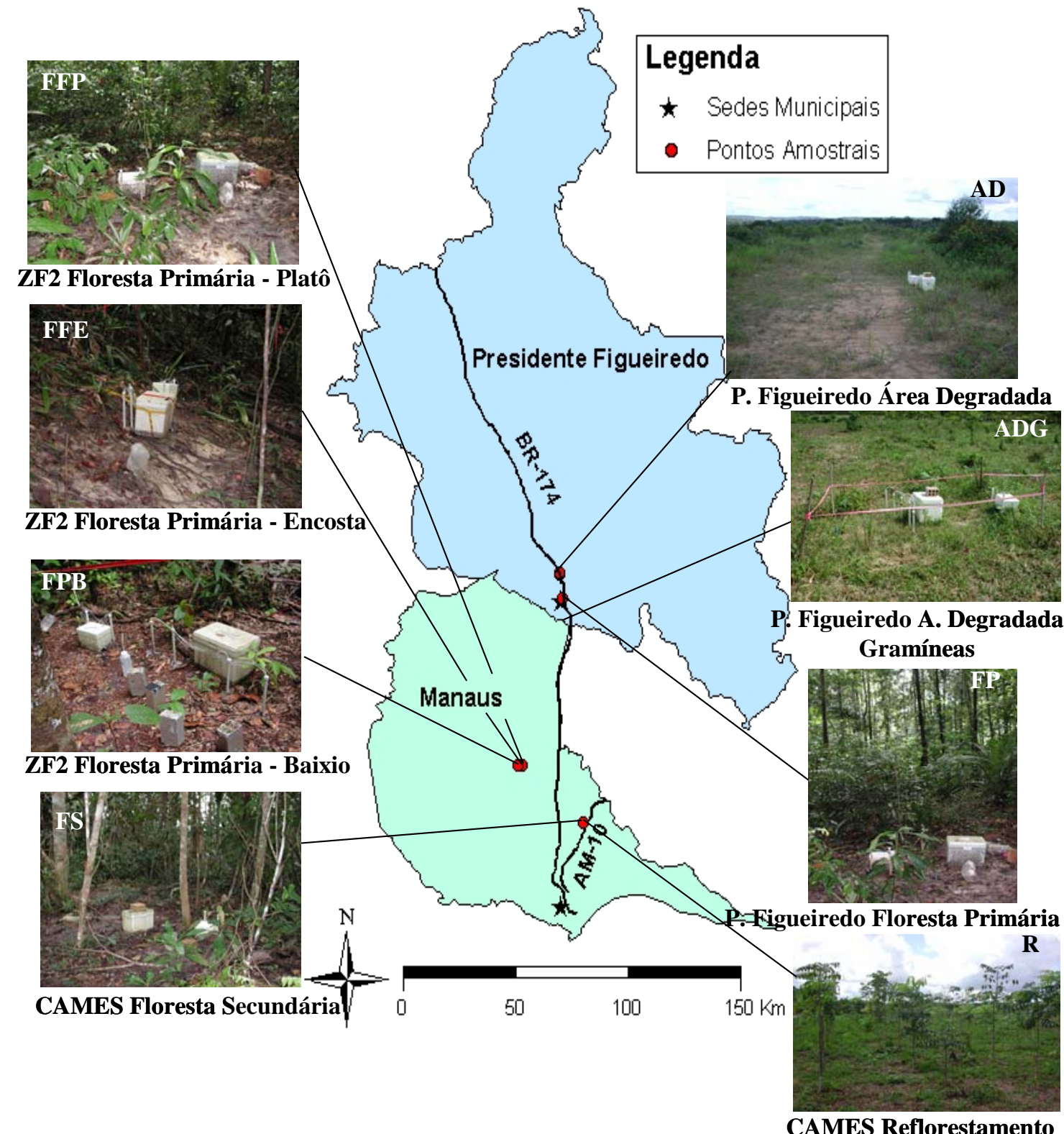

Figura 2 - Mapa dos municípios de Manaus e Presidente Figueiredo com a localização dos pontos de coleta 


\subsubsection{Histórico das Áreas e Características Vegetais}

\section{Experimento 1-CAMES}

Nesta área, a remoção da floresta primária aconteceu em 1958, com a finalidade de cultivar hortaliças e citrus. Devido ao intenso manejo da área com máquinas pesadas, para revolvimento do solo e retirada da vegetação em regeneração, ocorreu a compactação superficial deste solo, o que acarretou em posterior abandono da área.

Uma parcela ficou abandonada e, através da regeneração natural, estabeleceu-se uma vegetação secundária, formada basicamente por árvores do gênero Cecropia $s p$. Posteriormente, houve desenvolvimento de plantas de início de sucessão secundária. No início do período amostral, a floresta secundária estabelecida era composta basicamente, por árvores de pequeno à médio porte.

A outra parcela foi recuperada com a adição de adubos químicos à base de NPK ao solo, com posterior implantação de um reflorestamento com Mogno (Swetenia macrophylla) com espaçamento de 2 × 2 m, em abril de 2000. Após o plantio, adubações a base de NPK continuaram sendo aplicadas periodicamente, a fim de obter melhor sucesso no reflorestamento. Na época em que foram realizadas as coletas as plantas apresentavam uma altura média de $2,5 \mathrm{~m}$.

\section{Experimeto 2 - Reserva Florestal ZF2}

Segundo levantamento realizado por VIEIRA (2003) e CARNEIRO (2004), esta floresta apresenta uma elevada diversidade florística. CARNEIRO (2004) encontrou em sete hectares 737 espécies, 238 gêneros e 59 famílias botânicas. Obtendo uma média de 624 indivíduos arbóreos por hectare, com diâmetro à altura do peito (DAP) maior ou igual a $10 \mathrm{~cm}$.

As famílias que apresentaram maior número de indivíduos foram: Lecythidaceae com, Sapotaceae, Arecaceae, Euphorbiaceae, Burseraceae, Chrysobalanaceae, Fabaceae, 
Caesalpiniaceae, Lauraceae, Mimosaceae, Myristicaceae, Annonaceae, Moraceae, Bombacaceae e Humiriaceae, somando $80,1 \%$ do total de indivíduos amostrados.

Foi observado também que, das 737 espécies encontradas na área, apenas 254 foram comuns as áreas de platô e de baixio, representando 34,0\% do total de espécies registradas (CARNEIRO, 2004). Observando uma grande variação de espécies ao longo das toposequências.

\section{Experimento 3 - Presidente Figuiredo}

A área de estudo localizada na Fazenda Sta. Claudia, em Presidente Figueiredo, estava coberta por floresta primária até 1983, quando foi iniciado o corte seletivo de madeira. No ano seguinte, foi impalntado, uma pastagem com quicuio da Amazônia (Brachiaria humidicula) e posterior introdução de bovinos (CABRAL, com.pes. 2000; 2003).

No ano de 1993, foi introduzido a cultura do guaraná adensado (3 x $3 \mathrm{~m}$ ). No entanto, em 1995 as plantas de guaraná começaram a morrer, devido à grande competição com o quicuio da Amazônia. O solo não estava em boas condições, a compactação do mesmo levou ao acúmulo de água nas covas, com conseqüente apodrecimento das raízes desta cultura. A área do plantio foi então abandonada e estabeleceu-se posteriormente uma vegetação secundária. Nas áreas sobre platô, dominava a vassourinha (Scoparia dulcis), com aproximadamente $1 \mathrm{~m}$ de altura, e nos baixios o lacre (Vismia sp.), com cerca de $3 \mathrm{~m}$ de altura.

Em 1997 a área do baixio, na qual predominava o lacre, foi roçada e queimada. No início do ano 2000, a área foi preparada para plantio florestal, utilizando-se um trator de esteira para remoção da vegetação secundária e parte do solo superficial, para formação de amontoados em leiras.

$\mathrm{Na}$ área da Serraria Teixeira, também em Presidente Figueredo, assim como na Fazenda Santa Cláudia, a área, estava coberta por floresta primária até 1983, quando foi iniciado o corte seletivo de madeira. No entanto em 1985, grande parte da mata já havia sido derrubada e queimada. Em seguida, a área foi abandonada por aproximadamente 
oito anos. No ano de 1991, já havia se formado uma capoeira baixa nesta área. Em agosto-setembro de 1992, foi realizada a limpeza da área, com queima da vegetação regenerada. Em 1993, foram realizados plantios de Brachiaria humidicola, banana e mandioca. Devido à baixa produtividade das espécies introduzidas, o cultivo foi abandonado(Mendes, com pes. 2001). Através da regeneração estabeleceuram-se nesta área, gramíneas, as quais dominam a cobertura atualmente.

\subsection{Clima}

O clima da área de estudo, é do tipo "Afi", segundo a classificação climática de Köppen (1948), referente a um clima megatérmico (tropical úmido) e isotérmico. Pelo diagrama das zonas de vida (Holdridge, 1978) a região, é classificada como Floresta Tropical Chuvosa, sendo a vegetação um dos fatores relevantes na determinação do clima.

Baseado nos dados das Normais Climatológicas (1961-1990), elaborado pelo Instituto Nacional de Meteorologia (INMET, 1992), observou-se que a temperatura média durante este período foi de $26,7^{\circ} \mathrm{C}$, com mínima absoluta registrada de $18,5{ }^{\circ} \mathrm{C}$ e máxima absoluta de 36,2 . A precipitação média anual foi de $2286 \mathrm{~mm}$.

Adotou-se 100 mm mensais como limite para definição da estação seca (Telles, 2003), caracterizando assim os meses de julho à setembro como sendo o período seco na região (Figura 3). 


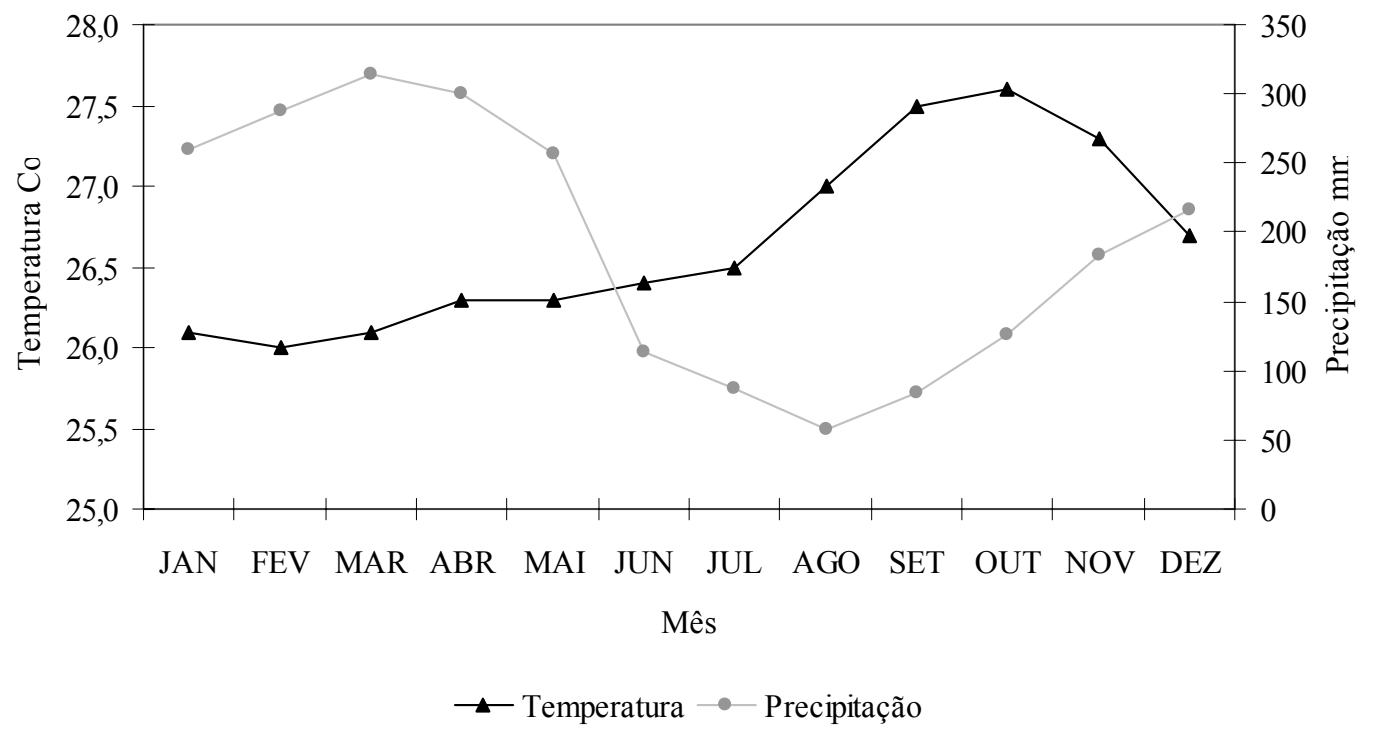

Figura 3 - Média histórica da temperatura e precipitação (1961-1990), obtidos pela Estação Meteorológica de Manaus

\subsection{Métodos de Amostragem}

Para coleta de solução do solo foram utilizados extratores de solução, com cápsulas de cerâmica. Para instalação destes equipamentos foi utilizado trado de rosca, com o qual abriu-se um ducto onde foi colocado o extrator, de maneira que a cápsula tivesse contato o mais próximo possível do solo (Figura 4).

As baterias de extratores, para análise de componentes inorgânicos, cátions e ânions e carbono inorgânico dissolvido, foram instaladas em cinco profundidades: 10, 20, 50, 100 e $150 \mathrm{~cm}$ (Figura 5A e 5B), enquanto para a coleta de amostras destinadas à análise do carbono orgânico dissolvido (COD), foram instalados apenas em duas profundidades: 20 e $100 \mathrm{~cm}$ (Figura 5C e 5D).

$\mathrm{O}$ extrator consiste de um tubo de PVC, com uma cápsula de cerâmica porosa na extremidade que fica em contato com o solo, na profundidade de coleta estabelecida (Figura 6). Essa cápsula coleta solução do solo através da diferença de pressão, 
produzida com bomba de vácuo manual da marca Nalgene (pressão aplicada ao sistema de 0,6 bar).

A instalação dos extratores, para análise da fase inorgânica, foi realizada em maio de 2002, e o período de amostragem compreendeu os meses de junho de 2002 a julho de 2003, com coletas efetuadas semanalmente em cada ponto. No início do período da seca, e transição entre época seca e chuvosa, que compreende os meses de agosto a dezembro de 2003, foram realizadas coletas mensais em cada ponto, devido à pouca disponibilidade de água no solo.

Para fase orgânica os mesmos foram instalados somente na primeira quinzena de março de 2003 e o seu período de amostragem compreendido entre os meses de abril a julho de 2003, com coletas semanais, e de julho a dezembro, com amostragens mensais em cada ponto.

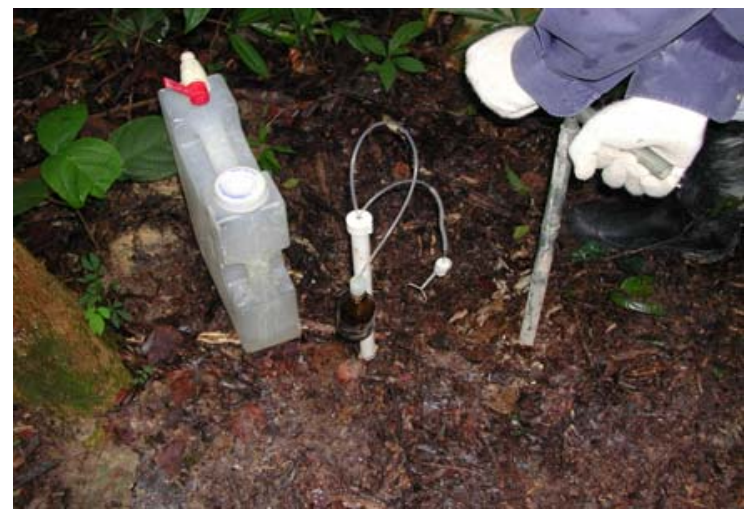

Figura 4 - Processo de instalação dos extratores de solução do solo 


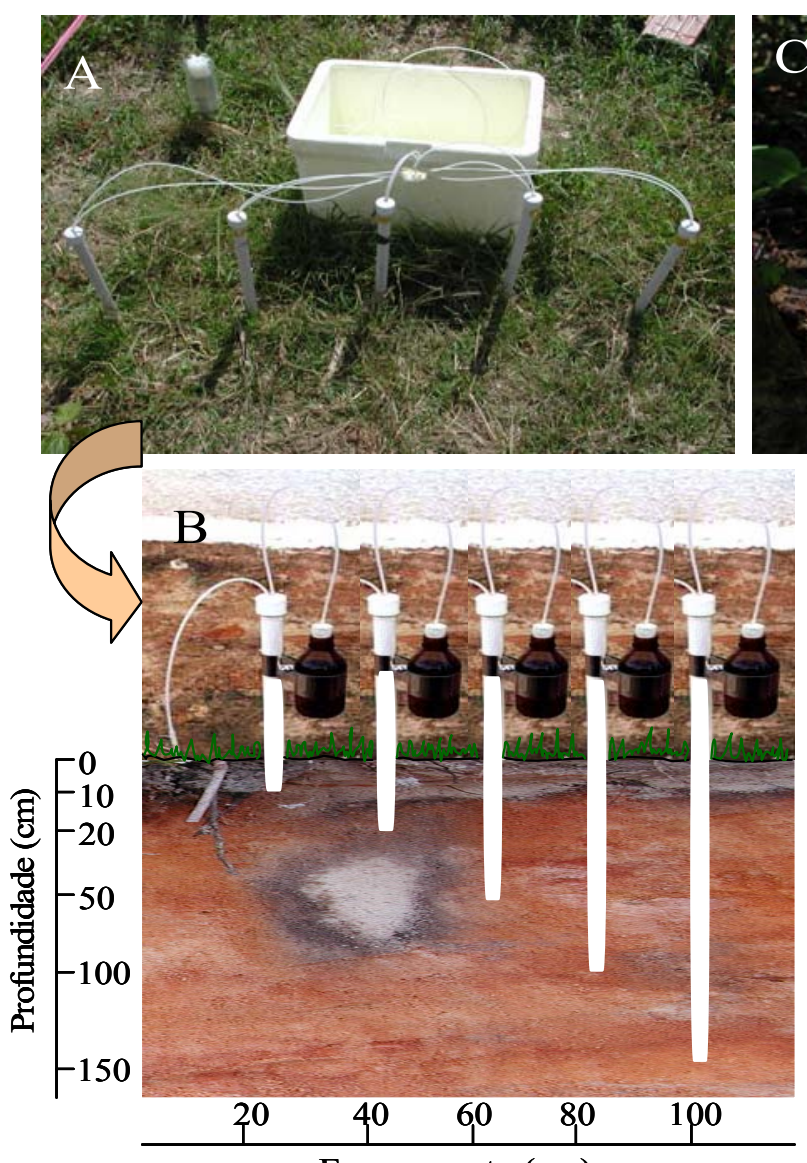

Espaçamento (cm)
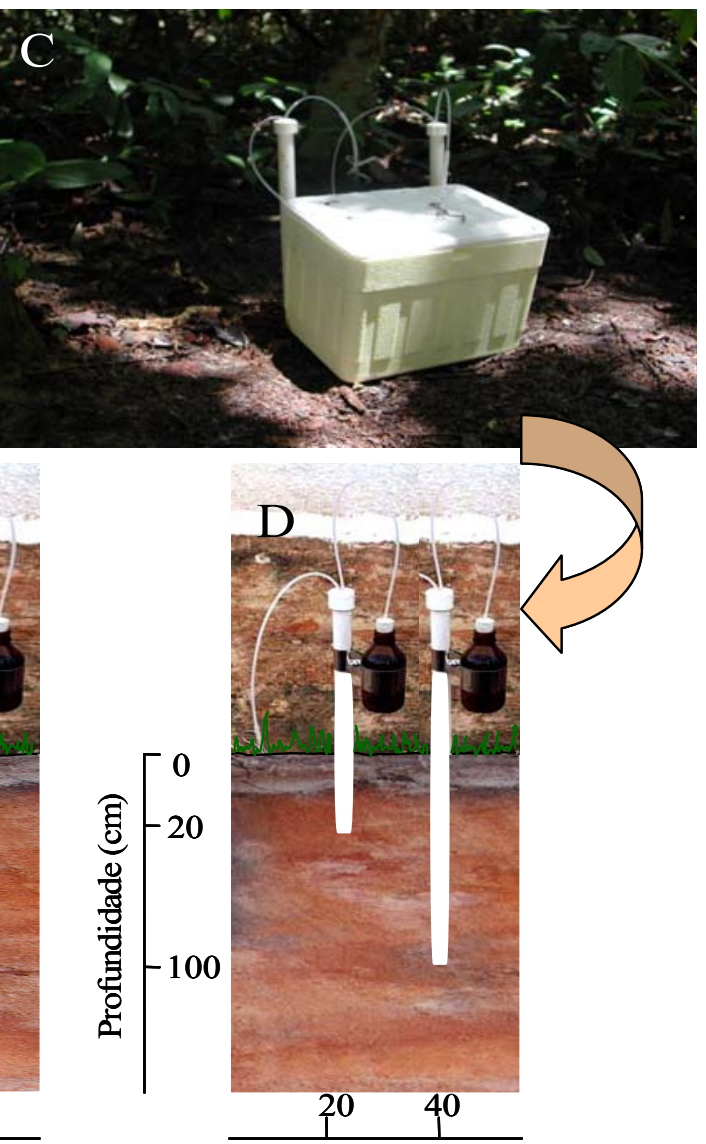

Espaçamento (cm)

Figura 5 - $\quad$ Extratores de solução de solo para coleta da fase inorgânica (A e B); e para fase orgânica $(C$ e D)

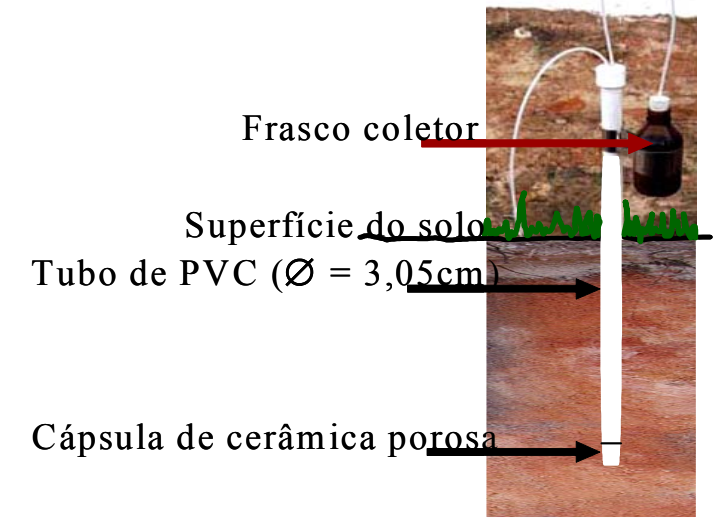

Figura 6 - Desenho esquemático do extrator de tensão utilizado para coleta de solução do solo 
A solução coletada é conduzida através de um tubo fino, até um frasco coletor acoplado ao sistema. O frasco é vedado com rolha de silicone perfurada pelo tubo de coleta; e um segundo tubo, utilizado para manter o sistema sob vácuo permanece vedado até a coleta da amostra. (Figura 7).

Para coleta da fase inorgânica, as amostras receberam como preservante thymol (100 mg/ $1000 \mathrm{ml}$ de solução), a fim de evitar alterações nos teores dos nutrientes devido à atividade biológica. No campo, as amostras foram filtradas com filtro de membrana de nitrato de celulose (porosidade $0,47 \mu \mathrm{m}$ ) e acondicionadas em frascos de polietileno, descontaminados com água ultrapura (Figura 8A).

Para a coleta orgânica, o procedimento é semelhante, alterando somente o preservante, utilizado-se, $\mathrm{HgCl}_{2}$ (concentração final de $300 \mu \mathrm{M}$ de $\mathrm{Hg}$ ). A filtragem das amostras foi realizada com filtros de membrana de fibra de vidro (porosidade de 0,7 $\mu \mathrm{m})$, e as mesmas foram acondicionadas em frascos de vidro. Os filtros e os frascos foram previamente calcinados à temperatura de $500{ }^{\circ} \mathrm{C}$ por aproximadamente 5 horas (Figura 8B). 

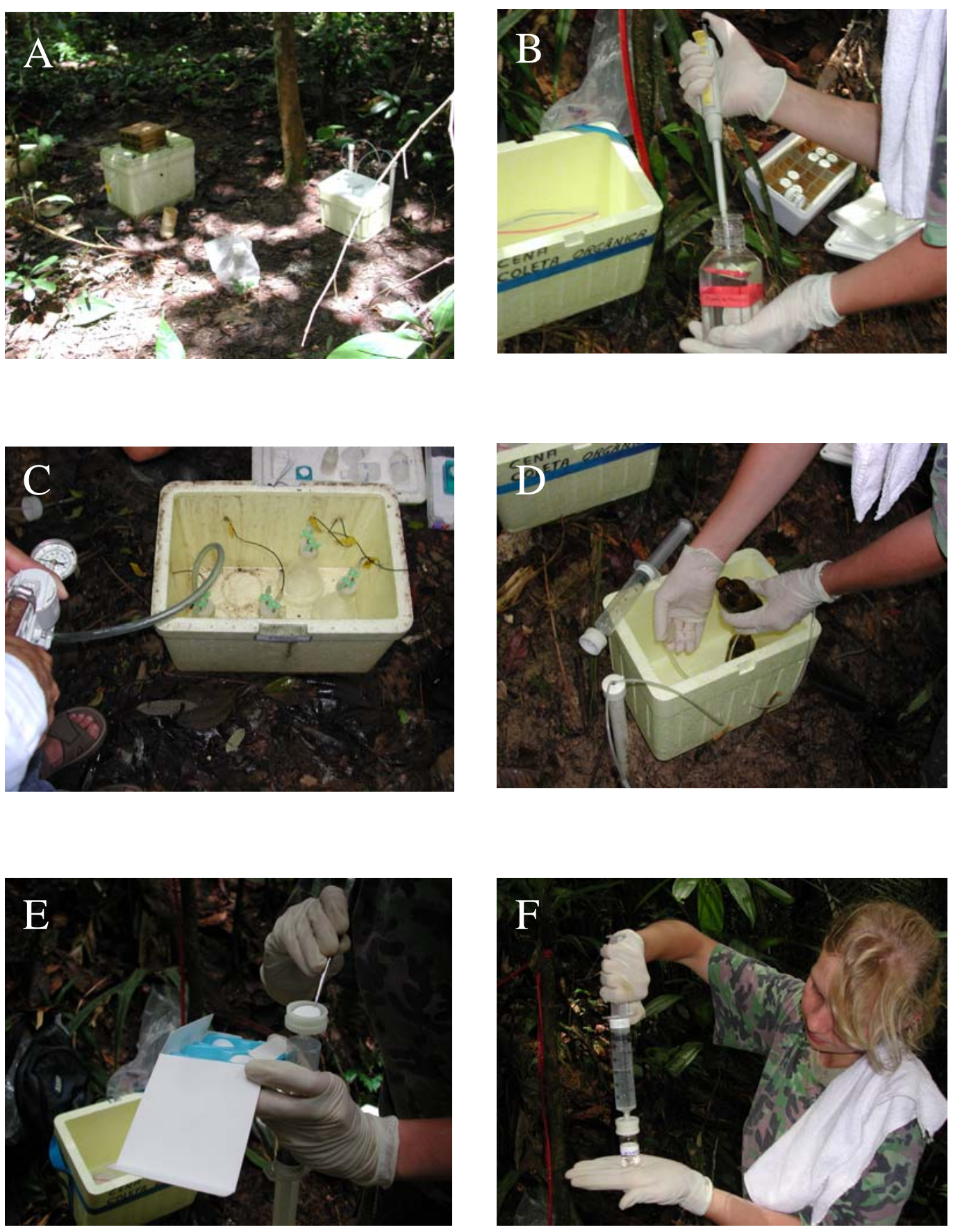

Figura 7 - Procedimento de amostragem da solução do solo. A a C - amostras inorgânicas, preservadas com Thymol (10 mg/100ml); D a F - amostras orgânicas, preservadas com HgCl2 (300 $\mu \mathrm{M}$ Hg) 
A

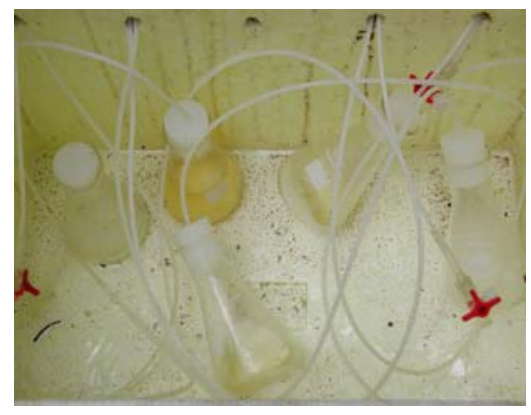

Amostras coletadas p/análise inorgânica

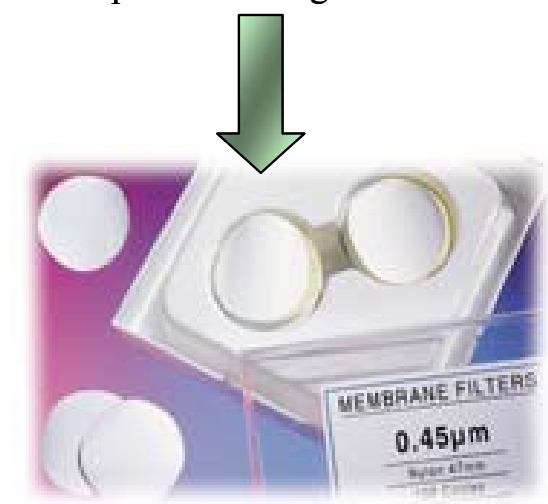

Filtro de nitrato de celulose

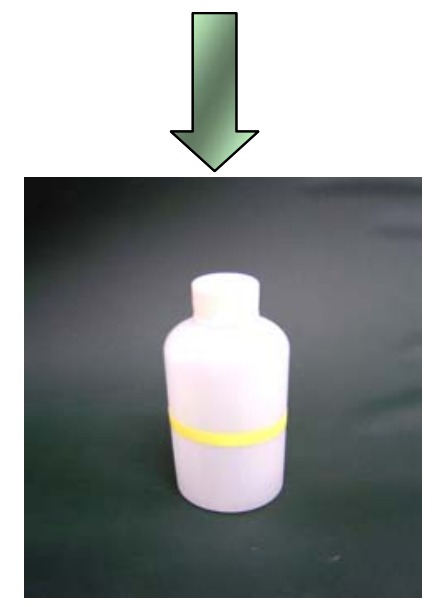

Frasco de polietileno

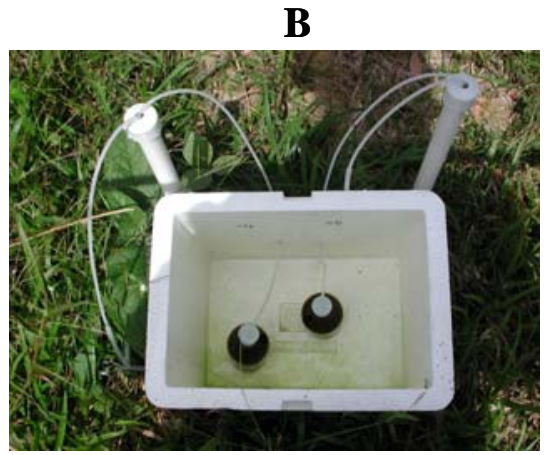

Amostras coletadas p/análise orgânica

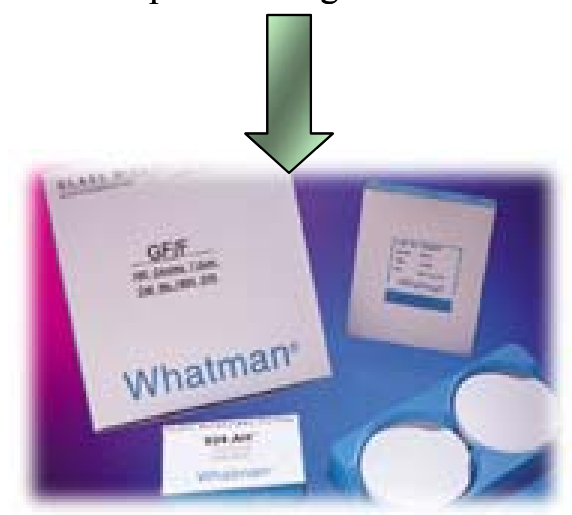

Filtro de fibra de vidro (GF/F)

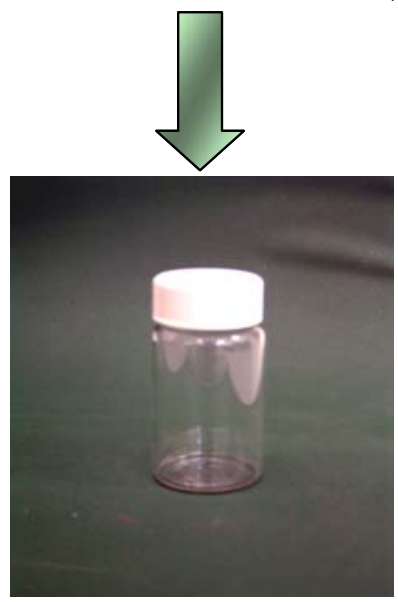

Frasco de vidro

Figura 8 - Ilustração do procedimento de coleta, filtragem e armazenamento das amostras de solução do solo 
As coletas de solo para análise química, foram realizadas nos meses de março e abril de 2003. Em cada ecossistema estudado foram coletadas amostras compostas até $155 \mathrm{~cm}$ de profundidade (Tabela 1). A cada profundidade foram retiradas 3 sub-amostras que foram homogeneizadas para formar uma amostra composta, da qual retirou-se uma amostra de aproximadamente 400 gramas de solo para análise.

Tabela 1. Profundidades de Coletas (z) da matriz do solo para cada ecossistema estudado

\begin{tabular}{cccccc}
\hline Coleta & 01 & 02 & 03 & 04 & 05 \\
\hline $\mathrm{z}(\mathrm{cm})$ & $0-20$ & $10-30$ & $40-60$ & $90-100$ & $140-160$ \\
\hline
\end{tabular}

Para coleta do solo, utilizou-se um trado holandês com $20 \mathrm{~cm}$ de altura de lâmina coletora. $\mathrm{O}$ interesse foi coletar na profundidade mais próxima da que foi instalada a cápsula coletora de solução do solo. Portanto, descartou-se os $5 \mathrm{~cm}$ superiores e inferiores da amostra coletada pelo trado (Figura 9).

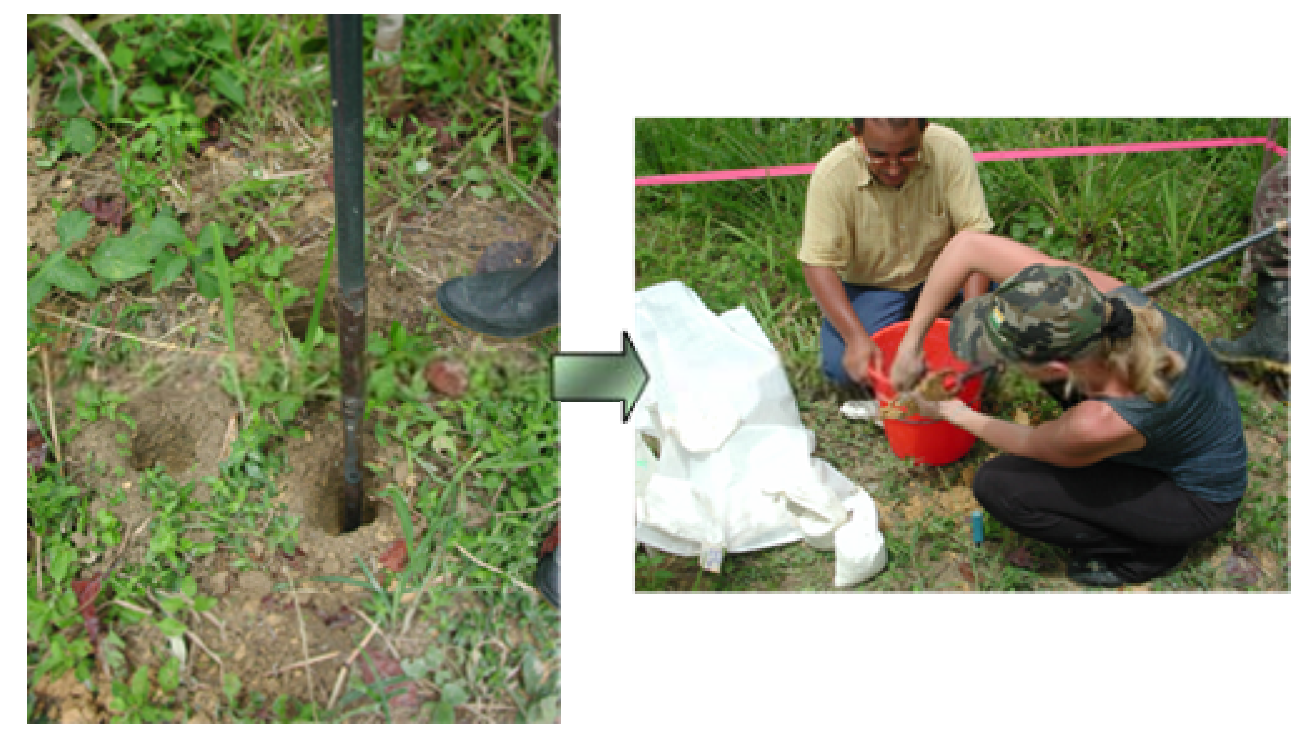

Figura 9 - Procedimento de coleta da matriz do solo para análise química. Retirada de três amostras simples, a cada profundidade, para formar uma amostra composta 
Para medida da precipitação total foram utilizados pluviômetros (constituídos de um funil captador de água, com raio de $117 \mathrm{~mm}$ ), conectados à um reservatório com capacidade para 20 litros (Figura 10). As amostras obtidas, nestes coletores serviram apenas para quantificar o volume de chuva, não sendo analisadas quimicamente.

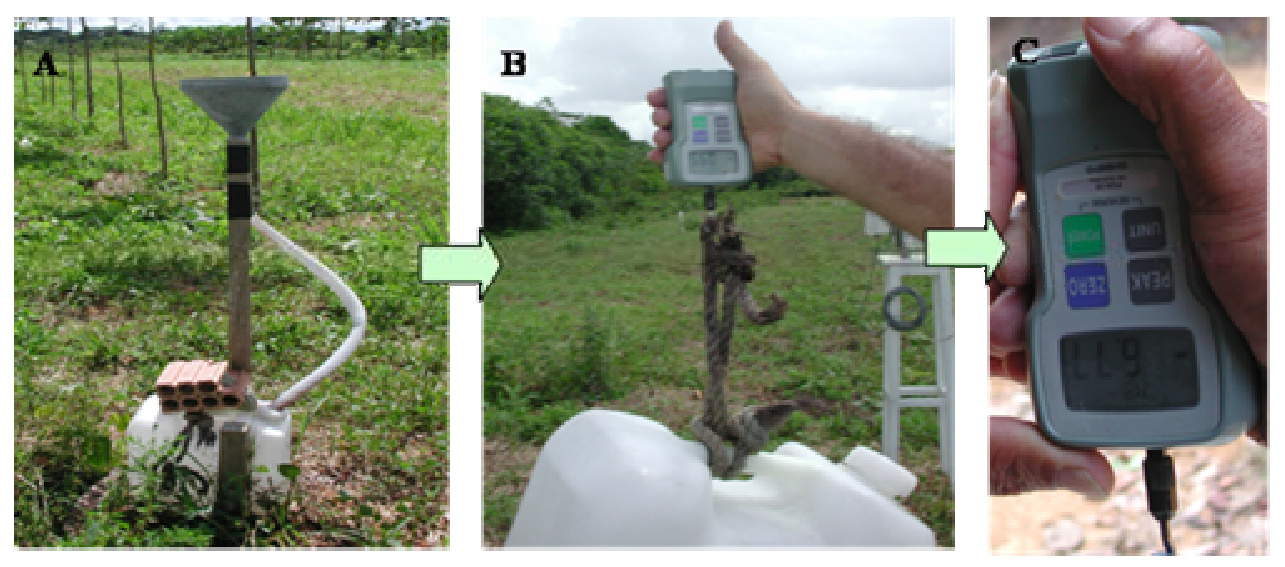

Figura 10 - Pluviômetro com funil captador de água (A); Determinação da massa de água da precipitação em $\mathrm{Kg}$ (B) e Balança (C)

O total de chuva foi quantificado semanalmente através da medida da precipitação armazenada no reservatório. Primeiramente, obteve-se a massa de todo sistema (água da chuva + reservatório). Depois, sem a água, obteve-se apenas o valor do reservatório, e com a diferença entre estes valores, determinou-se a massa da água referente a precipitação (adotando-se a densidade da água como: $1 \mathrm{~g}=1 \mathrm{~cm}^{3}$ ). Posteriormente a mesma foi transformada em volume. Com esses valores, aplica-se a relação abaixo (Eq. 1) e obtêm-se o valor da precipitação em mm.

$$
\mathbf{h}=\mathbf{V} /(\mathbf{1 0 0 0 )} \times \mathrm{A}
$$

Sendo $\mathrm{h}=$ altura da água $(\mathrm{mm}) ; \mathrm{V}=$ água da precipitação $\left(\mathrm{cm}^{3}\right)$ e $\mathrm{A}=$ área do pluviômetro $\left(\mathrm{mm}^{2}\right)$. 


\subsection{Procedimentos Analíticos}

Nas amostras de solução do solo (fase inorgânica) as concentrações dos cátions $\mathrm{NH}_{4}^{+}, \mathrm{Na}^{+}, \mathrm{K}^{+}, \mathrm{Ca}^{+2}, \mathrm{Mg}^{+2}$, e ânions $\mathrm{NO}_{3}^{-}, \mathrm{NO}_{2}^{-}, \mathrm{PO}_{4}^{-2}, \mathrm{SO}_{4}^{-2}, \mathrm{Cl}^{-1}$ foram determinadas por cromatografia líquida, em equipamento da marca Dionex, modelo DX500 (Figura 11A).

As concentrações de carbono inorgânico dissolvido $\left(\mathrm{HCO}_{3}^{-}+\mathrm{CO}_{3}^{-2}\right)$ foram determinadas em equipamento LiCor-820, cujo princípio analítico é a detecção por infravermelho, após acidificação da amostra para a conversão das espécies de carbono inorgânico à $\mathrm{CO}_{2}$, e extração do $\mathrm{CO}_{2}$ evoluído pelo método de equilíbrio em fases múltiplas (Onuska, 1998) Figura 11B.

A determinação das concentrações do carbono orgânico dissolvido (COD) foi realizada em analisador de Carbono Orgânico Total (Shimadzu, modelo TOC 5000A). O princípio analítico é o mesmo descrito acima, isto é, detecção de $\mathrm{CO}_{2}$ por infravermelho não dispersivo (Figura $11 \mathrm{C}$ ). Neste caso a amostra é queimada à $680^{\circ} \mathrm{C}$ e o $\mathrm{CO}_{2}$ gerado é quantificado.
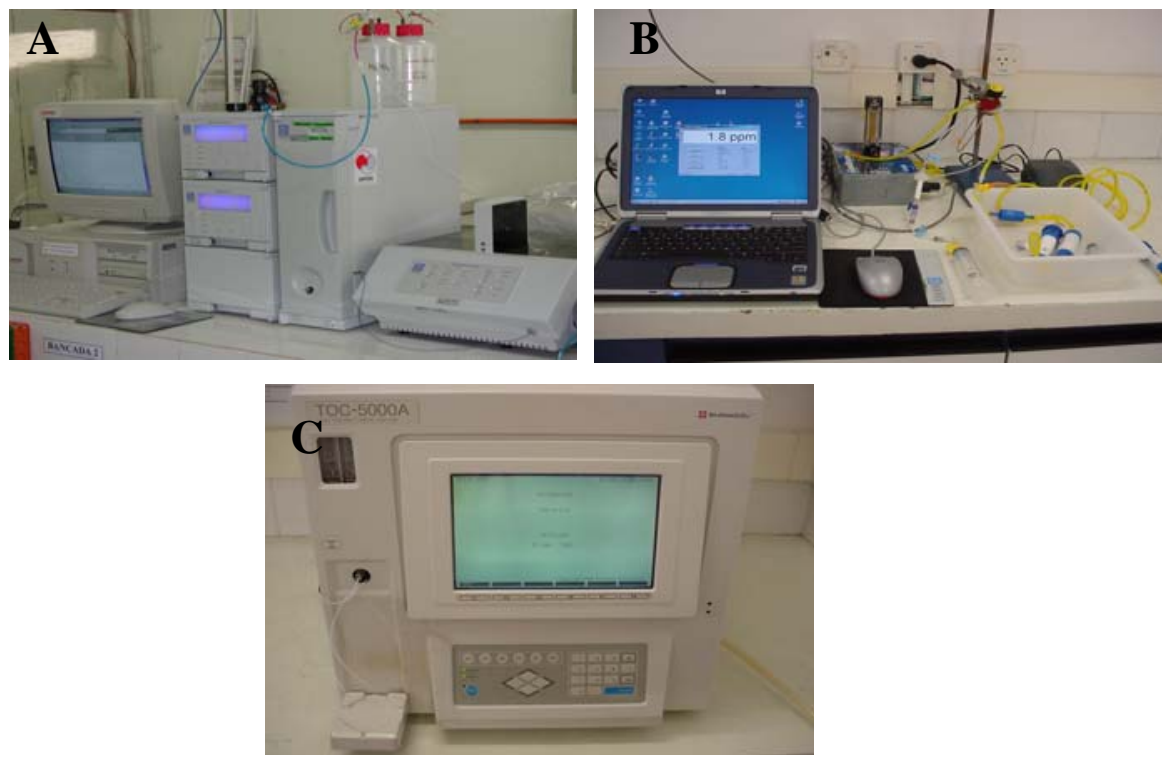

Figura 11 - Equipamentos utilizados para análise da solução do solo. Cromatógrafo Líquido para determinação de cátions e ânions (A); Analisador de Carbono Inorgânico Dissolvido (B); e Analisador de Carbono Orgânico Total (C) 
A determinação do conteúdo de carbono $(\% \mathrm{C})$, de nitrogênio $(\% \mathrm{~N})$, relação $\mathrm{C} / \mathrm{N}$ e da composição isotópica do carbono $\left(\delta^{13} \mathrm{C}\right)$ foi realizada com as amostras de solo secas, moidas, pesadas e posteriomente acondicionadas em cápsulas de estanho. Estas cápsulas foram queimadas em meio oxidante, equipamento analisador elementar Carlo Erba EA 1110. Os gases produzidos separados por cromatografia gasosa e carreados por fluxo contínuo de Hélio até um espectrômetro de massa Finnigan Delta Plus. Com estes dois equipamentos interligados, obtêm-se simultaneamente os valores destes elementos (Figura 12C).

A razão ${ }^{13} \mathrm{C} /{ }^{12} \mathrm{C}$ é definida pela Equação 2, expressa em $\delta(\%)$.Valor este que indica o desvio da razão isotópica de um determinado material em relação ao seu padrão.

$$
\begin{aligned}
& \delta^{13} \mathrm{C}=\left\{\underline{\mathrm{R}}_{\underline{\text { amostra }}}-\mathrm{R}_{\text {padrão }}\right\} * 1000 \\
& \mathrm{R}_{\text {padrão }}
\end{aligned}
$$

$$
\begin{aligned}
& \mathrm{R}_{\text {amostra }}=\text { razão isotópica }{ }^{13} \mathrm{C} /{ }^{12} \mathrm{C} \text { da amostra } \\
& \mathrm{R}_{\text {padrão }}=\text { razão isotópica }{ }^{13} \mathrm{C} /{ }^{12} \mathrm{C} \text { do padrão. O padrão universal é uma rocha }
\end{aligned}
$$
calcária da formação Pee Dee da região de Gran Canyon nos Estados Unidos.

A determinação da acidez potencial $\left(\mathrm{H}^{+}+\mathrm{Al}^{+3}\right)$, foi realizada utilizando como extrator o acetato de cálcio 0,5 mol. $1^{-1} \mathrm{em}$ pH 7,0. Pelo método da titulação com $\mathrm{NaOH}$ 0,025 mol. -1 $^{-1}$ em presença de fenolftaleína alcoólica, foi realizada a leitura da acidez potencial do solo.

$\mathrm{O}$ teor de $\mathrm{Al}^{+3}$ foi determinado pelo mesmo método citado acima, porém a extração foi realizada com $\mathrm{KCl}$ mol.1 ${ }^{-1}$.

A extração do cálcio, magnésio e ferro foi realizada pelo método da resina (catiônica e aniônica). A quantificação do $\mathrm{Ca}, \mathrm{Mg}$ e Fe foi realizada por espectrômetria de absorção atômica (Perkin Elmer, 1100B) e para o potássio, fotometria de chama (Metodologia IAC, Van Raij, 2001), Figura 12D. 

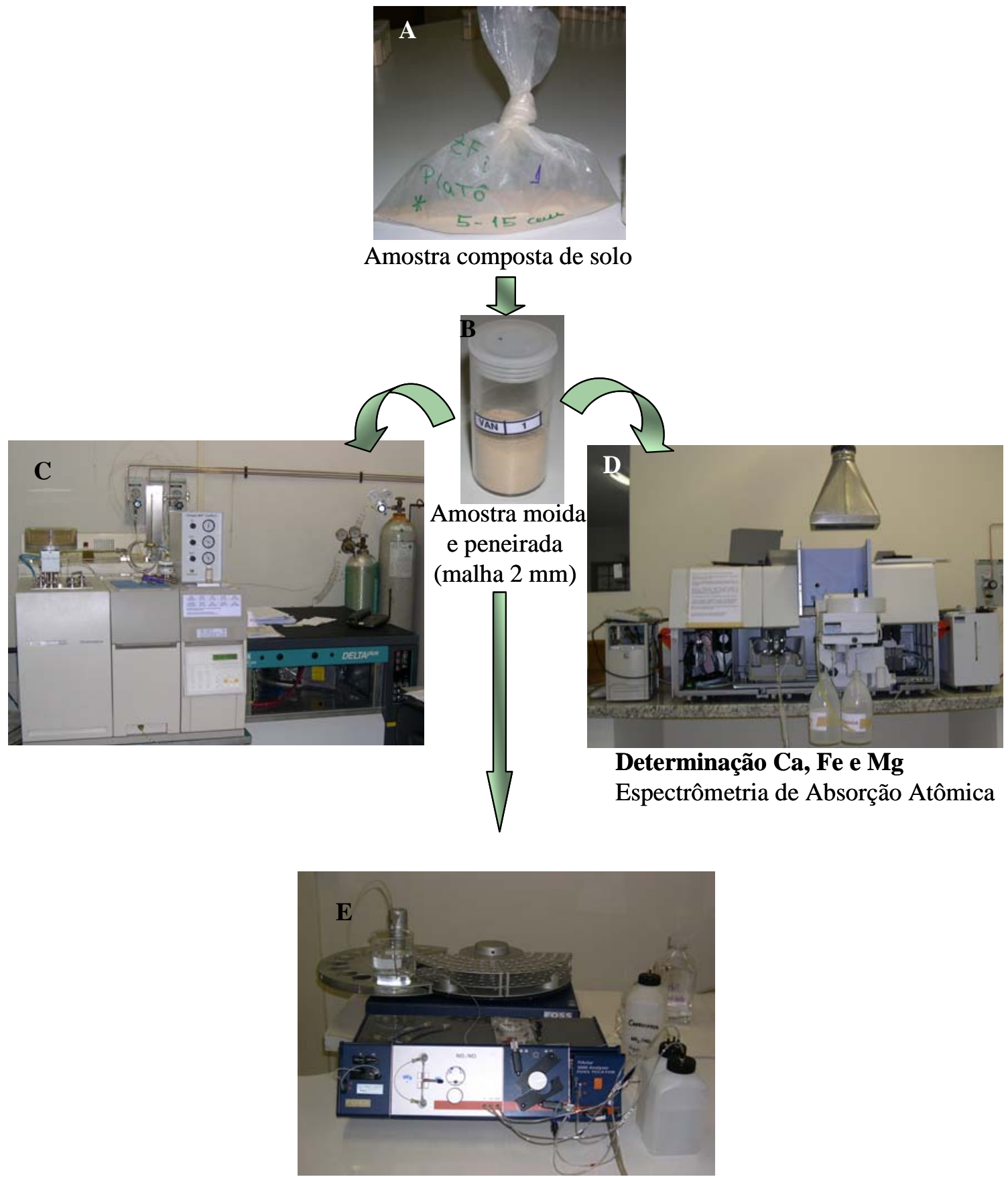

Determinação do P disponível

Sistema FIAstar, Foss Tecator modelo 5000 A.

Figura 12 - Amostras da matriz do solo e equipamentos utilizados para análise química 
A determinação do fósforo disponível foi realizada através de método colorimétrico em sistema por injeção em fluxo (FIA), empregando espectrofotômetro FIAstar 5000 A. (Figura 12E). A extração deste elemento foi realizada com solução duplo-ácido $\left(\mathrm{HCl}+\mathrm{H}_{2} \mathrm{SO}_{4}\right)$.

A CTC efetiva foi calculada pelo somatório de bases (SB) $\mathrm{Ca}^{+2}, \mathrm{Mg}^{+2}, \mathrm{~K}^{+}$e $\mathrm{Al}^{+3}$ trocável, e a CTC potencial pelo somatório de bases e $\mathrm{H}^{+}+\mathrm{Al}^{+3}$ (Van Raij, 2001).

A saturação de bases (V\%) foi calculada conforme a Equação 3.

$$
\mathrm{V} \%=\mathrm{SB} \times 100 / \mathrm{CTC}_{\text {potencial }}
$$

Adotou-se como sendo eutróficos os solos que apresentavam V\% > 50 (alta saturação de bases) e como sendo distróficos os solos com V\% < 50, (com baixa saturação de bases, solos inférteis) (EMBRAPA, 1999).

A saturação por alumínio (m\%) foi calculada através da Equação 3, descrita abaixo:

$$
\mathrm{m} \%=100 \times \mathrm{Al} / \mathrm{CTC}_{\text {efetiva }}
$$

A relação do tamanho de partículas no solo foi realizada através da análise granulométrica, pelo método do Densímetro de Bouyoucos (EMBRAPA, 1979). As amostras de solo peneiradas em malha $2 \mathrm{~mm}$ foram dispersas com solução de hidróxido de sódio $1,0 \mathrm{~N}$ e posterior agitação rápida (14.000 rpm) durante 15 minutos em Dispersor TE-147 (Marca Tecnal). A fração areia (2,0 a 0,05mm) foi obtida através da peneiração, lavagem, secagem e pesagem. A fração argila $(<0,002 \mathrm{~mm})$ através da sedimentação e leitura com o densímetro, e a fração silte $(0,05$ a $0,002 \mathrm{~mm})$ foi calculada por diferença. 


\subsection{Análise Estatística}

Os resultados obtidos foram submetidos a análise estatística empregando o Programa SAS, Software Release 8.2 (TS2MO). Para comparação aplicou-se ANOVA a 1\%, para determinação das diferenças mínimas entre as médias. Com a equação de regressão multivariada, obteve-se a contribuição de cada variável para o coeficiente de determinação das equações de regressão. 


\section{RESULTADOS E DISCUSSÃO}

\subsection{Precipitação}

A precipitação medida durante o ano de 2003, não mostrou diferenças significativas, quando comparada com a média histórica (INEMET, 1961-1990). No entanto, observou-se uma variação sazonal diferente na distribuição das chuvas em Presidente Figueiredo (Figura 13 e Tabela 2). Localizada à 120 km ao norte de Manaus, esta região apresentou distribuição distinta das outras áreas. Em Presidente Figueiredo registrou-se pluviosidade mínima nos meses de dezembro e janeiro, período caracterizado como chuvoso para a região.

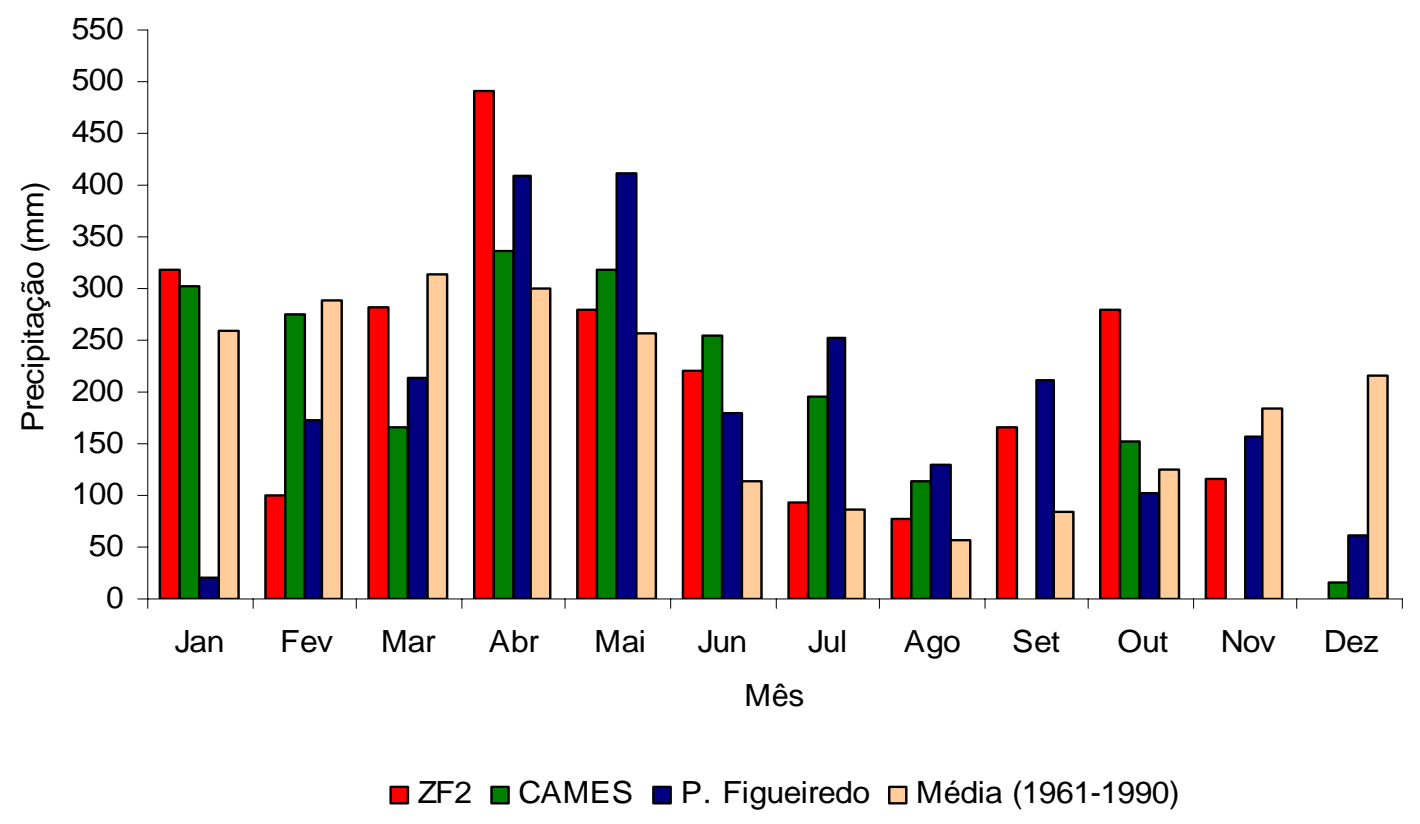

Figura 13 - Precipitação mensal (2003) e média histórica (1961 - 1990, dados INEMET) da região de Manaus 
Tabela 2. Precipitação total coletada durante o período estudado (2003) e média histórica

\begin{tabular}{lc}
\hline Local & Precipitação Total (mm) \\
\hline Reserva Florestal ZF2 & 2421 \\
CAMES & 2130 \\
Presidente Figueiredo & 2325 \\
Média Histórica (1961-1990/INEMET) & 2286 \\
\hline
\end{tabular}

\subsection{Caracterização dos Solos Estudados}

\subsubsection{Caracterização Física}

Na Amazônia Central, na região de Manaus, o relevo é dominado por áreas planas e levemente onduladas. Na Reserva Florestal ZF 2 observamos que a textura do solo varia significativamente ao longo das toposequências. As áreas sobre platô estão associadas aos Latossolos, bem drenados, de textura muito argilosa (argila $>70 \%$ ). Nas encosta ocorrem os Argissolos, bem drenados, de textura argilosa (argila $\pm 50 \%$ ) e, nos baixios, predominam os Espodossols, muito arenosos (teor de argila < 5\%), com fraca capacidade de retenção de águas e nutrientes (Figuras 14 e 15). As áreas de baixio sofrem variações sazonais no nível do lençol freático, possibilitando a saturação do solo com água durante parte do período chuvoso (Telles, 2003).

$\mathrm{Na}$ área da CAMES (reflorestamento e floresta secundária), Fazenda Santa Cláudia (área degradada) e na Serraria Teixeira (floresta primária) os solos são do tipo Latossolo Amarelo de textura muito argilosa (argila > 70\%), e encontram-se em áreas sobre platô. Para estes perfis observa-se aumento do teor de argila em profundidade (Figura 16). 


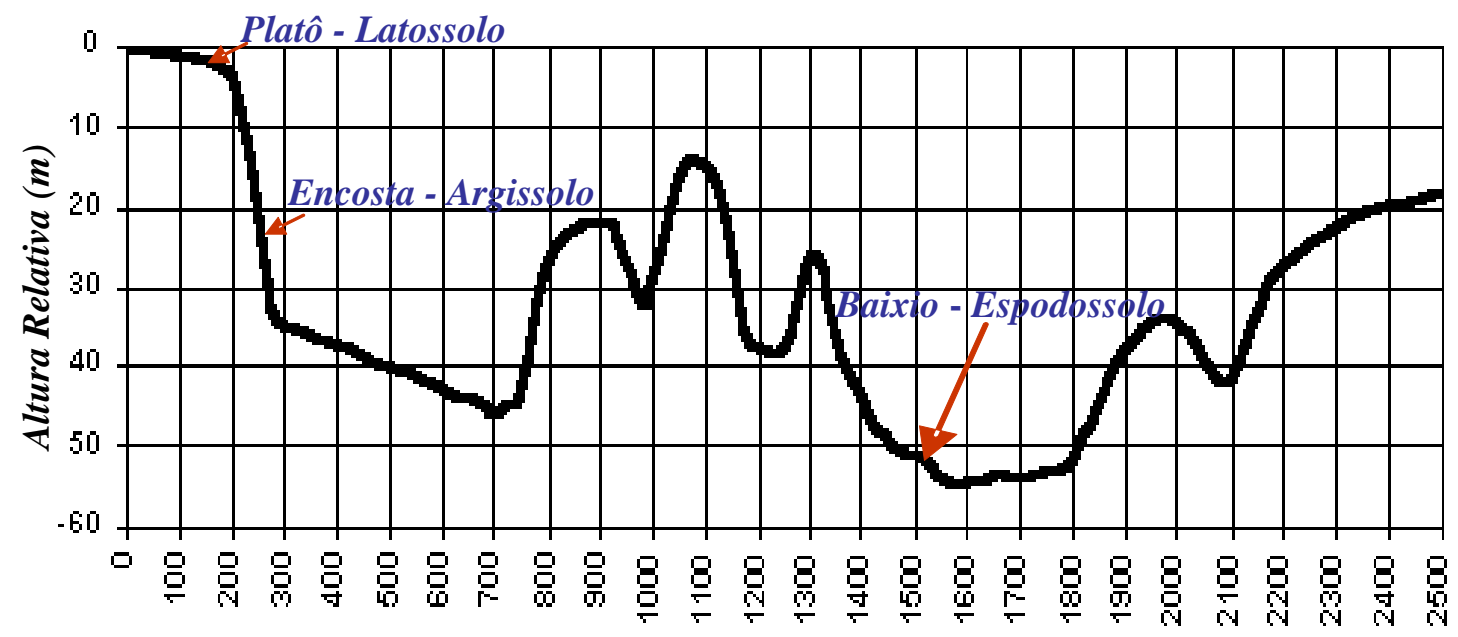

\section{Distância (m)}

Figura 14 - Perfil vertical do gradiente de elevação do relevo na Reserva Florestal (ZF2), no transecto Leste-Oeste, sob floresta primária, com indicação dos pontos amostrais na posição do relevo e o tipo de solo. (adaptado de Ferreira et al., 2003)

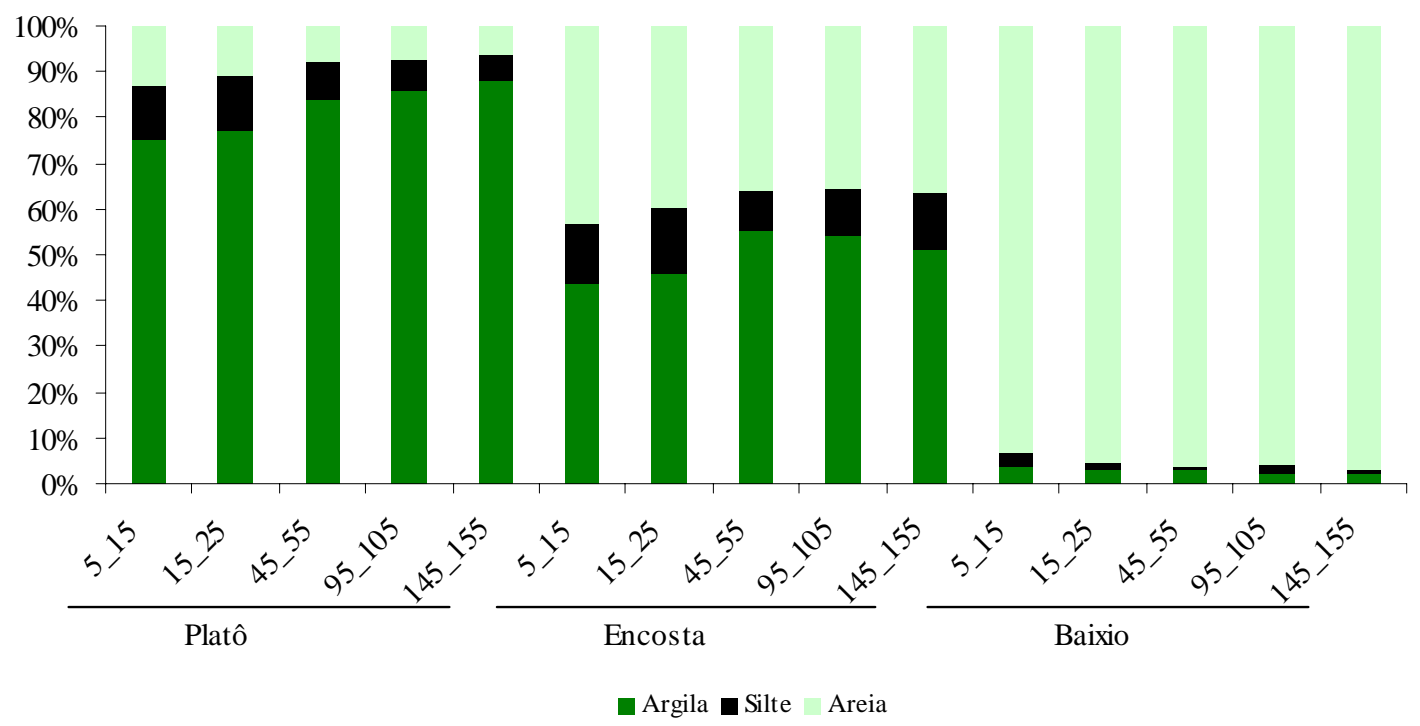

Figura 15 - Composição granulométrica (\%) dos solos da floresta primária (ZF-2), ao longo do gradiente de elevação 


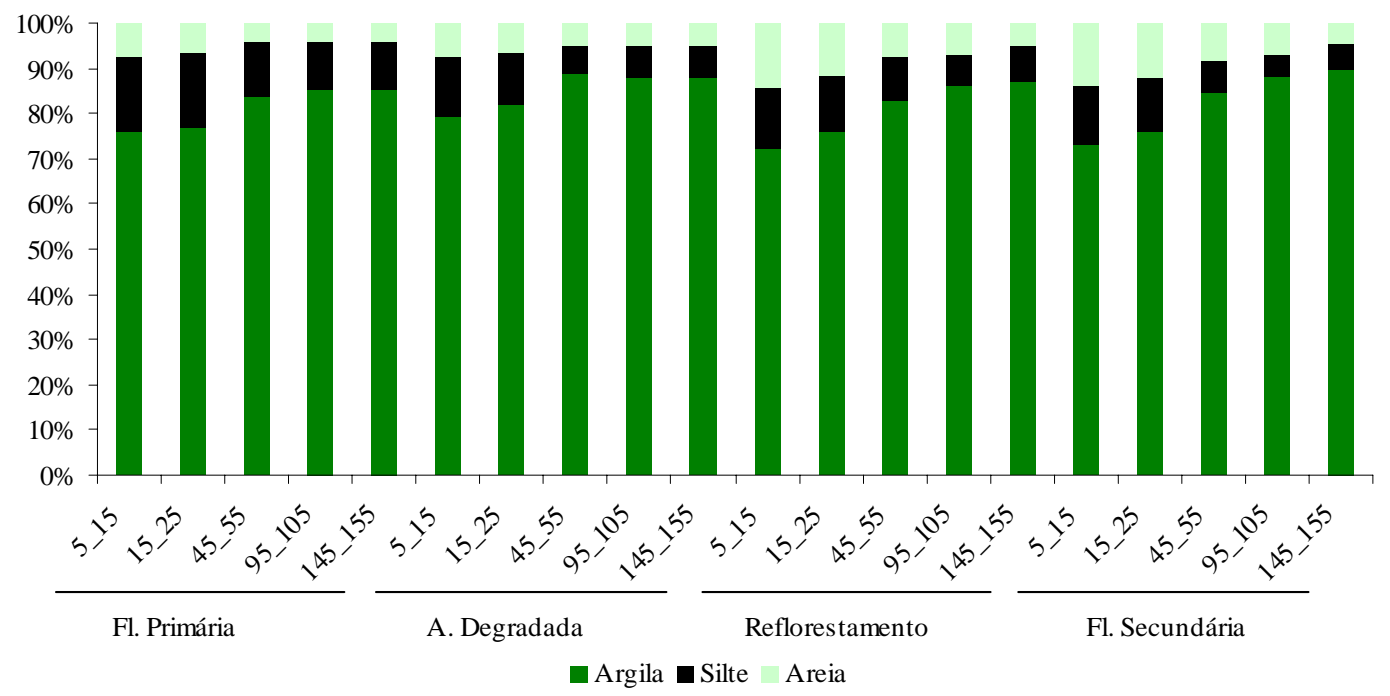

Figura 16 - Composição granulométria (\%) das áreas da CAMES (reflorestamento e floresta secundária), e de Presidente Figueiredo (floresta primária e área degradada)

\subsubsection{Caracterização Química}

Os solos avaliados apresentaram valores extremamente baixos de soma de bases trocáveis, especialmente o potássio, que apresentou concentrações abaixo do limite de detecção do equipamento, além de concentrações muito baixas de cálcio e magnésio, características de solos distróficos, de baixa fertilidade (Tabela 3). Segundo Jordan (1986), solos distróficos apresentam melhores características físicas quando comparado a solos eutróficos, devido, principalmente, à maior concentração de óxidos de ferro e alumínio, como subprodutos da ação do intemperismo.

Apesar da maior parte dos solos possuirem alta percentagem de argila (maior área superficial com possibilidades de maior retenção de cátions), a capacidade efetiva de troca de cátions $\left(\mathrm{CTC}_{\mathrm{Ef}}\right)$ destes é baixa, o que reflete, sob condições naturais, uma baixa capacidade de retenção e troca de cátions. Portanto em termos de $\mathrm{CTC}_{\mathrm{Ef}}$, os Latossolos argilosos e o Argissolo argiloso se comportaram de modo semelhante ao solo 
arenoso Espodossol. Isso pode ser explicado pelo fato destas argilas serem de baixa atividade, não expansivas que é o caso da caulinita (reticulado 1:1), com alto potencial de perdas de nutrientes via lixiviação.

Os solos apresentaram alta saturação por alumínio no complexo de troca, classificados como solos álicos. O íon alumínio foi o catíon trocável que mais contribuiu para os valores da $\mathrm{CTC}_{\mathrm{Ef}}$.

A concentração de fósforo disponível variou conforme o tipo de solo. No Latossolo de textura muito argilosa a disponibilidade foi significativamente menor, com

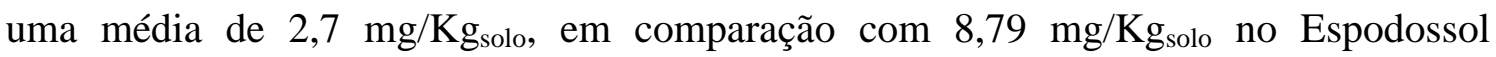
arenoso, e concentrações intermediárias, de $5,59 \mathrm{mg} / \mathrm{Kg}_{\text {solo }}$, no Argissolo argiloso (Tabela 3). Observando a disponibilidade do fósforo ao longo do perfil de solo, encontramos as maiores concentrações na camada superficial, de 05 a $25 \mathrm{~cm}$, e diminuindo com a profundidade, coincidindo com aumento do teor de argila e baixa mobilidade deste elemento (Tabela 3). Este elemento também apresenta correlação negativa com a acidez do solo, com decréscimo de sua disponibilidade quando o $\mathrm{pH}$ se torna ácido, abaixo de 5,5 (Laurance, 1999). A acidez dos solos estudados é um dos fatores que explica a baixa disponibilidade de fósforo. 
Tabela 3. Análise química dos solos das áreas de estudo

\begin{tabular}{|c|c|c|c|c|c|c|c|c|c|c|c|c|c|}
\hline Local & $\begin{array}{l}\text { Prof. } \\
\text { (cm) }\end{array}$ & $\mathrm{Al}^{+++}+\mathrm{H}^{+}$ & $\mathrm{Al}^{++}$ & $\begin{array}{l}\mathrm{K}^{+} \\
\mathrm{mmc}\end{array}$ & $\begin{array}{l}\mathrm{Ca}^{+} \\
\mathrm{dm}\end{array}$ & $\mathrm{Mg}^{+1}$ & SB & $\mathrm{T}$ & $\mathrm{CTC}_{\mathrm{Ef} .}$ & & & $\begin{array}{c}\mathrm{P}_{\text {disp. }} \\
\text { mg. } \mathrm{Kg}^{-1}\end{array}$ & $\begin{array}{l}\text { Fe } \\
\text { mmol.dm }{ }^{-3}\end{array}$ \\
\hline ZF2 Fl. Primária - Platô & 5-15 & 108 & 22.4 & 0 & 1 & 1 & 2 & 110 & 24 & 2 & 92 & 5.55 & 0.99 \\
\hline ZF2 Fl. Primária - Platô & $15-25$ & 99 & 19.9 & 0 & 0 & 1 & 1 & 100 & 21 & 1 & 95 & 3.62 & 0.46 \\
\hline ZF2 Fl. Primária - Platô & $45-55$ & 82 & 14.1 & 0 & 0 & 1 & 1 & 83 & 15 & 1 & 93 & 2.31 & 0.09 \\
\hline ZF2 Fl. Primária - Platô & $95-105$ & 77 & 9.3 & 0 & 0 & 1 & 1 & 78 & 10 & 1 & 90 & 1.00 & 0.05 \\
\hline ZF2 Fl. Primária - Platô & $145-155$ & 67 & 5 & 0 & 1 & 2 & 3 & 70 & 8 & 4 & 62 & 1.00 & 0.04 \\
\hline ZF2 Fl. Primária - Encosta & $5-15$ & 78 & 13.9 & 0 & 0 & 2 & 2 & 80 & 16 & 3 & 87 & 15.53 & 1.12 \\
\hline ZF2 Fl. Primária - Encosta & $15-25$ & 75 & 17 & 0 & 0 & 1 & 1 & 76 & 18 & 1 & 94 & 6.59 & 0.78 \\
\hline ZF2 Fl. Primária - Encosta & $45-55$ & 73 & 10.5 & 0 & 0 & 1 & 1 & 74 & 12 & 1 & 91 & 2.99 & 0.38 \\
\hline ZF2 Fl. Primária - Encosta & $95-105$ & 69 & 11 & 0 & 3 & 1 & 4 & 73 & 15 & 5 & 73 & 1.50 & 0.14 \\
\hline ZF2 Fl. Primária - Encosta & $145-155$ & 65 & 9.2 & 0 & 0 & 1 & 1 & 66 & 10 & 2 & 90 & 1.34 & 0.06 \\
\hline ZF2 Fl. Primária - Baixio & $5-15$ & 113 & 14.8 & 0 & 0 & 2 & 2 & 115 & 17 & 2 & 88 & 25.42 & 0.22 \\
\hline ZF2 Fl. Primária - Baixio & $15-25$ & 77 & 8.5 & 0 & 0 & 1 & 1 & 78 & 10 & 1 & 90 & 11.37 & 0.14 \\
\hline ZF2 Fl. Primária - Baixio & $45-55$ & 65 & 7.7 & 0 & 0 & 1 & 1 & 66 & 9 & 2 & 88 & 3.51 & 0.14 \\
\hline ZF2 Fl. Primária - Baixio & $95-105$ & 62 & 15.4 & 0 & 0 & 1 & 1 & 63 & 16 & 2 & 94 & 2.09 & 0.33 \\
\hline ZF2 Fl. Primária - Baixio & $145-155$ & 55 & 9.3 & 0 & 0 & 1 & 1 & 56 & 10 & 2 & 90 & 1.54 & 0.35 \\
\hline
\end{tabular}

SB = Soma de bases; $\mathrm{T}$ = Capacidade de Troca Cátions; $\mathrm{V}=$ Saturação de Bases; $\mathrm{CTC}_{\mathrm{Ef}}=$ Capacidade Efetiva de Troca de Cátions; $\mathrm{m}=$ Saturação $\mathrm{Al}$ 
Tabela 3. Análise quimica dos solos das áreas de estudo

\begin{tabular}{|c|c|c|c|c|c|c|c|c|c|c|c|c|c|}
\hline Local & $\begin{array}{l}\text { Prof. } \\
(\mathrm{cm})\end{array}$ & $\mathrm{Al}^{+++}+\mathrm{H}^{+}$ & $\mathrm{Al}^{++}$ & $\begin{array}{r}\mathrm{K}^{+} \\
\mathrm{mm}\end{array}$ & $\begin{array}{l}\mathrm{Ca}^{+} \\
\mathrm{dm}\end{array}$ & $\mathrm{Mg}^{+2}$ & SB & $\mathrm{T}$ & CTC $_{\text {Ef. }}$ & $\overline{\mathrm{V}}$ & & $\begin{array}{c}\mathrm{P}_{\text {disp. }} \\
\mathrm{mg} \cdot \mathrm{Kg}^{-1}\end{array}$ & $\begin{array}{c}\mathrm{Fe} \\
\mathrm{mmol} \cdot \mathrm{dm}^{-3}\end{array}$ \\
\hline P.Fig. Fl. Primária & $5-15$ & 132 & 21.9 & 0 & 0 & 1 & 1 & 133 & 23 & 1 & 95 & 6.38 & 1.08 \\
\hline P.Fig. Fl. Primária & $15-25$ & 127 & 18.7 & 0 & 0 & 1 & 1 & 128 & 20 & 1 & 94 & 3.32 & 0.78 \\
\hline P.Fig. Fl. Primária & $45-55$ & 84 & 15.5 & 0 & 0 & 1 & 1 & 85 & 17 & 1 & 93 & 1.10 & 0.14 \\
\hline P.Fig. Fl. Primária & $95-105$ & 77 & 7.5 & 0 & 0 & 1 & 1 & 78 & 9 & 1 & 88 & 1.17 & 0.06 \\
\hline P.Fig. Fl. Primária & $145-155$ & 76 & 5.9 & 0 & 0 & 1 & 1 & 77 & 7 & 1 & 85 & 0.61 & 0.06 \\
\hline P.Fig. A. Degradada & $5-15$ & 119 & 16.8 & 0 & 0 & 2 & 2 & 121 & 19 & 2 & 89 & 5.97 & 0.50 \\
\hline P.Fig. A. Degradada & $15-25$ & 98 & & 0 & 0 & 1 & 1 & 99 & 1 & 1 & & 4.39 & 0.25 \\
\hline P.Fig. A. Degradada & $45-55$ & 83 & 11.3 & 0 & 0 & 1 & 1 & 84 & 12 & 1 & 92 & 1.81 & 0.05 \\
\hline P.Fig. A. Degradada & $95-105$ & 76 & 9.1 & 0 & 0 & 1 & 1 & 77 & 10 & 1 & 90 & 1.10 & 0.04 \\
\hline P.Fig. A. Degradada & $145-155$ & 72 & 6.6 & 0 & 0 & 1 & 1 & 73 & 8 & 1 & 86 & 0.88 & 0.05 \\
\hline Cames - Reflorestamento & $5-15$ & 124 & 17.6 & 0 & 1 & 1 & 2 & 126 & 20 & 2 & 90 & 68.24 & 0.93 \\
\hline Cames - Reflorestamento & $15-25$ & 101 & 15.4 & 0 & 0 & 1 & 1 & 102 & 16 & 1 & 94 & 8.83 & 0.54 \\
\hline Cames - Reflorestamento & $45-55$ & 87 & 13.6 & 0 & 0 & 1 & 1 & 88 & 15 & 1 & 93 & 2.80 & 0.14 \\
\hline Cames - Reflorestamento & $95-105$ & 80 & 10.8 & 0 & 0 & 1 & 1 & 81 & 12 & 1 & 91 & 1.03 & 0.04 \\
\hline Cames - Reflorestamento & $145-155$ & 74 & 6.7 & 0 & 0 & 1 & 1 & 75 & 8 & 1 & 87 & 0.59 & 0.04 \\
\hline Cames - Fl. Secundária & $5-15$ & 119 & 20.5 & 0 & 0 & 2 & 2 & 121 & 23 & 2 & 91 & 8.72 & 0.98 \\
\hline Cames - Fl. Secundária & $15-25$ & 111 & 20.3 & 0 & 2 & 1 & 3 & 114 & 23 & 3 & 87 & 5.33 & 0.77 \\
\hline Cames - Fl. Secundária & $45-55$ & 94 & 16.9 & 0 & 0 & 1 & 1 & 95 & 18 & 1 & 94 & 2.20 & 0.16 \\
\hline Cames - Fl. Secundária & $95-105$ & 85 & 13.7 & 0 & 0 & 1 & 1 & 86 & 15 & 1 & 93 & 1.05 & 0.04 \\
\hline Cames - Fl. Secundária & $145-155$ & 76 & 9.4 & 0 & 0 & 1 & 1 & 77 & 10 & 1 & 90 & 0.22 & \\
\hline
\end{tabular}


4.2.3 Carbono, Nitrogênio, $\delta{ }^{13} \mathrm{C}$ e relação $\mathrm{C} / \mathrm{N}$ no solo

Os teores de carbono nos solos dos ecossistemas avaliados variaram de 2,67\% na superfície até $0,15 \%$ à $150 \mathrm{~cm}$ de profundidade. Os maiores teores foram encontrados na camada superficial do solo, até $25 \mathrm{~cm}$, decrescendo significativamente com a profundidade (Figura 17). Mello (2004), em estudo realizado no Estado do Acre e Telles (2003), em estudo realizado em Manaus, observaram correlação positiva entre o teor de argila e o estoque de carbono no solo. Neste trabalho também observamos esta tendência, mas de forma menos clara, devido à localização dos solos arenosos (Espodossolos) que estão associados às áreas mais baixas do relevo. Isso permite um acúmulo de material orgânico proveniente da montante, bem como o transporte de ácidos orgânicos, que é favorecido nas camadas mais arenosas, acarretando um aumento de carbono na superfície deste solo. Na camada inferior, aos $25 \mathrm{~cm}$ de profundidade, ocorre decréscimo significativo das concentrações de carbono, na qual esta correlação foi comprovada, quando se sompara o Latossolo com o Espodossolo.

Seria esperado que no Argissolo o teor de carbono fosse maior, quando comparado ao Espodossolo. Mas neste estudo isso não foi observado, provavelmente devido ao grau acentuado de declividade do solo, que não permite acúmulo de M.O. na superfície, e facilita o carreamento deste material até as áreas mais baixas.

O aumento do teor de carbono em solos argilosos se deve as características dos minerais de argila, e aos maiores teores de ferro (Tabela 3), que são apontados como um importante fator de proteção física do carbono orgânico no solo (Christensen, 1992; Telles et al., 2003). Esta retenção pode levar os solos mais argilosos a formar depósitos de carbono passivo (Christensen, 1992). Os solos arenosos, que não apresentam essa proteção física, possuem pequena capacidade de adsorção do carbono e as concentrações encontradas tornam-se menores.

A concentração de nitrogênio total também está correlacionada com o gradiente textural do solo, com valores significativamente maiores nos solos argilosos, quando comparados aos solos arenosos (Figura 18). Os teores de nitrogênio no solo decrescem 
com aumento da profundidade e, em geral, a variação do $\mathrm{N}$ acompanha as variações de C no solo.

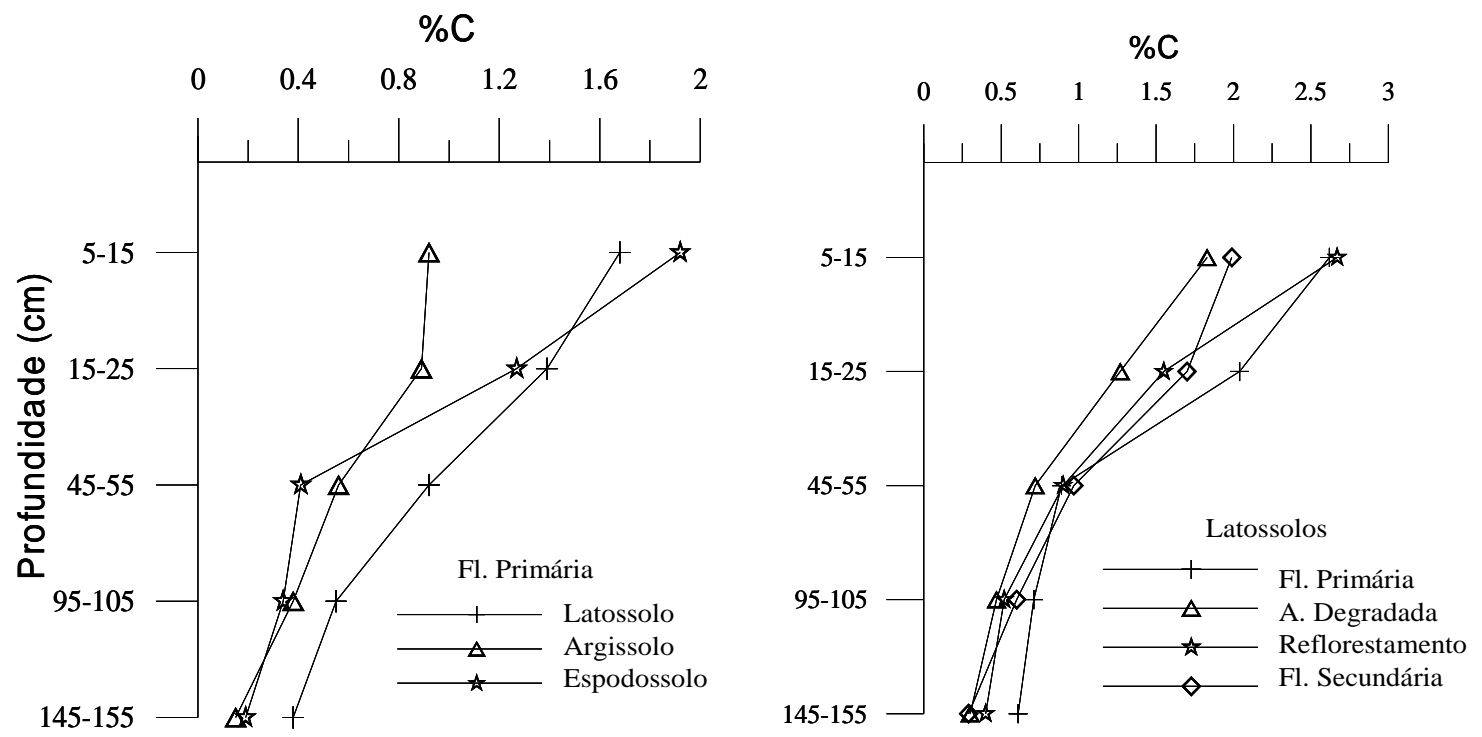

Figura 17 - Variações dos teores de carbono relacionados com a cobertura vegetal, profundidade e o tipo de solo
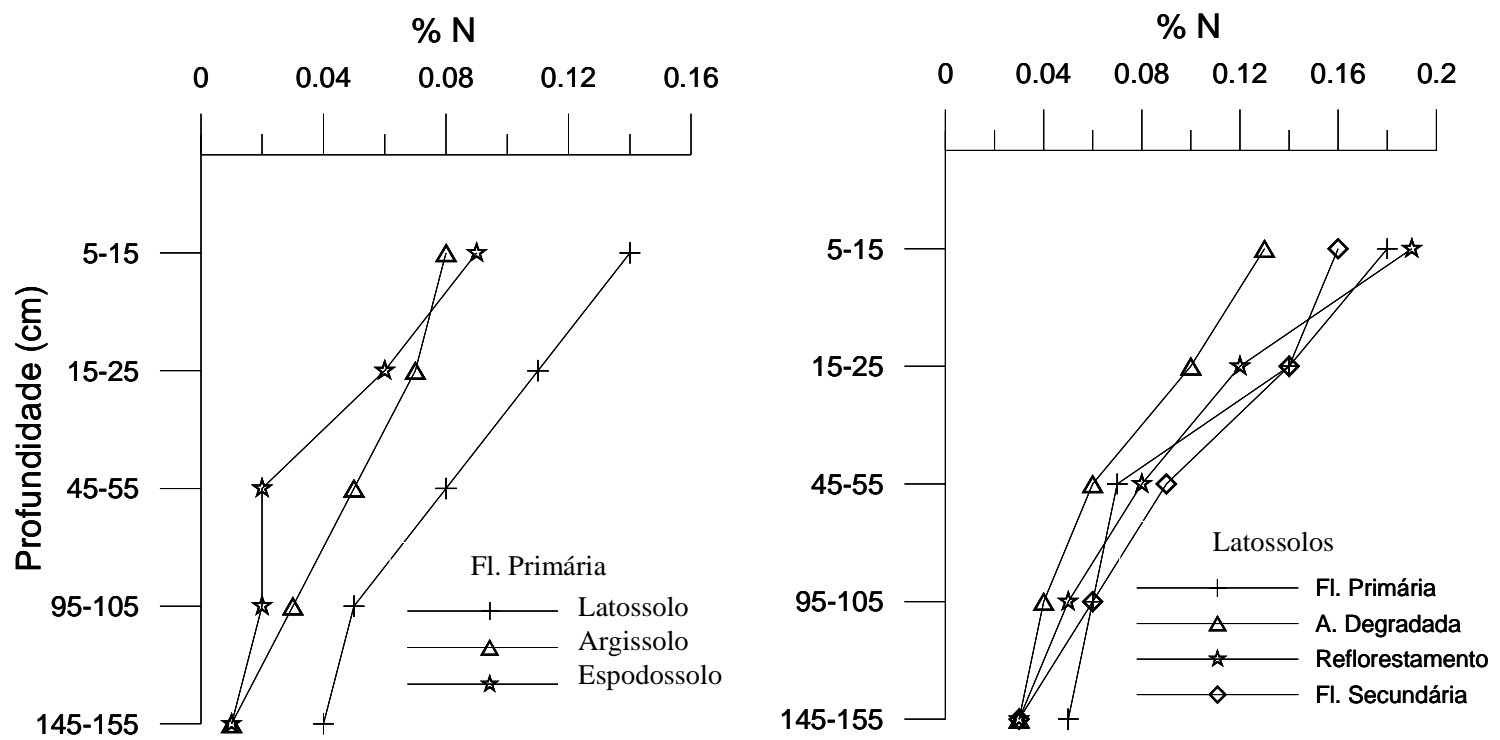

Figura 18 - Variações dos teores de nitrogênio relacionados com a cobertura vegetal, profundidade e o tipo de solo 
Nos Latossolos, a relação $\mathrm{C} / \mathrm{N}$ está próxima dos valores esperados para este tipo de solo, com valores que variaram entre 11,7 a 14,6 na superfície do solo. Em profundidade ocorreu um pequeno decréscimo com valores entre 9,8 a 13,3 (Figura 19). Valores similares foram observados por Telles (2003). A relação C/N nos Latossolos indica atividade biológica intensa, com maior grau de humificação e estabilidade da matéria orgânica nos mesmos.

Quanto à variação do tipo de solo não foram observadas variações significativas na razão $\mathrm{C} / \mathrm{N}$ do Latossolo para o Argissolo. Porém, para o Espodossolo foram observadas variações significativas, apresentando valores da relação $\mathrm{C} / \mathrm{N}$ em torno de 22,16 a 19,88 (Figura 19). Este fato pode estar relacionado com a menor disponibilidade de nitrogênio neste solo. Telles (2003) atribuiu este aumento ao fato deste solo apresentar carbono mais recente e pouco humificado.

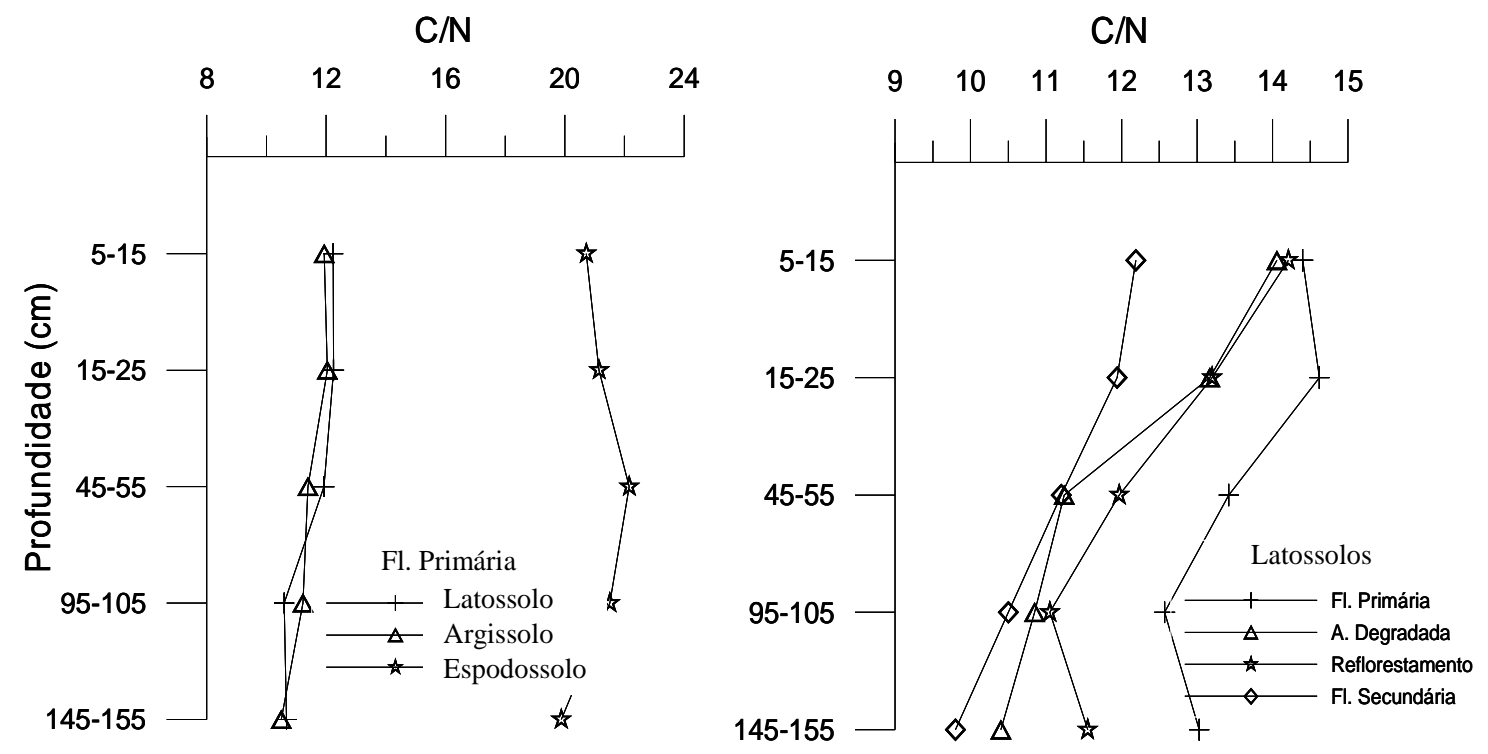

Figura 19 - Variações da relação C/N nos diferentes tipos de solo, cobertura vegetal e profundidades

Os valores de $\delta^{13} \mathrm{C}$ para os Latossolos variaram de $-27,59$ a $-24,7$ \%o, não mostrando diferenças significativas entre o mesmo tipo de solo, sob diferentes 
coberturas vegetais. O enriquecimento de ${ }^{13} \mathrm{C}$ observado em profundidade, indica que este carbono é mais humificado (Figura 20), o que pode ser confirmado a partir dos dados isotópicos de ${ }^{14} \mathrm{C}$ (Telles, 2002) que mostram a predominância de carbono recente em superfície e carbono mais antigo em profundidade.

Para o Espodossolo os valores de ${ }^{13} \mathrm{C}$ não apresentam uma tendência em profundidade variando de -27,19 a -27,73. Com base nos dados isotópicos de ${ }^{14} \mathrm{C}$, Telles (2002) demonstrou a presença de carbono mais recente e menos humificado ao longo deste perfil. Isto pode estar indicando a passagem de carbono pouco humificado pelo perfil de solo, com pouca retenção do mesmo à matriz sólida, devido à textura arenosado mesmo.

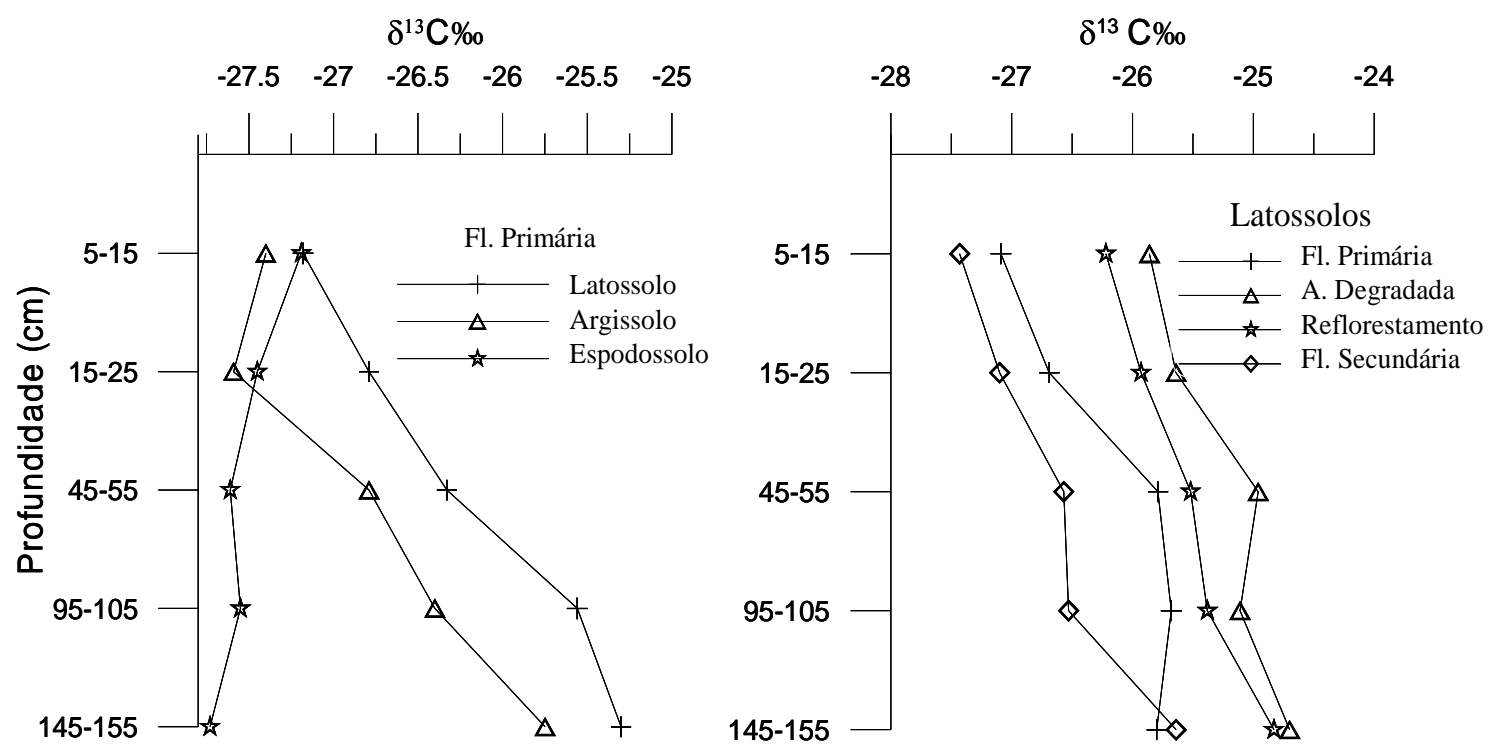

Figura 20 - Variações do $\delta 13 \mathrm{C} \%$ nos diferentes tipos de solo, cobertura vegetal e profundidades 


\subsection{Solução do Solo}

\subsubsection{Carbono Orgânico Dissolvido}

O carbono orgânico dissolvido é proveniente de produtos do metabolismo e decomposição de plantas, animais e microorganismos; é constituído basicamente de ácidos fúlvicos, húmicos e outros compostos orgânicos (Arzhanova \& Vertel, 1981). A concentração de COD está relacionada com a sazonalidade pluviométrica, cobertura vegetetal, a posição do solo no relevo, o pH da solução do solo, textura do solo e concentração de ferro e alumínio no mesmo.

Durante a estação chuvosa, de abril a junho, e de novembro a dezembro, a concentração mostrou-se mais elevada que na estação seca, um padrão também observado anteriormente por McClain et al. (1997). Observam-se picos de concentrações mais elevadas durante o periodo seco, que coincidem com eventos de chuvas. Estes aumentos se devem à lixiviação do material orgânico, armazenado sobre a biomassa viva e serrapilheira, acumulado durante o período seco. Com o aporte da água de lixiviação que chega até o solo, o material orgânico dissolvido é carreado e percola por meio da água intersticial no solo, aumentando assim as concentrações de COD no mesmo. Observa-se uma correlação positiva entre a concentração de COD e a umidade do solo, principalmente devido ao aumento da atividade biológica e conseqüente formação de compostos orgânicos solúveis em água (Post et al., 1985; Christ \& David 1996; Kalbitz, et al., 2000). De julho a outubro (período seco), o solo apresentou pouca disponibilidade de água, e a concentração de COD foi mais baixa, como pode ser observado na Figura 21 e Tabela 4. 

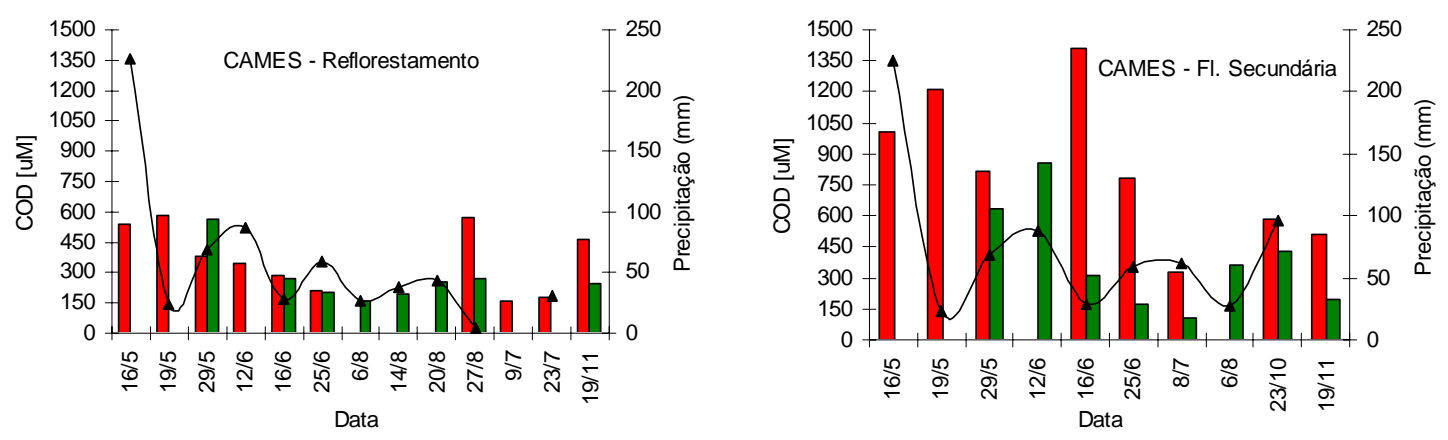

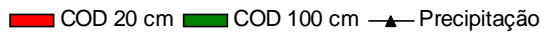
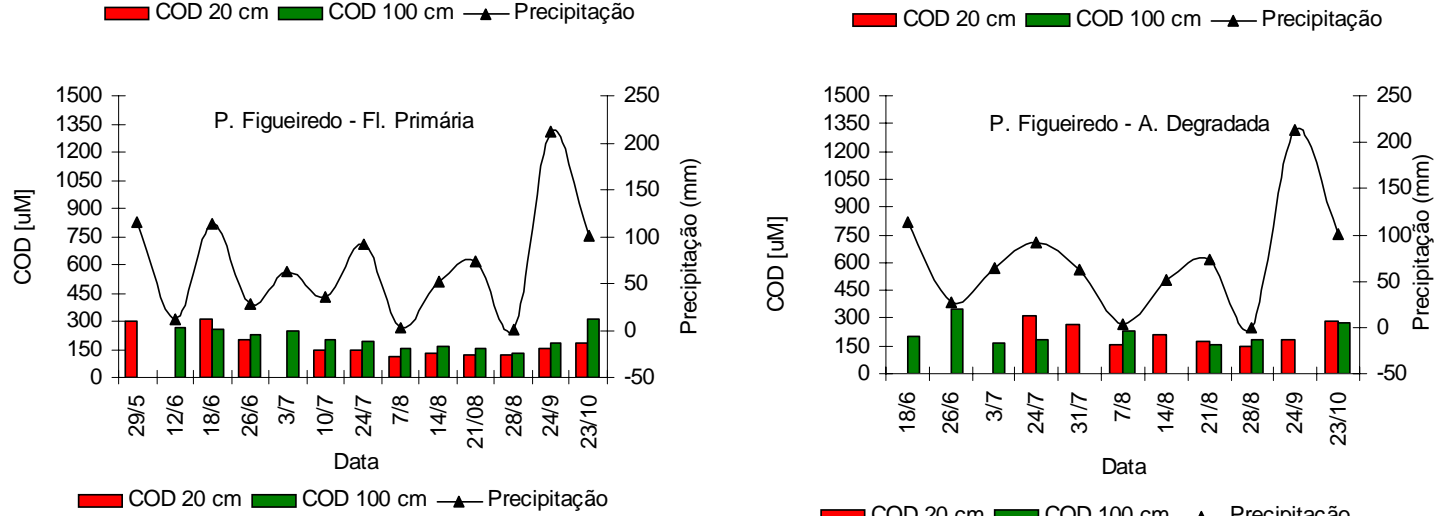

$\llbracket$ COD $20 \mathrm{~cm} \amalg$ COD $100 \mathrm{~cm} \multimap$ Precipitação
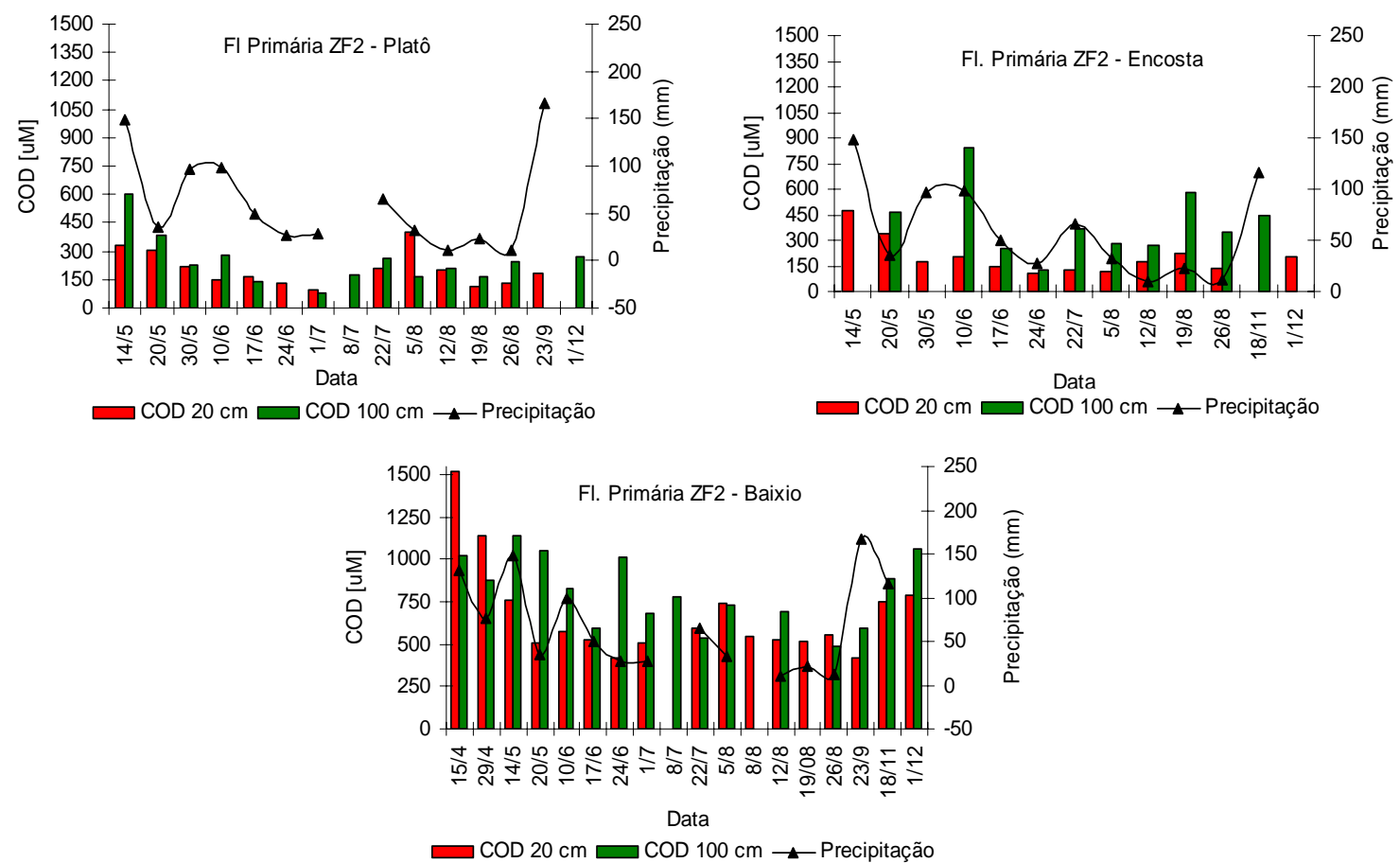

Figura 21 - Distibuição sazonal das concentrações de COD e da precipitacão durante o período amostral 
Tabela 4. Concentrações médias e desvio padrão das concentrações de carbono orgânico dissolvido para os perídos seco e chuvoso; pH da solução do solo e teores de ferro e alumínio no solo

\begin{tabular}{|c|c|c|c|c|c|c|c|c|}
\hline Local & Relevo & Solo & $\begin{array}{l}\text { Prof. } \\
(\mathrm{cm})\end{array}$ & $\mathrm{pH}$ & $\begin{array}{l}\mathrm{Fe} \\
\mathrm{mm}_{\mathrm{c}}\end{array}$ & $\begin{array}{r}\mathrm{Al} \\
\mathrm{dm}^{-3}\end{array}$ & $\begin{array}{r}\text { Chuvoso } \\
\text { [COD }\end{array}$ & $\begin{array}{l}\text { Seco } \\
\mu \mathrm{M}\end{array}$ \\
\hline \multirow[t]{2}{*}{ Fl. Primária } & Platô & Latossolo & 20 & 4,29 & 0,46 & 19,9 & $283 \pm 60$ & $153 \pm 39$ \\
\hline & & & 100 & 5,33 & 0,05 & 9,3 & $407 \pm 189$ & $199 \pm 65$ \\
\hline \multirow[t]{2}{*}{ Fl. Primária } & Encosta & Argissolo & 20 & 5,22 & 0,78 & 17 & $229 \pm 75$ & $148 \pm 40$ \\
\hline & & & 100 & 4,72 & 0,14 & 11 & $455 \pm 20$ & $275 \pm 85$ \\
\hline \multirow[t]{2}{*}{ Fl. Primária } & Baixio & Espodossolo & 20 & 3,53 & 0,14 & 8,5 & $754 \pm 222$ & $535 \pm 92$ \\
\hline & & & 100 & 3,52 & 0,33 & 15,4 & $974 \pm 127$ & $681 \pm 155$ \\
\hline \multirow[t]{2}{*}{ Fl. Primária } & Platô & Latossolo & 20 & 4,94 & 0,78 & 18,7 & $247 \pm 66$ & $131 \pm 19$ \\
\hline & & & 100 & 4,32 & 0,06 & 7,5 & $327 \pm 146$ & $177 \pm 36$ \\
\hline \multirow[t]{2}{*}{ A. Degradada } & Platô & Latossolo & 20 & 5,82 & 0,25 & * & $288 \pm 72$ & $209 \pm 62$ \\
\hline & & & 100 & 5,35 & 0,04 & 9,1 & $276 \pm 74$ & $186 \pm 27$ \\
\hline \multirow[t]{2}{*}{ Reflorestamento } & Platô & Latossolo & 20 & 5,20 & 0,54 & 15,4 & $462 \pm 101$ & $280 \pm 169$ \\
\hline & & & 100 & 5,25 & 0,04 & 10,8 & $524 \pm 266$ & $226 \pm 46$ \\
\hline \multirow[t]{2}{*}{ Fl. Secundária } & Platô & Latossolo & 20 & 4,27 & 0,77 & 20,3 & $922 \pm 354$ & $553 \pm 320$ \\
\hline & & & 100 & 4,11 & 0,004 & 13,7 & $487 \pm 263$ & $214 \pm 133$ \\
\hline
\end{tabular}

COD = Carbono Orgânico Dissolvido; * = não determinado

Quanto ao tipo de cobertura vegetal observaram-se na floresta secundária concentrações mais elevadas de COD na superfície, a $20 \mathrm{~cm}$ de profundidade, tanto no período seco $533 \pm 320 \mu \mathrm{M}$, como no período chuvoso $922 \pm 354 \mu \mathrm{M}$. Em profundidade, à 100 cm, a concentração decresceu significativamente, passando de 487 $\pm 263 \mu \mathrm{M}$ no período chuvoso, para $214 \pm 133 \mu \mathrm{M}$ no período seco (Tabela 4). Este fato deve estar relacionado com a quantidade de matéria seca que esta floresta perde durante o período seco, e a ciclagem deste material, que é uma fonte significativa de entrada de carbono no solo, que ocorre de forma mais intensa com o início da chuva. 
No reflorestamento, as concentrações de COD foram maiores, quando comparado à área degradada e aos platôs das florestas primárias. Isto pode ser resultado da influência da adição de adubos químicos à base de nitrogênio, fósforo e potássio nesta área quando foi implantado o reflorestamento, e posteriores aplicações anuais. Segundo Schindler et al. (1992), a adição de adubos fosfatados em florestas temperadas pode causar uma elevação nos níveis de carbono orgânico dissolvido. Este mesmo efeito pode estar sendo observado nesta área.

Estudos realizados em pastagem e floresta primária por Cerri (2003), mostram que, na floresta, os valores de COD na solução do solo são mais baixos que nas áreas de pastagem. Uma das possíveis causas para tais resultados é uma maior alocação da produtividade primária líquida na camada superficial do solo em áreas com Brachiaria sp.(Veldkamp, 1994). No presente trabalho, observou-se que na solução do solo dos platôs das florestas primárias, a concentração de COD é inferior aos outros ecossistemas. Entretanto, no baixio as concentrações são mais elevadas.

Comparando-se o mesmo tipo de vegetação com a variação na textura do solo na área de floresta primária, observa-se que a concentração de COD foi significativamente maior no solo de textura arenosa, Espodossol, com concentrações médias durante o período seco de $754 \pm 222 \mu \mathrm{M}$ à $20 \mathrm{~cm}$ de profundidade, e $535 \pm 92 \mu \mathrm{M}$ durante o período chuvoso. No Latossolos de textura muito argilosa as concentrações foram menores, com uma média à $20 \mathrm{~cm}$ de profundidade de $283 \pm 60 \mu \mathrm{M}$ no período chuvoso e $153 \pm 39 \mu \mathrm{M}$, no período seco. O teor de areia do solo apresentou significante correlação positiva com a concentração de COD, constituíndo um dos principais fatores controladores do teor de carbono no solo (Parton et al.,1987; Schimel et al.,1994).

Os processos de adsorção e as superfícies oxidantes dos Latossolos argilosos são mecanismos efetivos de remoção do material orgânico dissolvido da água de infiltração, proporcionando maior estabilidade e proteção à matéria orgânica (McClain et al., 1997). Essa proteção física permite a liberação lenta e gradual do material orgânico para a solução do solo. O mesmo não ocorre nos solos arenosos, como o Espodossol encontrado sobre as áreas de baixio, onde os níveis mais elevados de COD podem ser 
devidos à baixa ou nula capacidade de adsorção da areia, que não permite a estabilização do material orgânico, nem o armazenamento no solo. Desta forma, nestes solos o material orgânico é disponibilizado rapidamente via solução do solo.

$\mathrm{Na}$ encosta, os Argissolos argilosos apresentaram características intermediárias àquelas dos solos das áreas sobre platô (Latossolo), e sobre baixio (Espodossol). Os resultados da concentração do carbono orgânico dissolvido apresentam paralelismo com estas características, com valores também intermediários entre platô e baixio, confirmando a relação que existe entre as proporções, areia e argila do solo e a concentração de COD na solução do mesmo.

Os maiores teores de argila observados nos Latossolos, também estão associados com os maiores teores de óxidos de ferro e alumínio, e menores concentrações de COD (Tabela 4). Na superfície dos Latossolos e Argissolos, as concentrações destes metais são significativamente mais elevadas à $20 \mathrm{~cm}$, comparado à $100 \mathrm{~cm}$ de profundidade. $\mathrm{O}$ oposto ocorre com a concentração de COD em solução, para a qual observam-se as maiores concentrações à $100 \mathrm{~cm}$ (Figura 22).

O alumínio e o ferro são os cátions dominantes nos solos estudados. Estes metais são fortes controladores de COD, devido ao mecanismo de adsorção dos mesmos e remoção de material orgânico dissolvido da solução do solo, formando precipitados (McDowell \& Wood, 1984; Nelson et al., 1993; McKnight et al., 1992; Drever, 1997). Nos solos estudados, as menores concentrações de COD na superfície, devem estar relacionadas com estes processos de adsorção do mesmo às partículas de argila e à complexação com ferro e alumínio (Figura 22 e 23). Em profundidade (100 cm), observou-se um decréscimo significativo destes metais com aumento significativo dos teores de COD. O que demonstra a existência de correlação negativa entre os teores de COD e de ferro e alumínio.

No Espodossolo, a dinâmica do ferro e alumínio é um pouco diferenciada, não ocorrendo a adsorção destes metais à matriz arenosa, resultando em menores teores destes no solo. 


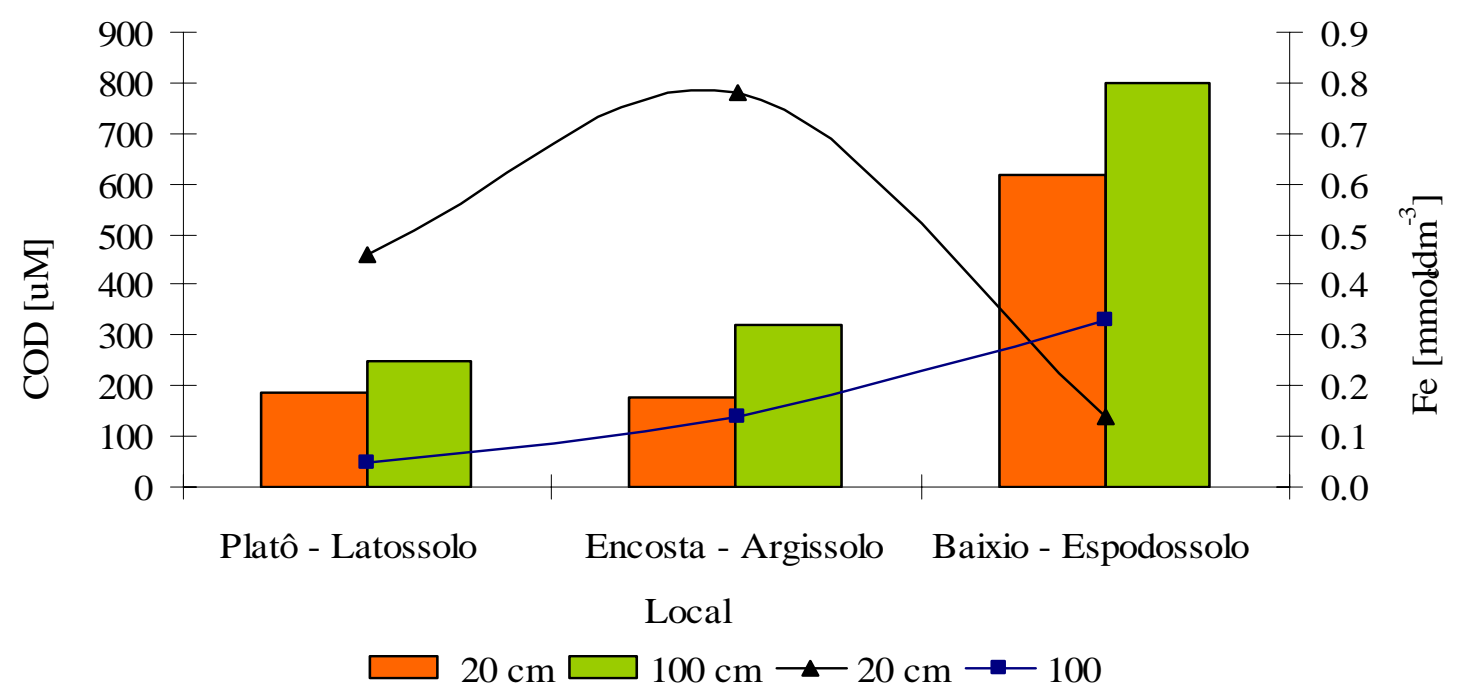

Figura 22 - Concentrações médias de COD e ferro na solução do solo, nos diferentes tipos de solo na floresta primária ZF2

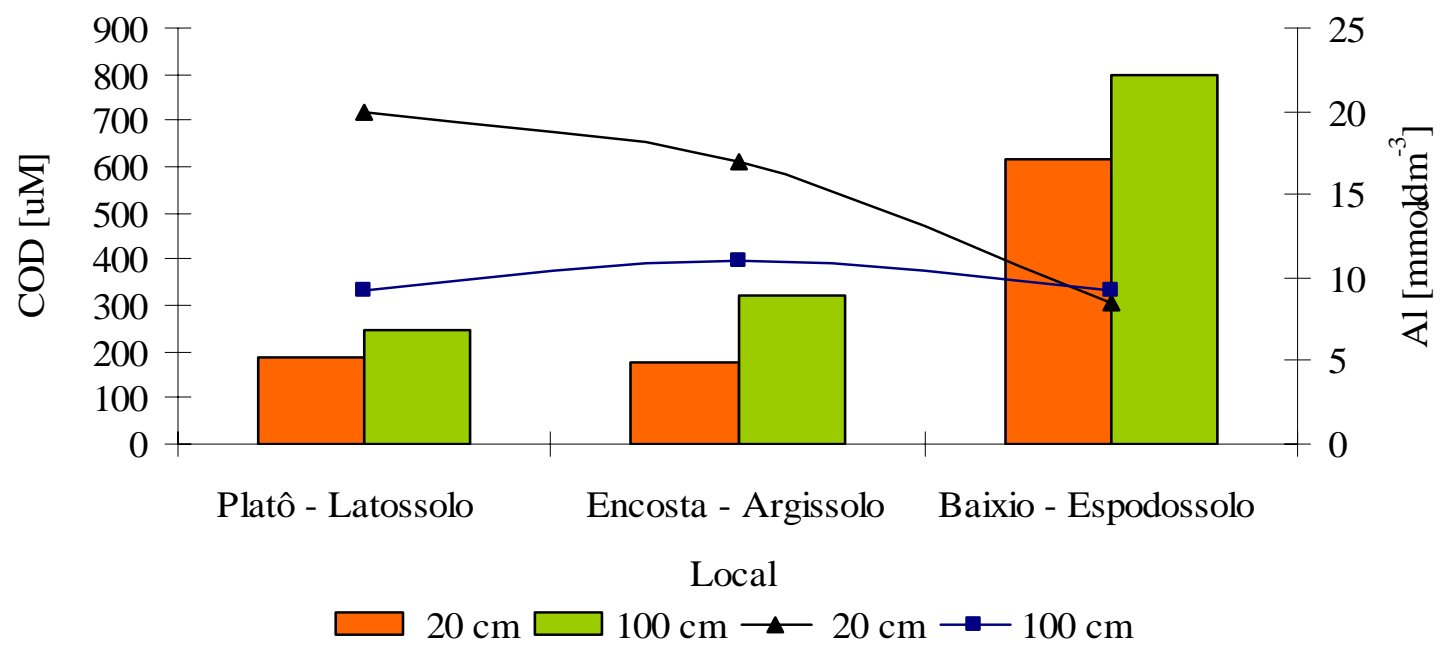

Figura 23 - Concentrações médias de COD e alumínio na solução do solo, nos diferentes tipos de solo na floresta primária ZF2 
A associação do baixo conteúdo de argila ( $<5 \%$ ), com os menores teores de ferro e alumínio, resultam em valores máximos de COD em solução nos Espodossolos.

Ao contrário do que foi proposto anteriormente por alguns autores, como Dawson (1981), Meyer \& Tate (1983), Thurman (1985), McClain et al. (1997), BATJES et al. (1999), Kalbitz (2001), Fiedler \& Kalbitz (2003), Schwesig et al. (2003), neste estudo observou-se aumento de COD em profundidade (Figura 21). Nos solos onde há vegetação, o aumento foi mais acentuado, indicando como fonte potencial de contribuição os exudados de raízes. Segundo McClain et al. (1997), existem indicativos de que os exudados produzidos pelas raízes podem contribuir com cerca de $40 \%$ do material seco produzido pelas plantas, mas isto não foi comprovado.

No Espodossol, observou-se acúmulo de carbono orgânico, com distribuição relativamente uniforme no perfil. Telles (2003), avaliando estoques de carbono no solo desta mesma área, observou que, à $45 \mathrm{~cm}$ de profundidade, ocorre um ligeiro aumento, o que se explica pelo meio hidromórfico do solo.

Na Amazônia Central, as áreas sobre baixio geralmente estão associadas à solos arenosos, que podem ser grandes fontes contribuidoras de COD, exportado para os rios, terras úmidas e solos de regiões ripárias, durante períodos de maiores precipitações. De acordo com Hinton et al. (1998), apenas 8\% do total da área da bacia exporta cerca de 32 a $46 \%$, do carbono.

As concentrações de COD na solução do solo estão correlacionadas negativamente com o pH da solução. Observa-se que a solução do solo é ácida em todos os solos estudados, apresentando uma pequena tendência de aumento com a profundidade. Na superfície, o teor de matéria orgânica no solo proporciona um meio mais básico. Ocorrem variações nos diferentes tipos de solo e cobertura vegetal, sendo observadas na floresta primária, sob baixio, as concentrações mais elevadas de COD e os menores valores de pH, demonstrando a relação entre pH e concentração de COD.

Essa variação do pH, tornando o meio mais ácido no solo Espodossol, é devida à presença de ácidos orgânicos e à atividade biológica. Estes fatores previnem a rápida decomposição da matéria orgânica pelas bactérias e aumento do carbono orgânico 
dissolvido (Thurman, 1985). Guggenberger \& Zeach (1993), detectaram concentrações significativamente elevadas de COD em florestas de coníferas com grande aporte de ácidos e pH baixo, em relação a outros locais, sugerindo que o grande aporte de ácidos

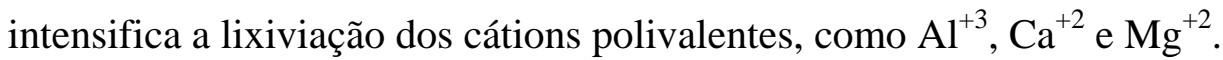

Além dos fatores já discutidos, a concentração de COD também está relacionada com a posição do solo no perfil e no relevo. O aumento de COD à $100 \mathrm{~cm}$ de profundidade, indica deslocamento do mesmo em relação à posição do relevo, fato que pode ser observado em quase todos os ecossistemas, com exeção da floresta secundária e da área degradada. Ao longo da toposequência na floresta primária, observa-se nitidamente este aumento em profundidade no solo e aumento no sentido das áreas mais altas (platô) as mais baixas do relevo (Tabela 04, Figura 21). Este incremento com a profundidade é significativo no perfil e na toposequência, o que pode representar uma via de perda de carbono do ecossistema terrestre via solução do solo (Solinger et al., 2001).

\subsubsection{Nitrogênio}

O nitrogênio é encontrado nas formas orgânica e inorgânica na solução do solo. Em geral a forma inorgânica predominante nestes ecossistemas é a de nitrato, com exceção da área com maior grau de degradação, na qual observa-se a predominância de nitrito e amônio, que se deve a degradação física desta área (Figura 24).

As frações nitrito e o amônio, apresentaram distribuição relativamente uniforme ao longo dos perfis, com valores extremamente baixos, como observar-se nas Figuras 25 e 26. Em muitas amostragens, não foi possível detectar estas frações, devido às concentrações estarem abaixo do limite de detecção do equipamento, que no caso do nitrito é de 0,0005 $\mu \mathrm{M}$ e para o amônio é de 0,0015 $\mu \mathrm{M}$. 
Floresta Primária ZF2 - Platô

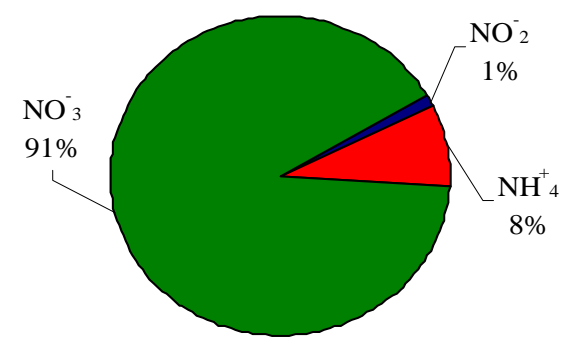

Área Degradada - Platô

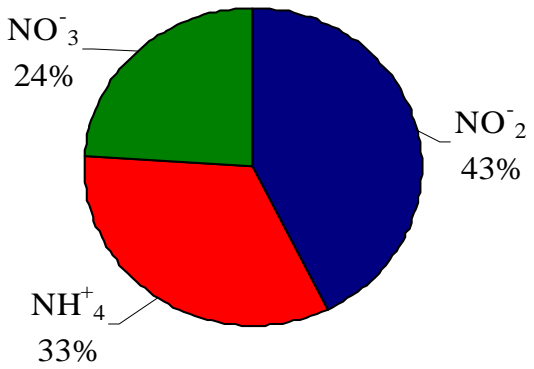

Figura 24 - Percentual das frações inorgânicas de nitrogênio na floresta primária e área degradada

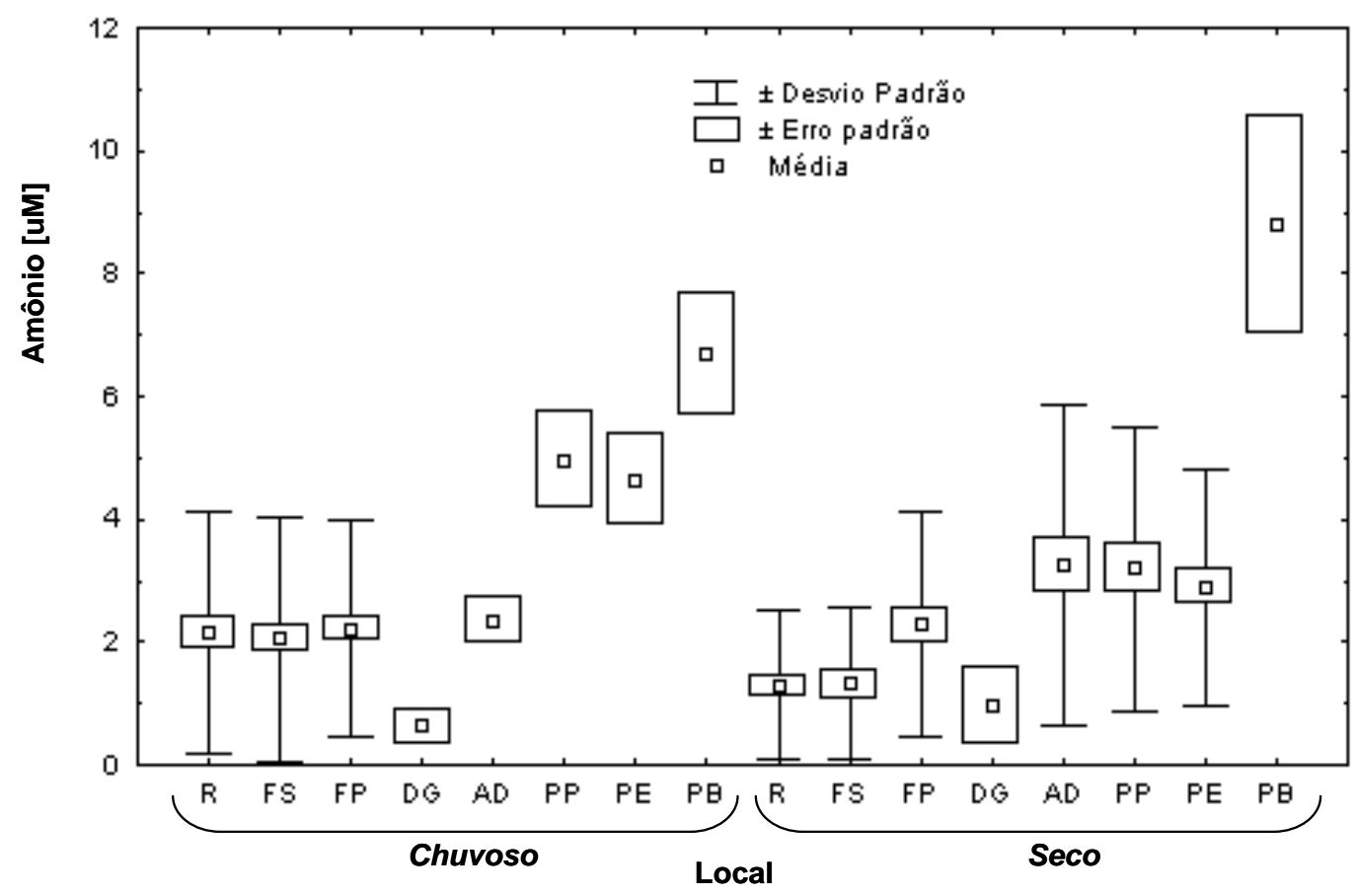

Figura 25 - Concentrações médias de amônio $[\mu \mathrm{M}]$ e desvio padrão, durante o período chuvoso e seco, na solução do solo, para os diferentes ecossistemas estudados. R= Reflorestamento; FS = Fl. Secundária; DG = A. Degradada com Gramíneas; $\mathrm{AD}=$ Área com maior grau de Degradação; PP = Fl. Primária Platô; PE = Fl. Primária Encosta; PB = Fl. Primária Baixio 
Este comportamento, com baixas concentrações de nitrito e amônio e concentrações mais elevadas de nitrato é característico de florestas tropicais, onde não existe limitação de nitrogênio para os processos de nitrificação. Quando o solo está sob condições favoráveis, de boa drenagem e aerobiose, o meio se torna propício para o desenvolvimento de organismos aeróbios. Neste caso, o ciclo do nitrogênio segue a seqüência de reações na qual o amônio se oxida à nitrito pela ação de bactérias (Nitrossomonas). O nitrito não é acumulado no solo, como é observado na Figura 26; parte se perde e outra parte é oxidada pelas bactérias (Nitrobacter) à forma de nitrato.

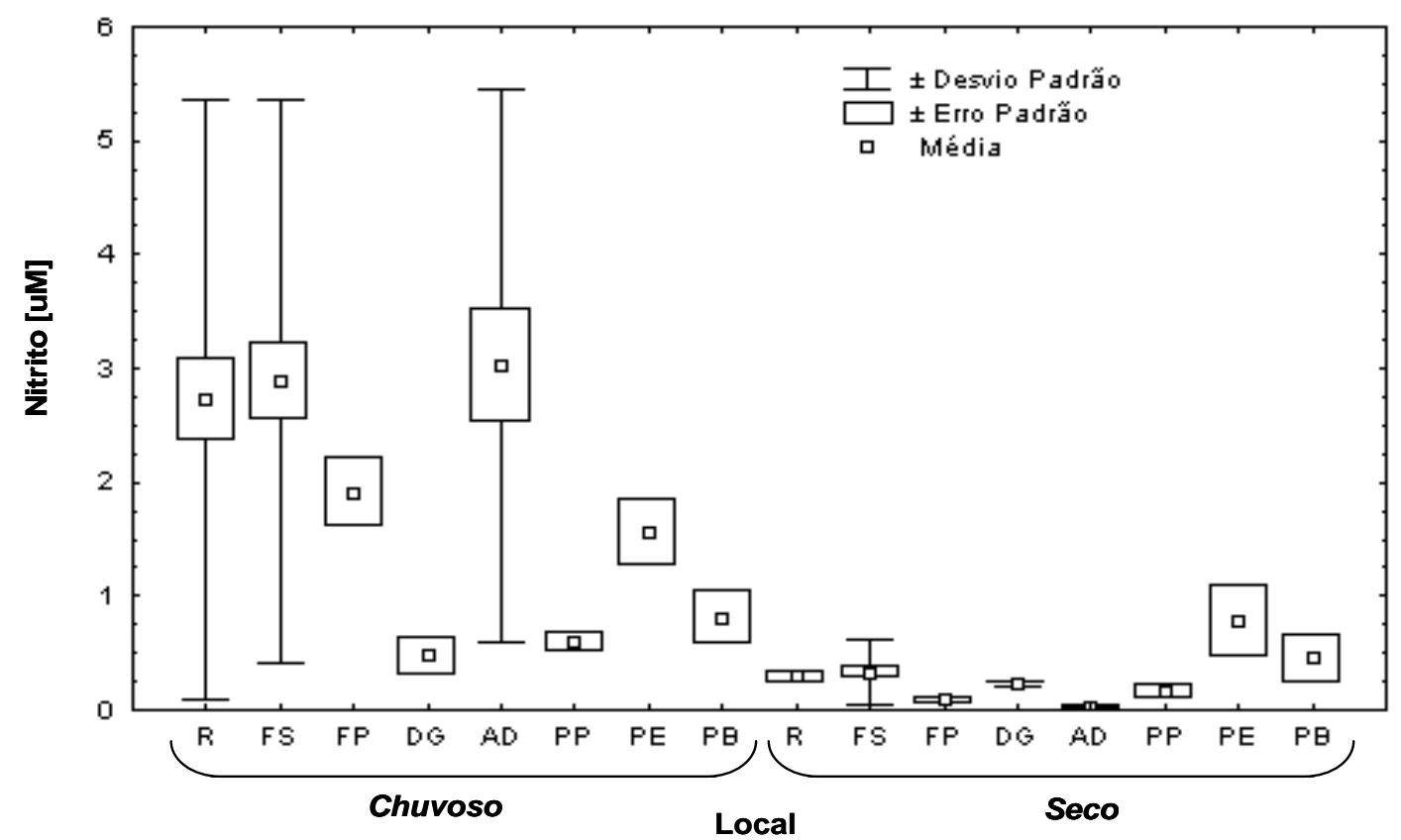

Figura 26 - Concentrações médias de nitrito $[\mu \mathrm{M}]$ e desvio padrão, durante o período chuvoso e seco, na solução do solo, para os diferentes ecossistemas estudados (Legenda Figura 25)

Acompanhando as variações pedológicas e topográficas ao longo do gradiente de elevação na floresta primária, observa-se que as concentrações de nitrato e amônio aumentaram significativamente do platô em direção ao baixio. Um dos fatores responsáveis pelas concentrações mais elevadas de amônio no baixio é o contínuo 
abastecimento deste solo, mal drenado, pelo lençol freático, levando ao aumento desta fração, fator que não ocorre nas áreas sobre os platôs e as encostas, que se caracterizam por solos de boa drenagem.

Nos trópicos úmidos, o nitrato pode ser levado a profundidades maiores no solo, através dos processos de lixiviação (Brady \& Weil, 1999). Neste trabalho, observou-se concentrações significativas até 1,5 m de profundidade em todos os solos, indicando a lixiviação desta fração, devido à baixa capacidade que este elemento apresenta de se adsorver as partículas de solo. Na comparação entre as diferentes texturas de solo, observa-se correlação positiva do nitrato com o teor de areia do solo, que pode ser observado na toposequência da floresta primária (Figura 27). No Espodossolo arenoso, foram obtidos os teores mais elevados da fração de nitrato a todas as profundidades, se comparado ao Argissolo (argilosso) e ao Latossolo (muito argiloso). Isso pode ser consequência da suscetibilidade que os solos arenossos apresentam em perder nitrato via lixiviação. A perda de nitrato leva também à lixiviação de cátions que aumentam a acidez do solo, como constatado no Espodossolo, com baixo pH.

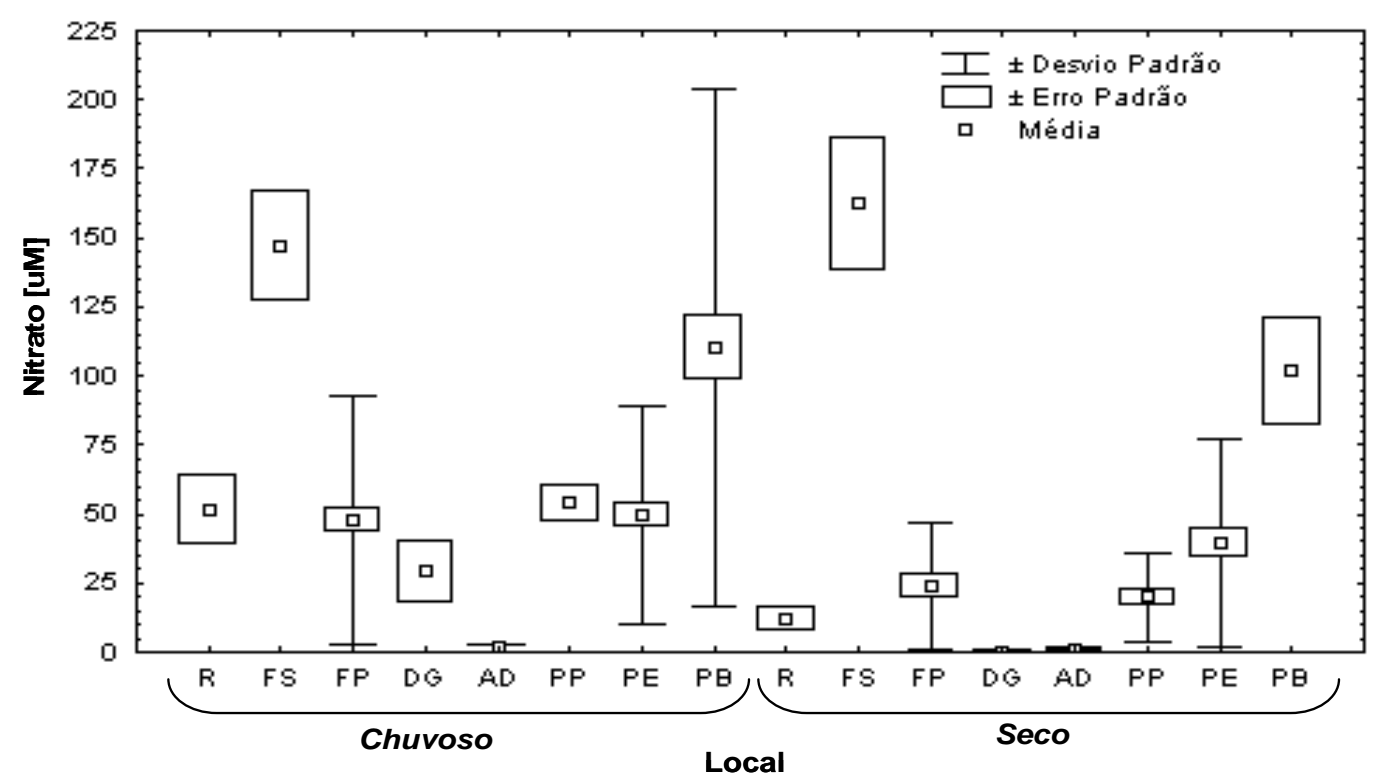

Figura 27 - Concentrações medias de nitrato $[\mu \mathrm{M}]$ e desvio padrão, durante o período chuvoso e seco, para os diferentes ecossistemas estudados (Legenda Figura 25) 
Com relação ao tipo de cobertura vegetal, a floresta secundária apresenta fortes sinais de recuperação, com teores significativamente maiores de nitrato, comparado ao que foi encontrado na floresta primária sobre Latossolos. Nesta floresta ocorre grande perda de biomassa durante o período seco, que pode ser constado pela presença de uma densa camada de serrapilheira sobre o solo no final deste período. Como resultado disso, a fração nitrato apresentou concentrações significativamente maiores neste ecossistema, principalmente até a profundidade de $50 \mathrm{~cm}$. Neste ecossistema, o nitrato apresentou uma dinâmica diferente na camada superficial em relação à camada mais profunda do solo. Na superfície as concentrações mantiveram-se elevadas durante o período seco. Por outro lado, na camada inferior aos $50 \mathrm{~cm}$ de profundidade, seu comportamento foi semelhante ao dos outros ecossistemas, com concentrações significativamente maiores somente após os primeiros eventos de chuva e caíndo significativamente durante os eventos de seca e no decorrer do período chuvoso. Este decréscimo mostra a forte influência da matéria orgânica na concentração deste elemento.

As duas áreas degradadas avaliadas apresentaram as menores concentrações das frações de nitrogênio. A área com maior grau de degradação apresentou como formas predominantes o amônio e o nitrito, enquanto a área degrada, com as mesmas condições geológicas e pedológicas, porém coberta por um denso povoamento de gramíneas, seguiu o padrão das outras áreas estudadas, no qual a forma predominante é o nitrato na solução do solo. Nesta área observam-se valores significativos no período chuvoso, o que pode ser explicado pela grande eficiência das gramíneas como introdutoras de matéria orgânica ao sistema. Estes dados são mais um indicativo da influência da cobertura vegetal na concentração das frações de nitrogênio no solo.

A precipitação também influencia as frações de nitrogênio, uma vez que as principais via de entrada deste elemento são a decomposição e mineralização da matéria orgânica, a água da chuva, e a água de lavagem da biomassa viva e morta, que são acumulados sobre o solo e a vegetação durante o período seco (Smethust, 2000). Com o início da chuva, este material é lavado e grande parte entra no sistema solo, levando a um aumento significativo de nitrato na solução (Figuras 27 e 28). 
A precipitação apresentou grande influência sobre as concentrações de amônio e nitrito (Figura 29). Para o amônio e o nitrito, foi observado que o pico de maior concentração coincide com o final do período chuvoso, quando o solo apresentou o maior estoque de água, menor presença de oxigênio, e a atividade biológica passa a ser anaeróbia, que está correlacionado com fatores físicos do solo e a topografia local.

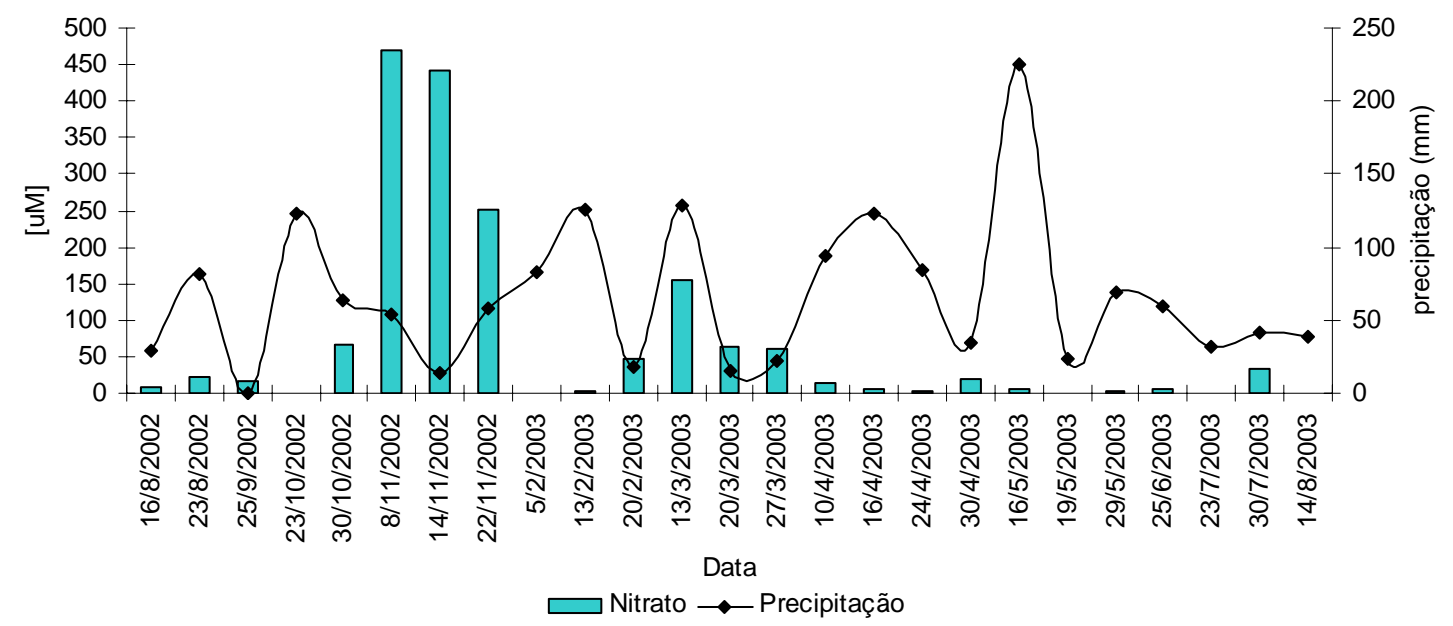

Figura 28 - Variações sazonais da precipitação $(\mathrm{mm})$ e concentrações de nitrato $[\mu \mathrm{M}]$ na solução do solo

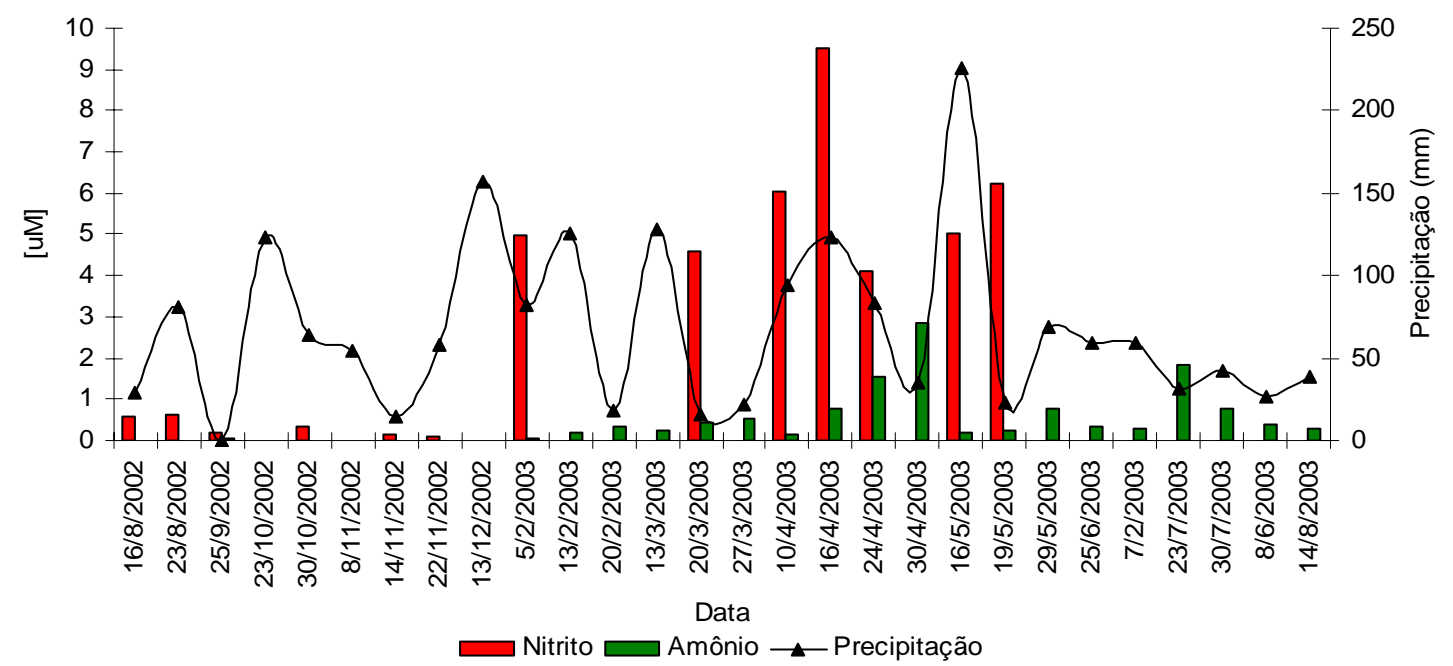

Figura 29 - Variações sazonais da precipitação (mm) e concentrações de nitrito e amônio $[\mu \mathrm{M}]$ na solução do solo 


\subsubsection{Cátions}

Ao avaliar as características químicas da solução do solo, deve-se considerar, inicialmente, a influência dos aportes atmosféricos. Mortatti (1995), em trabalho realizado na região Amazônica, observou que, para alguns elementos, o aporte atmosférico é significativo. Na composição química da água da chuva na região de Manaus, este mesmo autor observou que, no ano de 1989, somente via precipitação ocorreu a entrada de 7,02 $\mu \mathrm{M}$ de sódio, 4,61 $\mu \mathrm{M}$ de potássio, 6,50 $\mu \mathrm{M}$ de cálcio e 0,36 $\mu \mathrm{M}$ de magnésio ao sistema.

Para caracterizar as tendências quanto à predominância de cátions na solução do solo foram utilizados diagramas ternários, gerados a partir das concentrações médias de: sódio $\left(\mathrm{Na}^{+}\right)$, potássio $\left(\mathrm{K}^{+}\right)$, cálcio $\left(\mathrm{Ca}^{+2}\right)$ e magnésio $\left(\mathrm{Mg}^{+2}\right)$ para os períodos seco e chuvoso (Figura 30).

Observou-se uma tendência sódica-potássica da solução do solo, para a maioria dos ecossistemas avaliados, sendo o sódio o elemento de maior contribuição para esta tendência, fato também observado por Ferreira (1999). O sódio apresentou correlação com a sazonalidade pluviométrica, a pedologia local e a cobertura vegetal. Durante o período seco, o sódio originário da ciclagem de aerosóis marinhos, se deposita sobre a vegetação, e com o ínicio do período chuvoso, ocorre a lavagem da vegetação e uma entrada significativa deste cátion via transprecipitação e também pela água da chuva (Likens \& Bormann, 1977; Mortatti, 1995; Grimaldi, 2004).

Neste trabalho isso pode ser constatado, pelas concentrações mais elevadas de sódio durante o período chuvoso e após eventos isolados de chuva (Figura 31 e 32) sendo estas as principais fontes de sódio para esta região. Outra via de entrada é através dos processos de podzolização, no qual ocorre a hidrólise de aluminossilicatos, como a albita $\left(\mathrm{NaAlSi}_{3} \mathrm{O}_{8}\right)$, mineral primário que se transforma em caulinita, liberando sódio e alumínio para a solução do solo (Mortatti, 1995). 


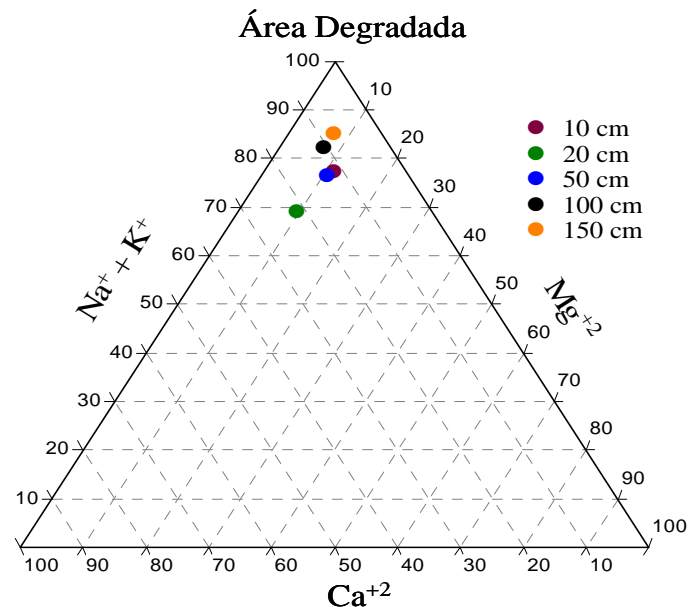

Floresta Secundária

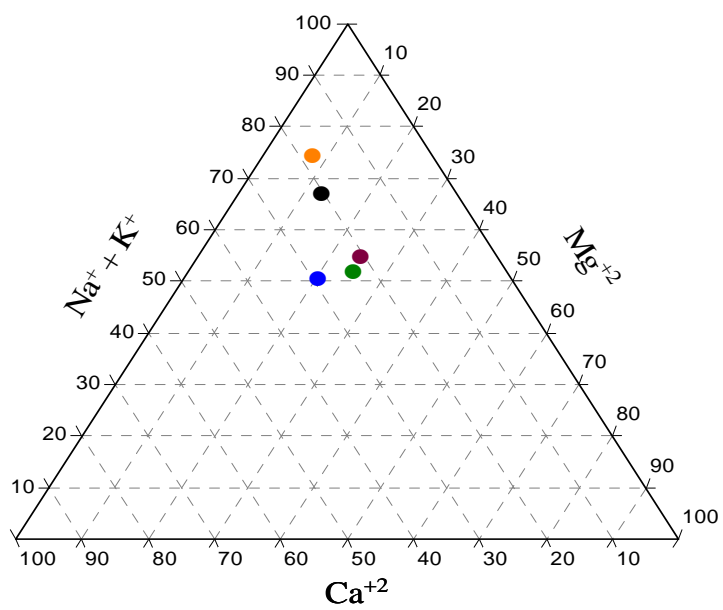

Floresta Primária Platô

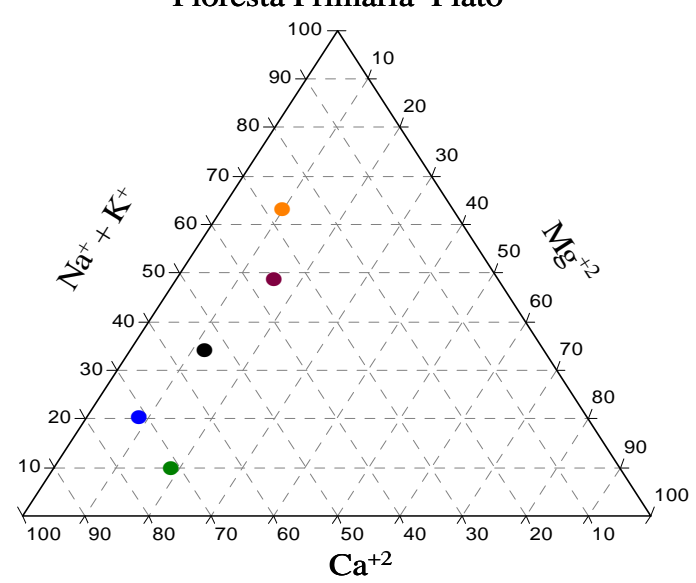

Reflorestamento

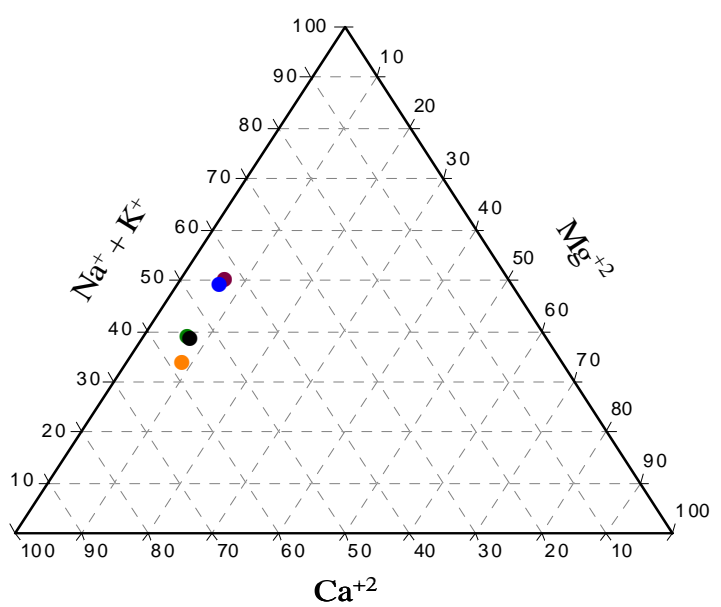

Figura 30 - Diagramas ternários elaborados a partir das concentrações médias dos cátions presentes na solução do solo

Este fato pode ser observado na Figura 32, pela presença significativa de sódio em todos os ecossistemas. Na floresta primária, as concentrações de sódio foram maiores, mas não significativamente, isto resulta da produção des exudados de raízes, sendo esta uma via importante de entrada de sódio em ecossistemas cobertos por vegetação.

Observamos que a vegetação apresentou influência na predominâncias dos cátions em cada ecossistema. A área com maior grau de degradação foi a que apresentou a maior tendência sódica-potássica para os dois períodos (seco e chuvoso). Isso indica 
que a principal via de entrada destes nutrientes em ecossistemas sem cobertura vegetal é abiótica, via precipitação e deposição atmosférica (Figura 30). Nas florestas primária e secundária, observa-se a influência da matéria orgânica, com contibuição do cálcio e magnésio.

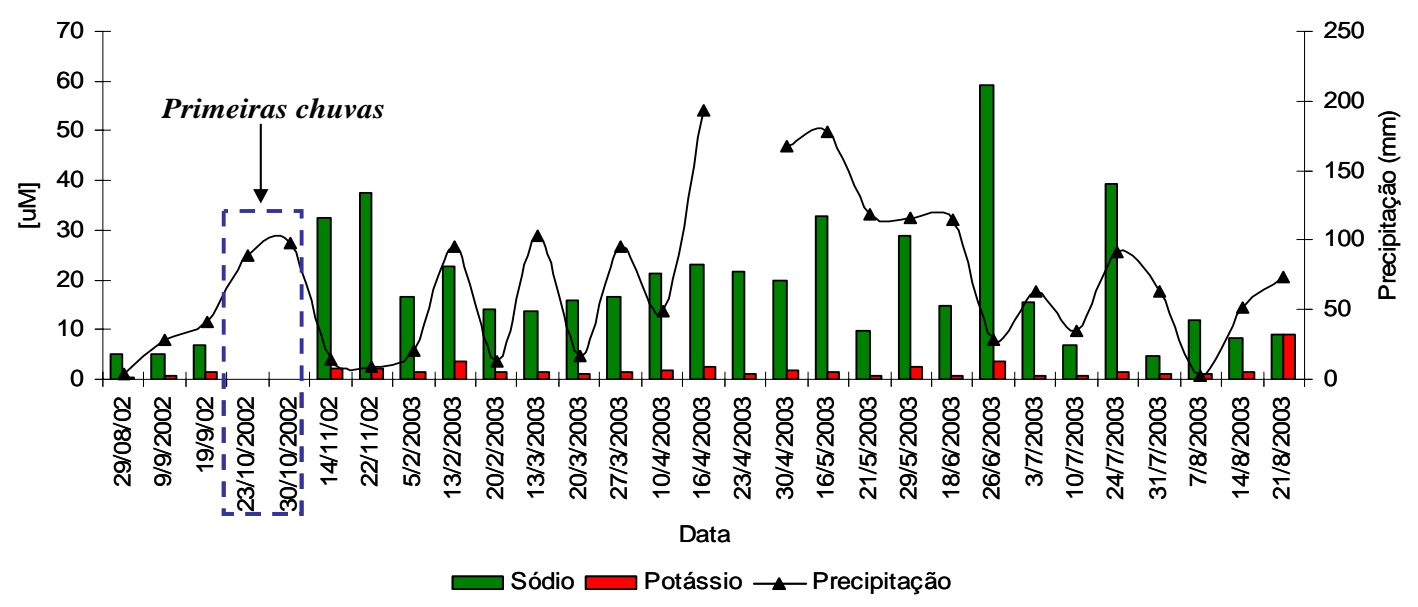

Figura 31 - Variações sazonais da precipitação (mm) e concentrações de sódio e potássio $[\mu \mathrm{M}]$ na solução do solo

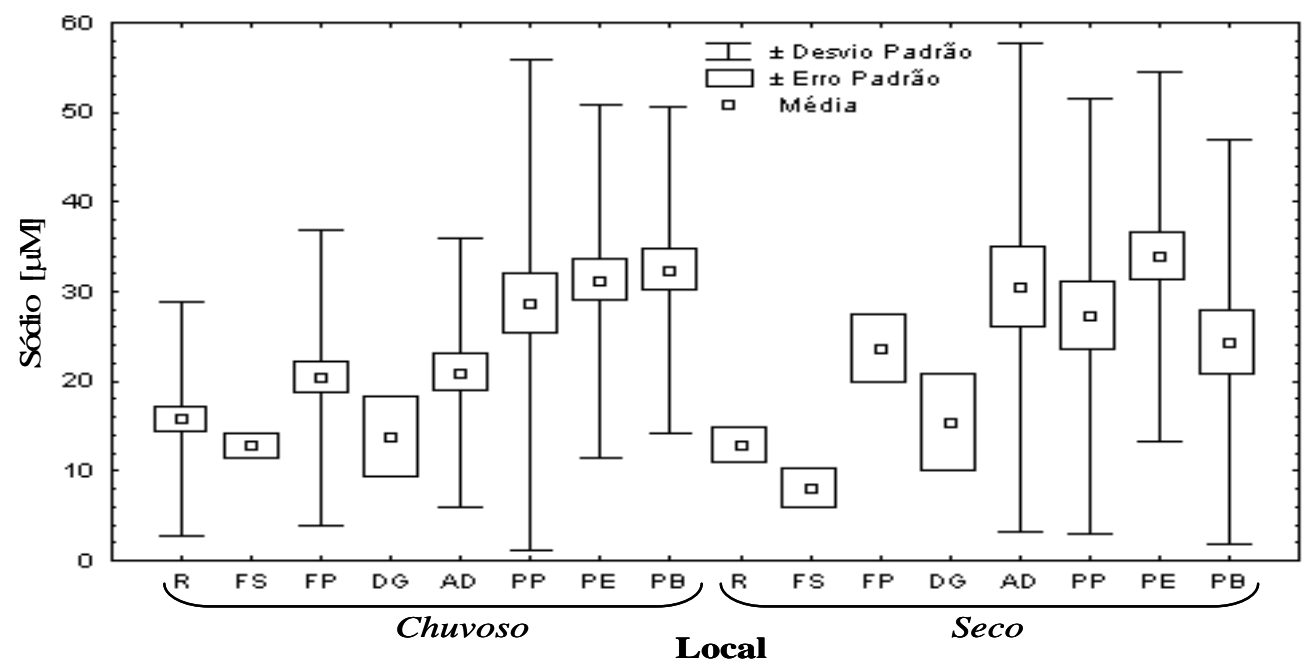

Figura 32 - Concentrações médias e desvio padrão das concentrações de sódio $[\mu \mathrm{M}]$ na solução do solo, durante o período seco e chuvoso. $\mathrm{R}=$ reflorestamento; FS= fl. secundária; $\mathrm{DG}=$ degradada com gramíneas; $\mathrm{AD}=$ maior grau de degradação; $\mathrm{PP}=$ fl. primária platô; $\mathrm{PE}=$ fl. primária encosta; $\mathrm{PB}=$ fl. primária baixio 
De forma geral, observaram-se concentrações extremamente baixas de potássio na solução do solo, tanto no período seco como chuvoso, com concentrações de muitas amostragens abaixo do limite de detecção do equipamento $(0,12 \mu \mathrm{M})$. Um dos fatores responsáveis pela limitação de potássio nos ecossistemas pode ser a facilidade com que este cátion é perdido, devido à sua grande mobilidade, que facilita sua lixiviação. Este elemento apresenta como principais fontes de entrada, a transprecipitação, e a lavagem do material acúmulado (excremento de animais e material orgânico) sobre os troncos, galhos e folhas das árvores (Vitousek et al., 1986; Arocena, 2000).

O potássio apresentou variações significativas com a vegetação, com valores máximos de concentração no baixio da floresta primária. Na área com maior grau de degradação, observou-se concentrações significativas de potássio e também de cloreto, que podem ser decorrência das várias práticas aplicadas à esta área, na tentativa de recuperação. Iniciamente foi introduzida nesta área a cultura do guaraná, que não teve sucesso e, posteriomente, o pau de balsa. A fim de se obter maior sucesso na recuperação desta área, foi realizada a aplicação de fertilizantes, dentre os quais foi adicionado cloreto de potássio. Acredita-se que neste solo deva haver resíduos destes íons, que estão influenciado as concentrações na solução do solo.

A textura do solo também apresentou influência na distribuição dos cátions na solução do solo. Com o aumento do teor de areia, ocorre a diminuição da capacidade de retenção de potássio pelo solo. O Espodossol arenoso disponibilizou mais rapidamente este íon para solução do solo, com concentrações significativamente maiores em todas as profundidades, quando comparado aos solos com maior conteúdo de argila, como o Latossolo e o Argissolo (Figura 33).

Nos ecossistemas cobertos por vegetação, observa-se que a tendência não é apenas sódica-potássica, mas também cálcica, com influência do magnésio, fato que resulta das vias principais de entrada de cálcio e magnésio nos ecossistemas Amazônicos. Segundo Brinkmann \& Santos (1973), as fontes importantes de adição de cálcio solúvel ao solo são as águas provenientes da lavagem pela chuva, das copas, dos caules, folhas e a dissolução de produtos metabólicos de macro e microorganismos. 
Devido a esses processos, o transporte de cálcio solúvel ocorreu principalmente no início da estação chuvosa, e também durante eventos isolados de chuva (Figura 34).

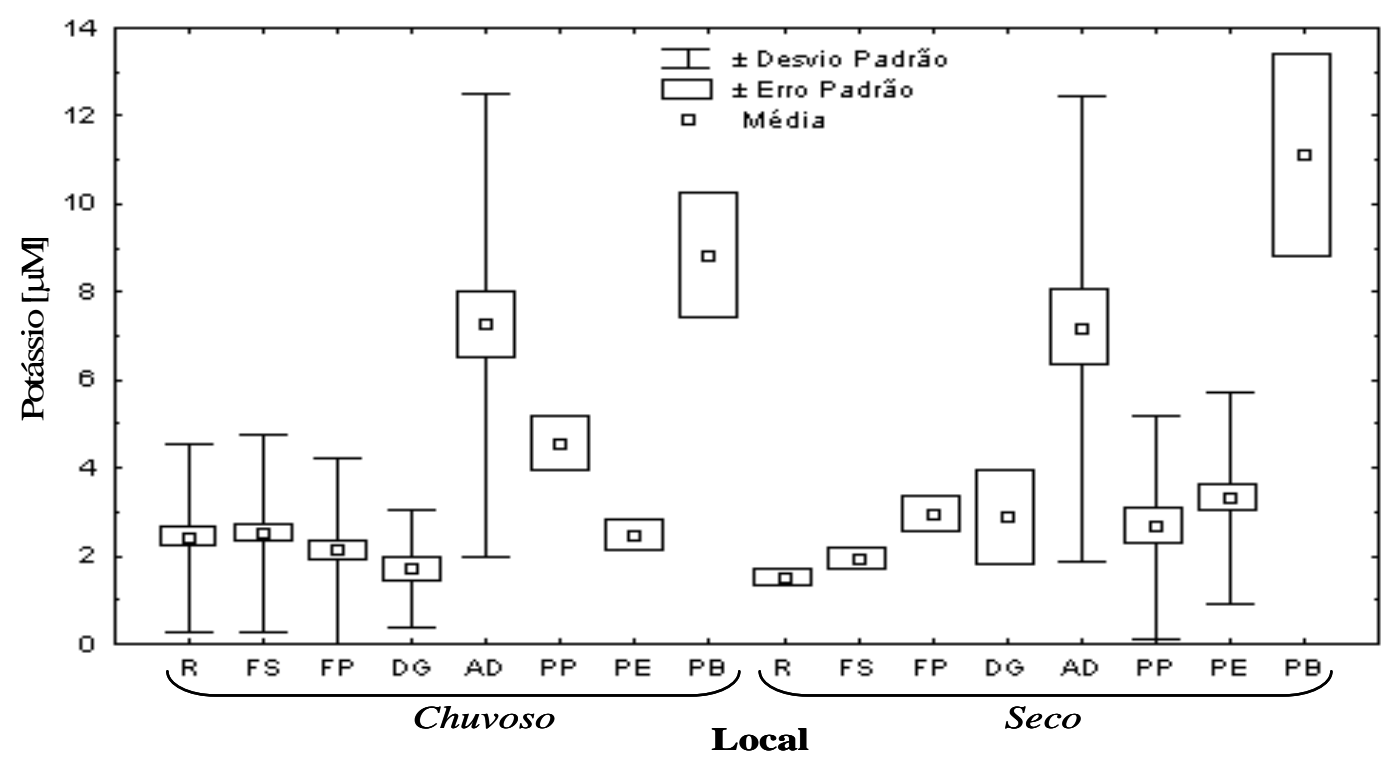

Figura 33 - Concentrações médias e desvio padrão das concentrações de potássio na solução do solo durante o período chuvoso e seco (Legenda Figura 32)

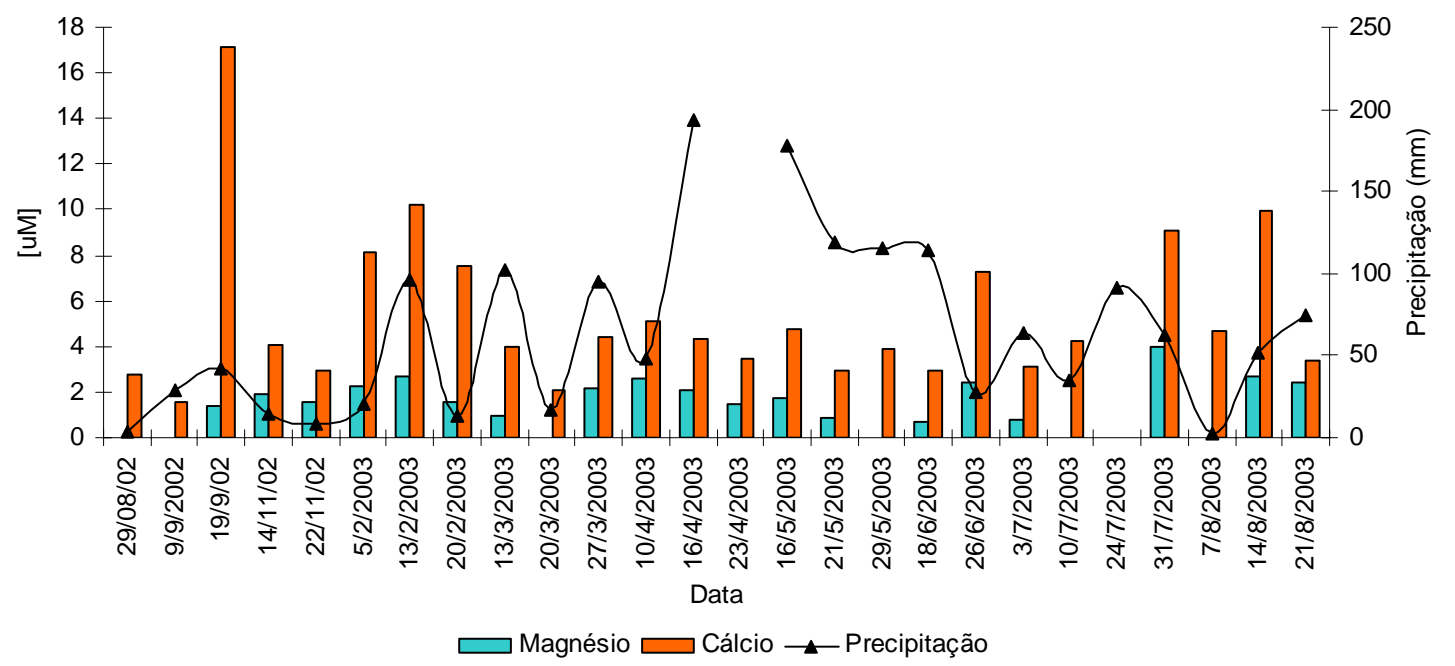

Figura 34 - Variações sazonais da precipitação $(\mathrm{mm})$ e concentrações de magnésio e cálcio[ $\mu \mathrm{M}]$ na solução do solo 
De modo geral, o cálcio e o magnésio apresentaram concentrações extremamente baixas em todos os ecossistemas. Apresentaram correlação estatísticamente significativa com o tipo de cobertura vegetal, que influencia as vias de entrada. Em ecossistemas sem cobertura vegetal, a principal entrada de cálcio e magnésio no sistema solo é através do intemperismo de silicatos e carbonatos, como a anortita $\left(\mathrm{CaAl}_{2} \mathrm{Si}_{2} \mathrm{O}_{2}\right)$, a calcita $\left(\mathrm{CaCO}_{3}\right)$ e a dolomita $\left(\mathrm{CaMg}\left(\mathrm{CO}_{3}\right)_{2}\right)$ Como os solos estudados são muito intemperizados, está é uma fonte pouco significativa na contribuição de cálcio e magnésio ao solo.

Por meio dos diagramas ternários percebe-se que nas áreas de florests primária e secundária e no reflorestamento, existe uma tendência maior da contribuição de cálcio e em menor proporção do magnésio, que o observado na área degradada (Figura 30, 35 e 36). Para o reflorestamento, o aumento do cálcio deve também estar associado ao processo de recuperação do solo desta área, ao qual foi adicionado calcário, antes e durante a implantação do reflorestamento.

Já na área degradada, coberta por gramíneas, o cálcio apresentou concentrações similares aos valores encontrados na floresta primária. Isto pode ser devido à influência das várias práticas de corte e queima que está área sofreu, que introduziram cálcio ao sistema. Como este cátion apresenta baixa mobilidade, ocorrem poucas perdas pela lixiviação, fato que pode, ainda, estar associado à falta de cobertura vegetal lenhosa, que apresenta maior potencial e necessidade de extração deste íon. O denso povoamento de gramíneas, também é uma fonte de cálcio através da ciclagem de raízes.

Outro fator que influencia significativamente a dinâmica do cálcio e do magnésio é a textura do solo, a qual apresentou forte correlação com a concentração destes íons. Em solos argilosos, estes cátions são retidos pelo matriz do solo de forma mais eficiente, enquanto nos arenosos são liberados com maior facilidade para a solução. Esta condição foi observada no Espodossol da floresta primária, o qual apresentou concentrações significativamente maiores em relação aos demais solos com maiores teores de argila. CAMPO et al. (2000), observou, em águas de rios que drenam solos arenoso, concentrações relativamente altas de magnésio o que, provavelmente, se deve à 
exportação proveniente do solo, uma vez que os mesmos apresentam baixa capacidade de retenção deste íon.

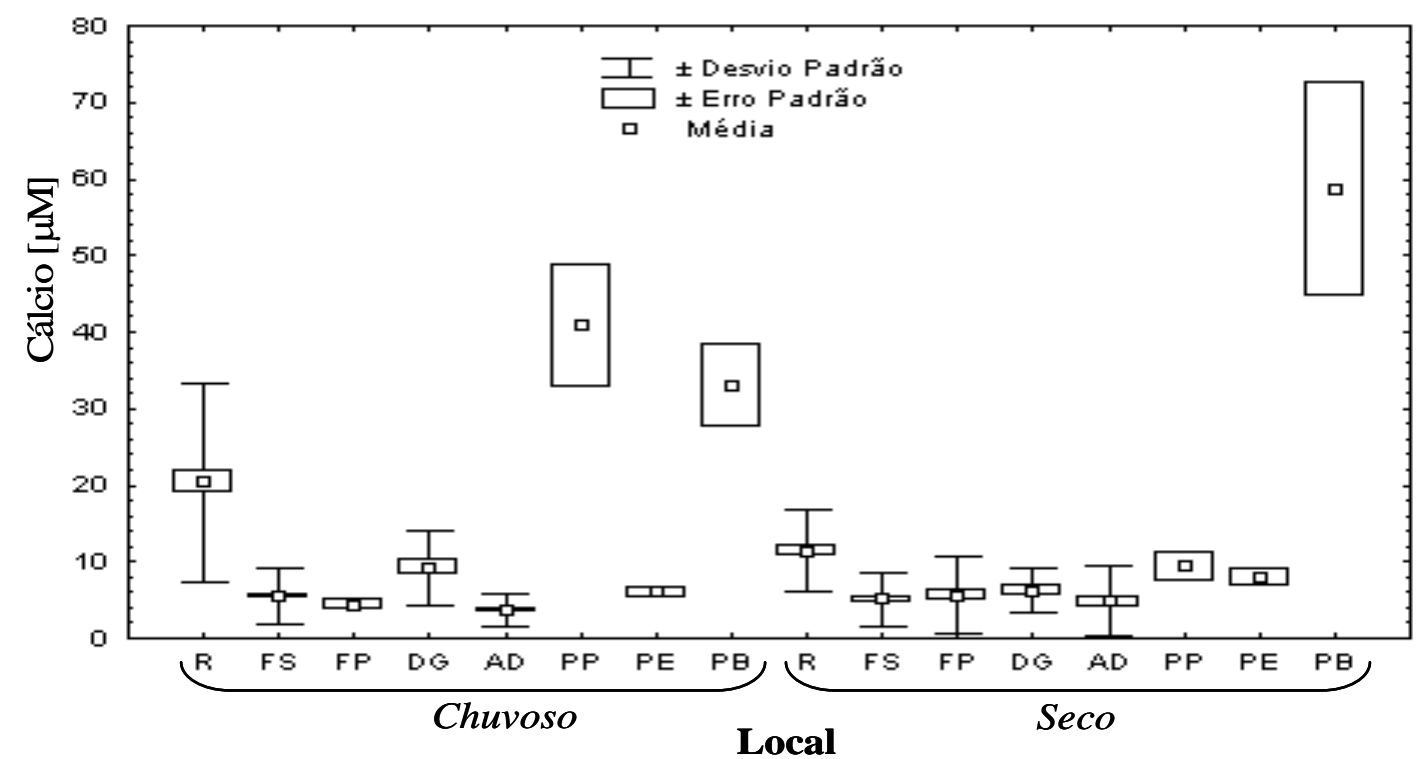

Figura 35 - Concentrações médias e desvio padrão das concentrações de cálcio na solução do solo durante o período chuvoso e seco (Legenda Figura 32)

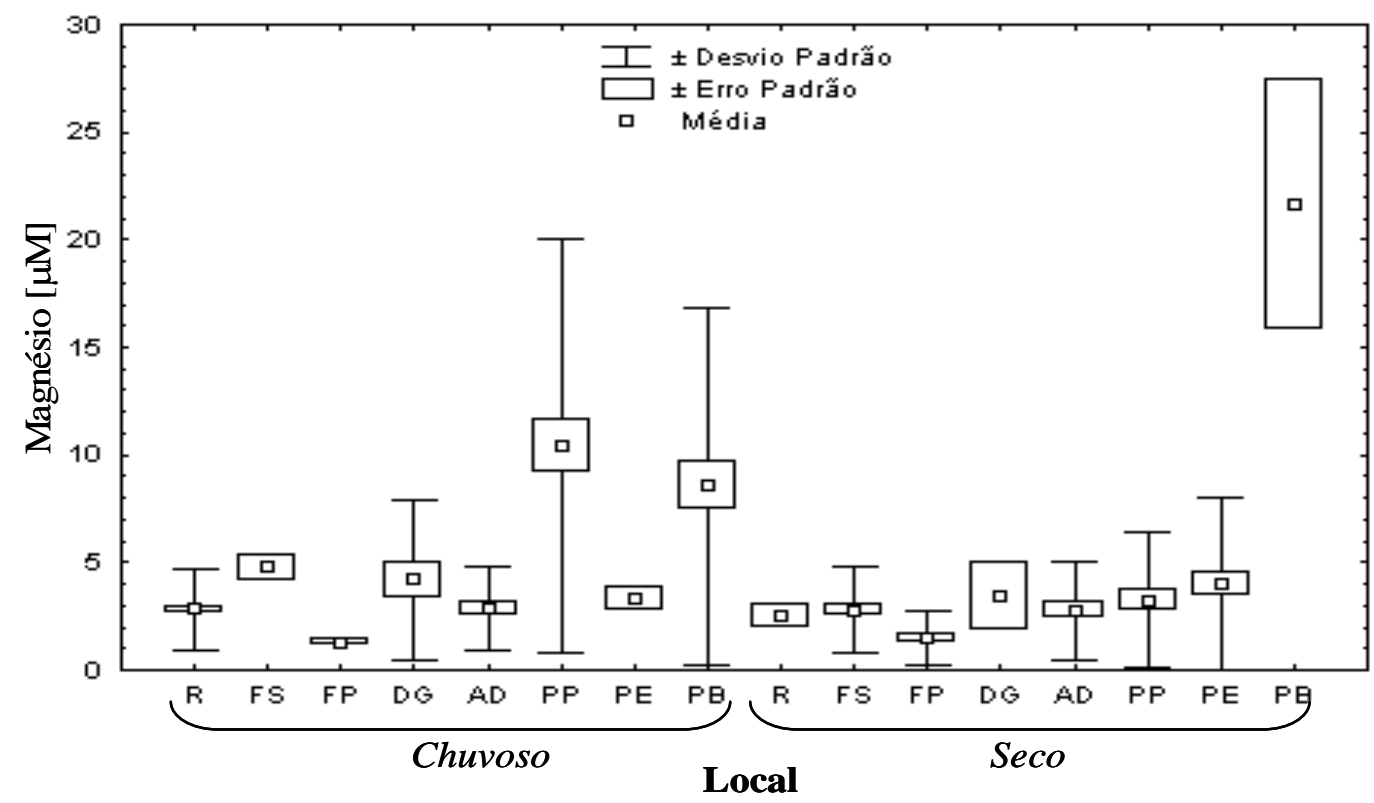

Figura 36 - Concentrações médias e desvio padrão das concentrações de magnésio na solução do solo durante o período chuvoso e seco (Legenda Figura 32) 


\subsection{4 Ânions}

Para a região de Manaus foi estimada uma entrada via precipitação de 10,66 $\mu \mathrm{M}$ de $\mathrm{SO}_{4}^{-}$e 7,78 $\mu \mathrm{M}$ de $\mathrm{Cl}^{-}$no ano de 1989 por Mortatti (1995). O mesmo calculou a influência dos aportes atmosféricos na carga dissolvida do Rio Solimões, com base na concentração química da chuva na região, corrigida pelo fator de evapotranspiração em função da distância do oceano, encontrando valores de contribuições significativos, pela água da chuva de 56,9\% de $\mathrm{SO}_{4}^{-}$e 21,9\% de $\mathrm{Cl}^{-}$.

Para caracterizar as tendências quanto à predominância de ânions na solução do solo, foram utilizados diagramas ternários, gerados a partir das concentrações médias de bicarbonato $\left(\mathrm{HCO}_{3}{ }^{-}+\mathrm{CO}_{3}{ }^{-}\right)$, cloreto $\left(\mathrm{Cl}^{-}\right)$e sulfato $\left(\mathrm{SO}_{4}{ }^{-}\right)$para os períodos seco e chuvoso (Figura 37).

De modo geral observou-se que o ânion predominante na solução do solo foi o bicarbonato, em quase todos os ecossistemas, exceto na área com maior grau de degradação. Observa-se que estas tendências apresentam variações significativas conforme a cobertura vegetal, a sazonalidade pluviométrica e a profundidade.

Com relação a cobertura vegetal, observou-se maiores concentrações de bicarbonato na floresta primária, e na área degradada coberta por gramínias. Isto é resultante da oxidação da matéria orgânica e intensa atividade biológicas, como respiração de raízes e microorganismos do solo, nestas áreas. Enquanto na área com maior grau de degradação observa-se que a contribuição do cloreto e bicarbonato são similares.

Através dos resultados obtidos e apresentados pelos diagramas ternários (Figura 37) pode-se inferir que o bicarbonato não é somente originário de fontes bióticas, mas também de fontes abióticas que é a dissolução de carbonatos e silicatos.

No reflorestamento e na floresta primária (platô e baixio), a predominância foi bicarbonatada, mas também observou-se a influência de 20-40\% do sulfato (Figura 37 e 38). Mortatti (1995), identificou como fonte significativa de entrada de sulfato ao sistema amazônico, as emissões terrestres, que retornam ao solo via precipitação. Likens 
\& Bormann (1977) propuseram uma entrada significativa deste ânion via transpecipitação e serrapilheira. Neste trabalho observou-se picos de concentrações mais elevadas no final do período chuvoso, que deve ser consequência da reoxidação de sulfetos à sulfatos, quando o solo apresenta maior estoque de água (Figura 39).

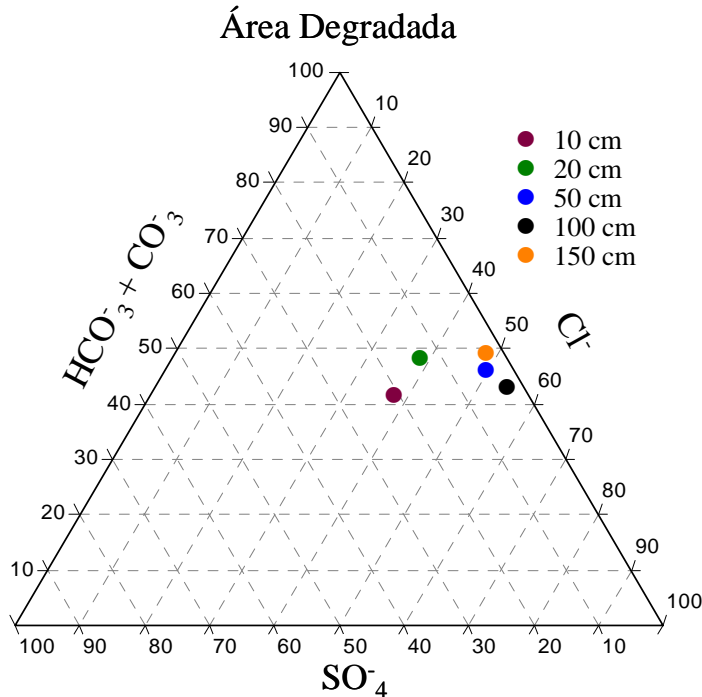

Floresta Secundária

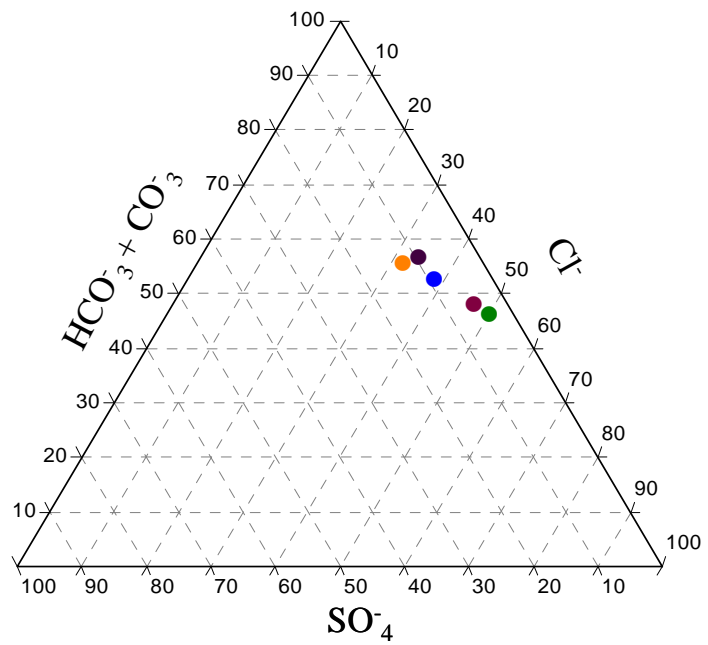

Floresta Primária Platô

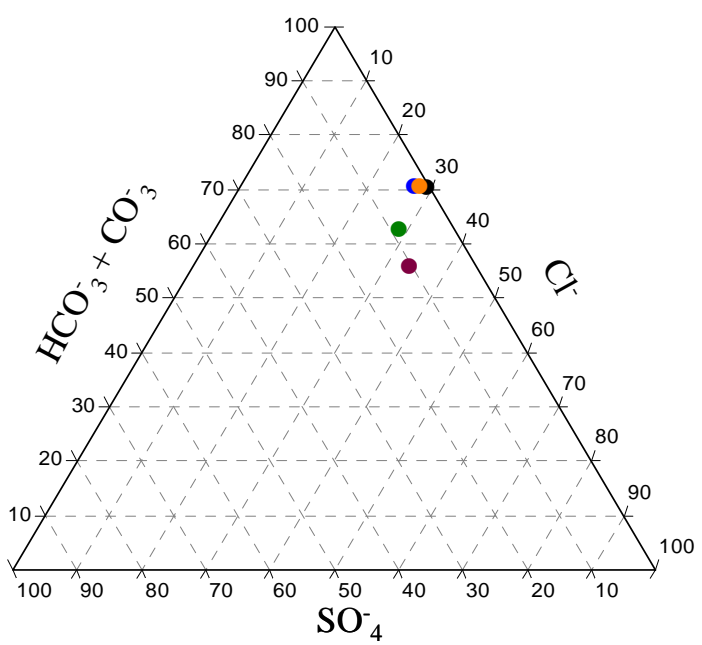

Reflorestamento

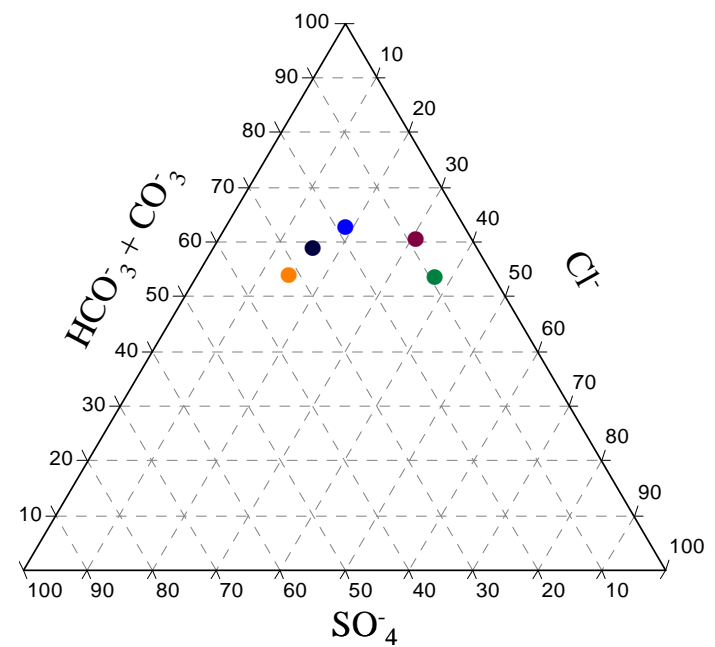

Figura 37 - Diagramas ternários elaborados a partir das concentrações médias dos ânions, cloreto, sulfato e bicarbonato, presentes na solução do solo 


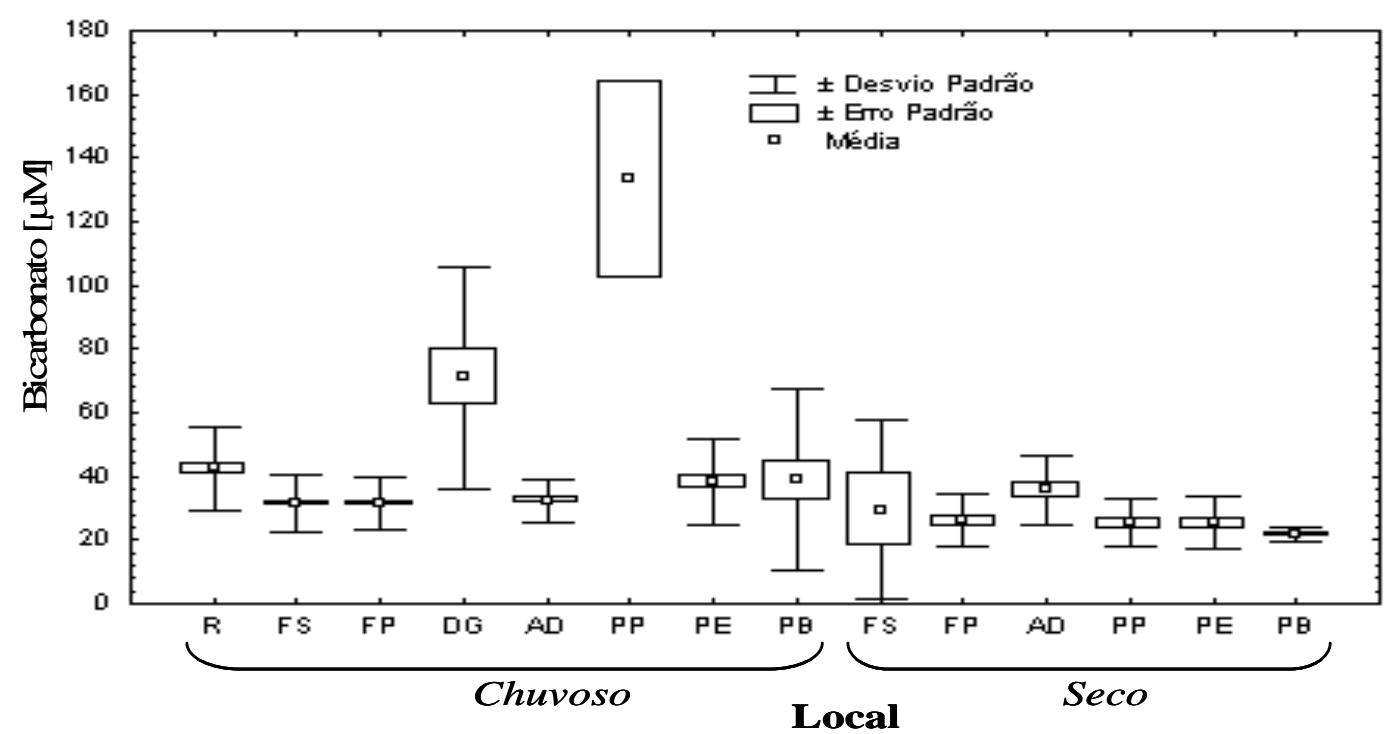

Figura 38 - Concentrações médias e desvio padrão das concentrações de bicarbonato na solução do solo durante o período chuvoso e seco. $\mathrm{R}=$ reflorestamento; FS= fl. secundária; $\mathrm{DG}=$ degradada com gramíneas; $\mathrm{AD}=$ maior grau de degradação; $\mathrm{PP}=$ fl. primária platô; $\mathrm{PE}=$ fl. primária encosta; $\mathrm{PB}=$ fl. primária baixio

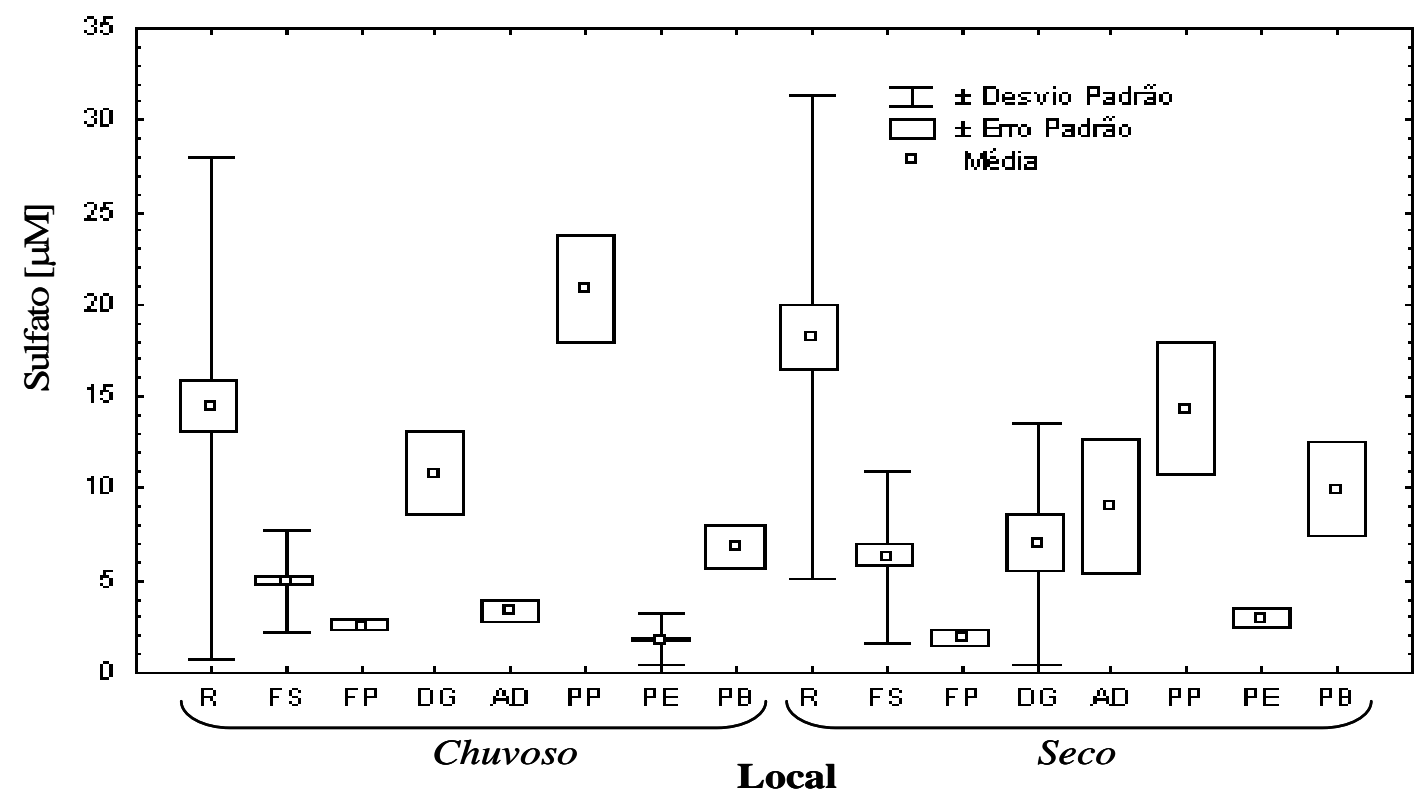

Figura 39 - Concentrações médias e desvio padrão das concentrações de sulfato na solução do solo durante o período chuvoso e seco (Legenda Figura 38) 
O cloreto apresentou correlação com a precipitação, observando-se picos de concentrações significativamente maiores no início do período chuvoso, com declíneo no decorer do período (Figura 40). O cloreto apresenta como principal via de entrada a precipitação pela reciclagem de sais marinhos na atmosfera Mortatti (1995). Durante o período seco ocorre a deposição deste ânion sobre a vegetação e com o início da chuva ocorre a lavagem da biomassa e entrada significaticva de cloreto no sistema solo. O cloreto apresentou concentrações relativamente altas na solução do solo, mostrando também concentrações significativas à grandes profundidades, devido à facilidade com que este é lixiviado.

Quanto à cobertura vegetal, observou-se que na floresta primária as concentrações são mais elevadas, que é devido a fonte de contribuição biótica, via exudados de raízes (Figura 41). Já na com maior grau de degradação, o cloreto apresentou concentrações elevadas, que pode ser influência do uso de fertilizantes minerais, como o cloreto de potássio, aplicados a este solo, quando foram introduzidas as culturas do guaraná, pau de balsa (Ochroma pyramidale) e jatobá (Hymenaea courbaril).

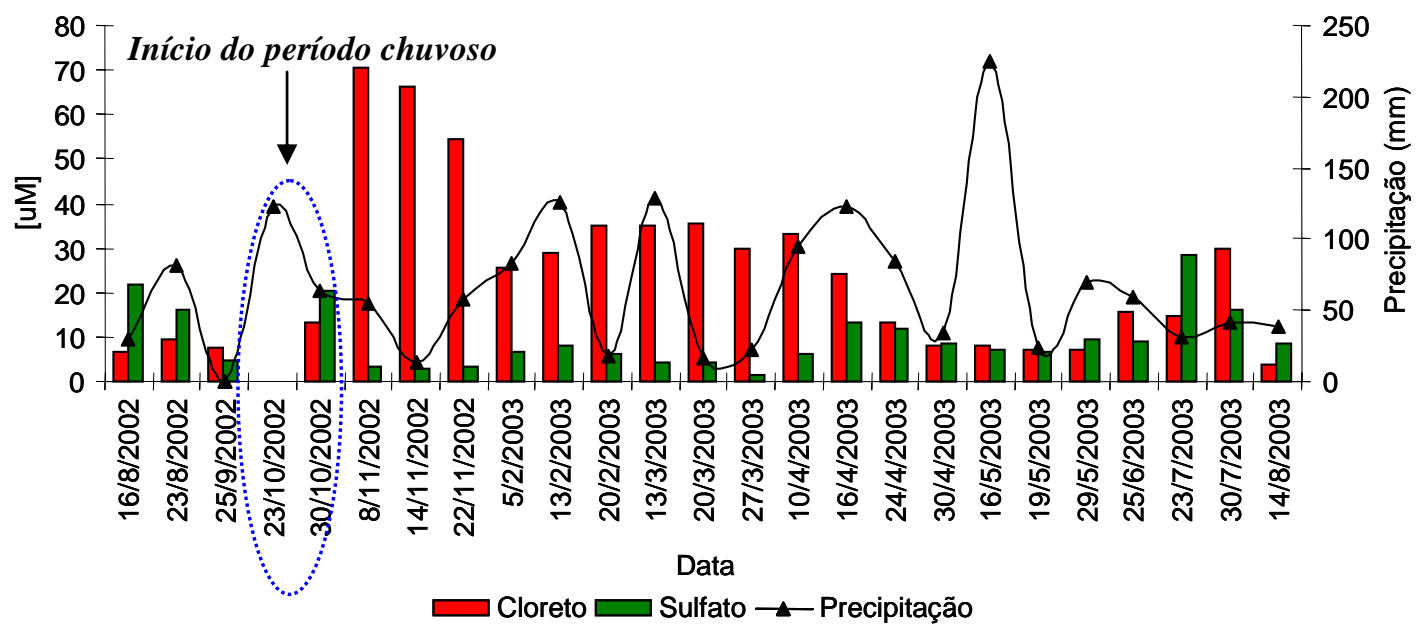

Figura 40 - Variações sazonais da precipitação $(\mathrm{mm})$ e concentrações de cloreto e sulfato $[\mu \mathrm{M}]$ na solução do solo 


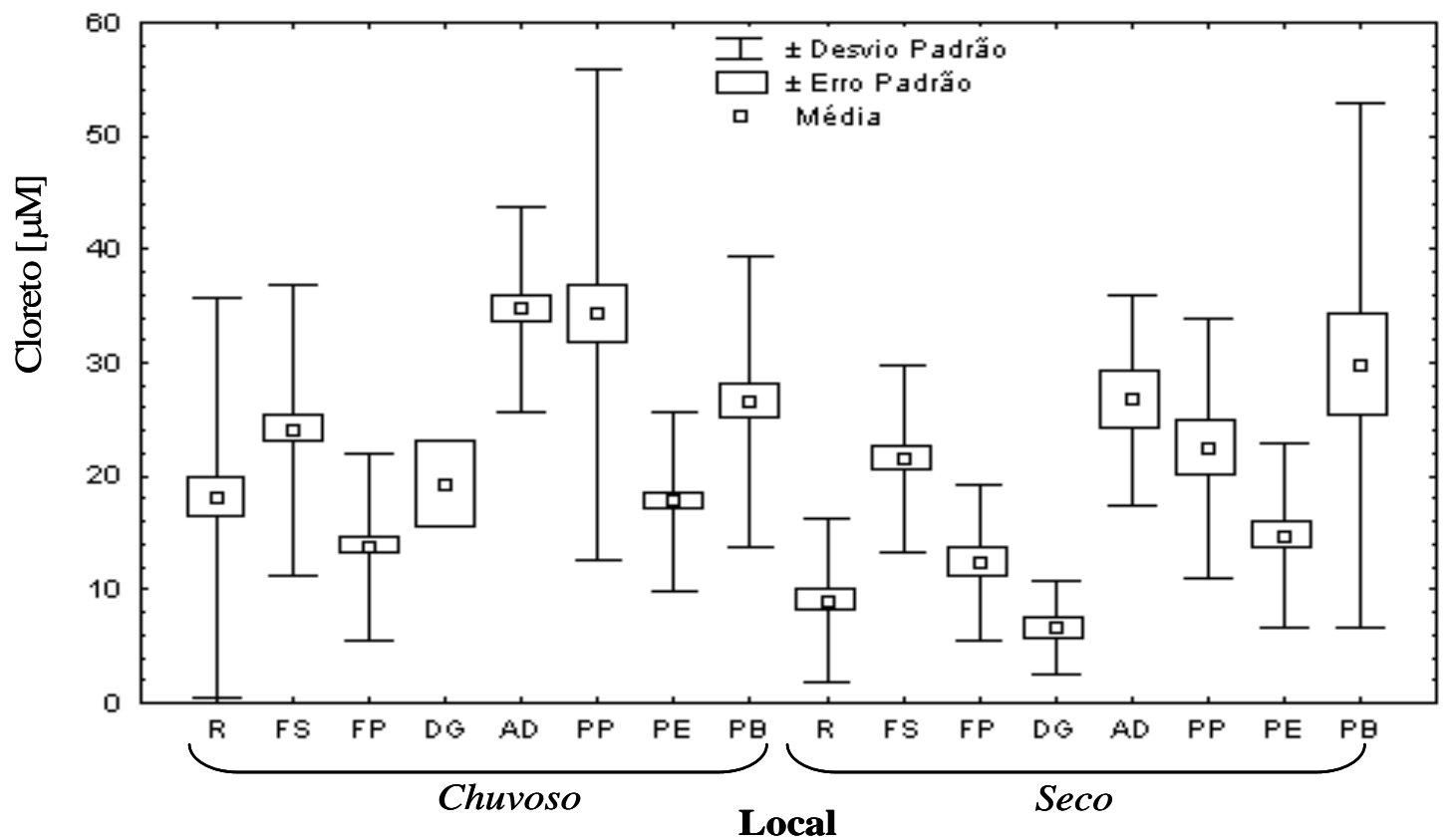

Figura 41 - Concentrações medias e desvio padrão das concentrações de cloreto na solução do solo durante o período chuvoso e seco(Legenda Figura 38)

Conforme já observado por Laurance (1999), o fosfato apresentou concentrações extremamente baixa; muitas amostras apresentaram concentrações abaixo do limite de detecção do equipamento $(0,2234 \mu \mathrm{M})$. As concentrações acima deste limite, na sua maioria, foram menores que $1 \mu \mathrm{M}$. Apresentou correlação negativa com a presença de óxidos de ferro e alumínio, e com o aumento do conteúdo de argila no solo. Altos teores de argila favorecem as reações do fosfato com o ferro e alumínio, formando compostos pouco solúveis e precipitados.

Quanto a cobertura vegetal observamos que as concentrações mais elevadas na floresta primária são decorrentes da via de entrada deste ânion ser dependente da vegetação. Como princiapal fonte, Likens \& Bormann (1977) identificaram a serrapilheira e comop fontes menos significativas, a transprecipitação, liteira de raízes e exudado de raízes.

A área degradada com gramínieas apresentou os menores teores de fosfato, enquanto a área com maior grau de degração apresentou concentrações similares a 
floresta primária, decorrente da fertilização química desta área. Enquanto a floresta secundária já mostrou sinais de recuperação com concentrações intermediárias entre a área degradada com gramíneas e a floresta primária.

A textura do solo apresentou grande influência na disponibilidade de fosfato, o que pode ser observado no Espodossol arenoso, baixio da floresta primária. Nestá áreas foram encontradas as concentrações mais elevadas comparado aos outros tipos de solo. Os valores médios foram de $1,38 \mu \mathrm{M}$, decorrente da baixa capacidade de adsorção do fosfato às particulas de areia, e sua liberação para a solução do solo (Figura 42). Já no reflorestamento, solo de textura muito argilosa, na qual observou-se a maiores concentrações de fosfato na matriz do solo, devido a adição de feretilizantes químicos. Já na solução do solo as concentrações se mantiveram baixas, devido a adsorção deste ânion ao solo, liberando quantidades mínimas para a solução do solo.

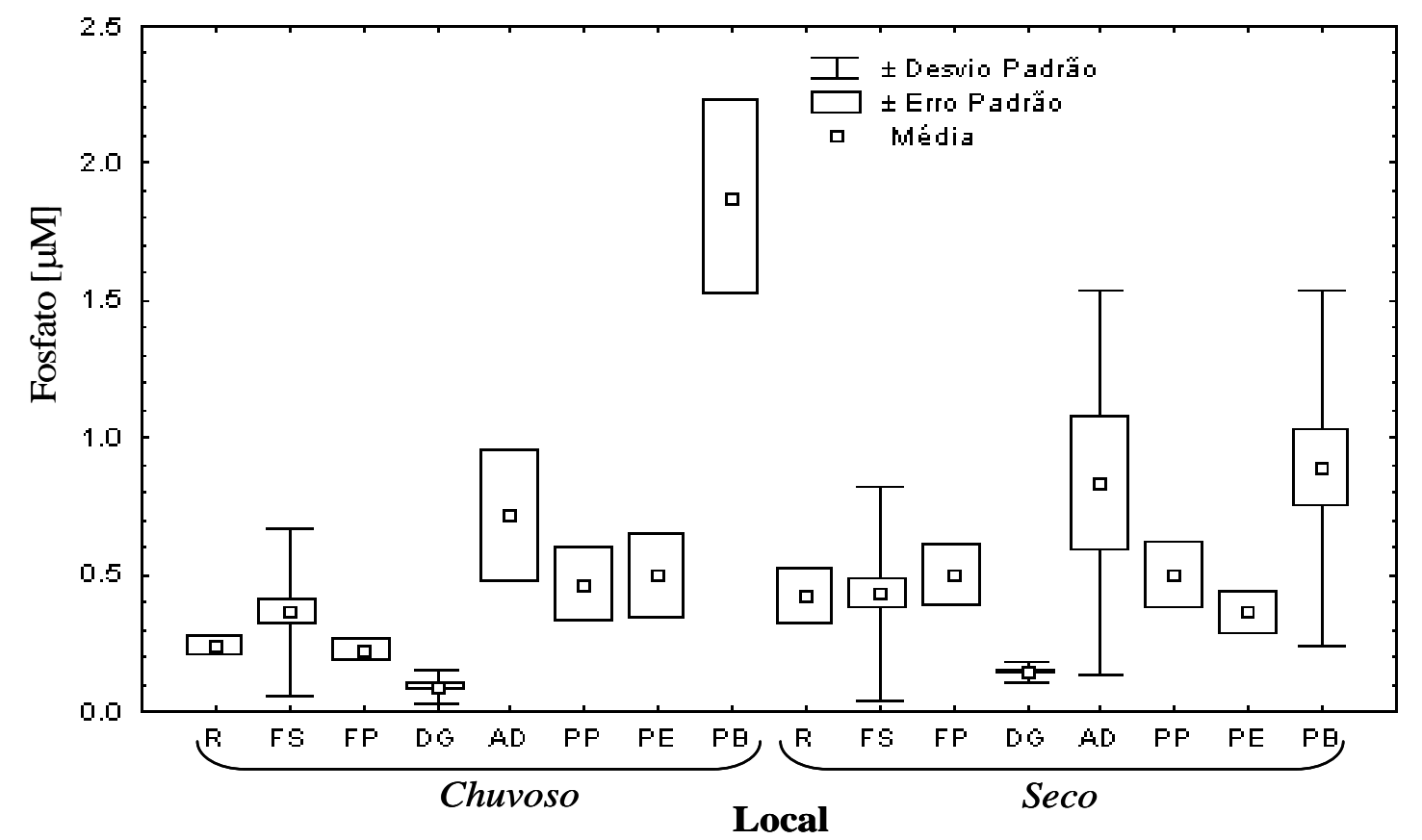

Figura 42 - Concentrações médias e desvio padrão das concentrações de fosfato na solução do solo durante o período chuvoso e seco (Legenda Figura 38) 


\section{CONCLUSÕES}

A dinâmica do carbono e nutrientes na solução do solo sob floresta primária, secundária, reflorestamento e área degradada foram avaliados em Manaus e Presidente Figueiredo, através da coleta de solução do solo com extratores de tensão. Os resultados mostraram que:

- Os solos são extremamente ácidos, de caráter alumínico e com baixa disponibilidade de nutrientes e matéria orgânica.

- A tendência catiônica da solução do solo pode ser caracterizada como sódicapotássica, com indícios de grande influência dos aportes atmosféricos na entrada de íons ao sistema.

- A tendência aniônica, caracterizada como bicarbonatada, nas áreas cobertas por vegetação, indicando a importância da vegetação, como principal fonte, a atividade biológica (respiração de raízes e microorganismos do solo) e baixa contribuição do intemperismo de silicatos e carbonatos. Portanto na área degradada, o cloreto apresentou predominância similar ao bicarbonato, indicando uma mudança na fonte de entrada, com maior influência abiótica (aportes atmosféricos).

- A textura do solo apresenta forte influência na dinâmica dos nutrientes e do carbono, sendo que solos argilosos apresentaram menor disponibilidade de todos os elementos avaliados para a solução do solo, quando comparados aos solos arenosos.

- A dinâmica dos íons, fósforo, nitrato, cálcio, magnésio, sódio, cloreto e carbono orgânico dissolvido está relacionada com a sazonalidade da 
precipitação, apresentando grandes aportes na soluçaõ dos solo com início do período chuvoso.

- Quanto à cobertura vegetal, a floresta secundária apresenta uma via de ciclagem de nutrientes mais rápida. Isso leva a maiores teores de carbono orgânico dissolvido e nitrato, provavelmente em função da maior adição da matéria orgânica neste sistema. Isto indica sinais de recuperação do ecossistema, assim como o reflorestamento e a área degradada coberta com gramíneas, também apresentam sinais de recuperação, menos significativos, porém com níveis mais elevados de nutrientes e do carbono, comparado a A.D.

- Na área com maior grau de degradação, ocorre a predominancia de elementos que apresentam como fonte de entrada a precipitação cloreto e sódio. Os elementos, nitrogênio, cálcio, magnésio e fósforo apresentam menores teores nesta área. Para recuperação de uma área muito degradada, faz-se necessário a adição destes elementos, que são indispensáveis para o desenvolvimento vegetal e que apresentam como principal fonte de entrada a reciclagem da serrapilheira.

- O enriquecimento de carbono orgânico dissolvido à $1 \mathrm{~m}$ de profundidade, provavelmente em função dos menores teores de ferro e alumínio, pode estar indicando, que os sistemas terrestres funcionam como possíveis exportadores de carbono para os sistemas aquáticos.

- Quanto ao nitrogênio, observa-se que as frações inorgânicas são fortemente influenciadas pela precipitação e a vegetação. Com a chuva ocorre aporte de muito material nitrogenado ao solo. Com relação à vegetação, observou-se que os ecossistemas em recuperação (reflorestamento e floresta secundária) apresentaram os maiores teores de nitrato, seguido da floresta primária (ecossistema mais estável) e com os menores teores, as áreas degradadas.

- A mundaça de cobertura vegetal, degradação química e física do solo, leva à mudanças na predominância das frações de nitrogênio. Enquanto na floresta 
primária, na qual o solo apresentou boas condições físicas como, drenagem e porosidade, o nitrogênio, segue as sequências normais da nitrificação, sendo o nitrato a forma predominate. Já na área dregradada, com solo compactado e desestruturado, o nitrogênio além de apresentar baixos teores, consequentes da falta de cobertura vegetal, a fração predominante foi o amônio.

- A dinâmica dos nutrientes está relacionada não somente com o tipo de cobertura vegetal, mas com uma série de fatores bióticos e abióticos. Como fator biótico de grande influência, é a atividade de organismos do solo, e como, fatores abióticos de grande relevância, observaram-se as características físicas do solo, a sazonalidade pluviométrica, a acidez dos solos e os aportes atmosféricos. 
ANEXOS 
Anexo A. Concentrações médias e desvio padrão das frações de nitrogênio na solução do solo para os perídos seco e chuvoso

\begin{tabular}{|c|c|c|c|c|c|c|c|c|c|}
\hline Local & Vegetação & $\begin{array}{l}\text { Prof. } \\
\text { (cm) }\end{array}$ & Solo & $\mathrm{NH}_{4}^{+}$ & $\begin{array}{c}\mathrm{NO}_{2}^{-} \\
\text {ríodo Chuvo }\end{array}$ & $\mathrm{NO}_{3}^{-}$ & $\mathrm{NH}_{4}^{+}$ & $\begin{array}{c}\mathrm{NO}_{2}^{-} \\
\text {Período Seco }\end{array}$ & $\mathrm{NO}_{3}^{-}$ \\
\hline \multirow[t]{5}{*}{ ZF 2} & Fl. Primária & 10 & Latossolo & $4,69 \pm 7,23$ & $0,57 \pm 0,71$ & $85,47 \pm 74,95$ & $2,18 \pm 2,39$ & $0,07 \pm 0,15$ & $35,96 \pm 20,22$ \\
\hline & & 20 & & $5,76 \pm 6,06$ & $0,16 \pm 0,27$ & $22,18 \pm 23,56$ & $4,35 \pm 3,42$ & $0,01 \pm 0,02$ & 9.45 \\
\hline & & 50 & & $6,63 \pm 9,04$ & $0,47 \pm 0,14$ & $31,88 \pm 45,87$ & $4,10 \pm 2,94$ & $0,22 \pm 0,21$ & $24,28 \pm 32,03$ \\
\hline & & 100 & & $5,65 \pm 4,01$ & $0,36 \pm 0,22$ & $54,95 \pm 65,99$ & $2,81 \pm 1,27$ & $0,06 \pm 0,10$ & $7,36 \pm 5,57$ \\
\hline & & 150 & & $2,87 \pm 2,14$ & $1,12 \pm 0,74$ & $41,62 \pm 34,5$ & $3,51 \pm 2,01$ & $0,11 \pm 0,1$ & $11,09 \pm 6,28$ \\
\hline \multirow[t]{5}{*}{ ZF 2} & Fl. Primária & 10 & Argissolo & $5,89 \pm 6,37$ & $1,23 \pm 1,93$ & $37,09 \pm 38,71$ & $3,06 \pm 2,65$ & $0,88 \pm 0,73$ & $28,88 \pm 36$ \\
\hline & & 20 & & $4,77 \pm 6,49$ & $2,16 \pm 2,45$ & $26,40 \pm 21,57$ & $2,66 \pm 1,51$ & $1,59 \pm 2,67$ & $62,54 \pm 54,14$ \\
\hline & & 50 & & $*$ & $*$ & * & $3,50 \pm 1,29$ & $0,19 \pm 0,18$ & $38,73 \pm 37,59$ \\
\hline & & 100 & & $4,03 \pm 3,48$ & $1,25 \pm 1,97$ & $69,53 \pm 42,18$ & $2,92 \pm 2,42$ & $0,60 \pm 0,30$ & $30,86 \pm 14,05$ \\
\hline & & 150 & & $3,85 \pm 3,17$ & $2,00 \pm 2,36$ & $54,01 \pm 35,57$ & $1,93 \pm 0,77$ & $0,02 \pm 0,02$ & $21,01 \pm 16,97$ \\
\hline \multirow[t]{5}{*}{ ZF 2} & Fl. Primária & 10 & Espodossolo & $10,45 \pm 11,56$ & $0,52 \pm 0,84$ & $70,60 \pm 101,7$ & $15,07 \pm 12,5$ & $1,50 \pm 1,27$ & $64,05 \pm 62,45$ \\
\hline & & 20 & & $5,61 \pm 4,72$ & $1,18 \pm 2,21$ & $140,58 \pm 94,08$ & $5,78 \pm 7,29$ & 0.00 & $108,51 \pm 79,3$ \\
\hline & & 50 & & 9.93 & 0.00 & 114.02 & $11,21 \pm 16,1$ & 1.29 & $278,10 \pm 202,2$ \\
\hline & & 100 & & $4,05 \pm 3,59$ & $0,89 \pm 1,15$ & $127,41 \pm 88,74$ & $5,69 \pm 4,99$ & 0.00 & $103,27 \pm 57,47$ \\
\hline & & 150 & & $5,91 \pm 5,02$ & $0,68 \pm 1,02$ & $97,23 \pm 86,19$ & $5,52 \pm 9,99$ & $0,13 \pm 0,09$ & $54,27 \pm 65,95$ \\
\hline \multirow[t]{5}{*}{ P. Figueiredo } & Fl. Primária & 10 & Latossolo & $1,98 \pm 1,04$ & $1,09 \pm 1,47$ & $29,68 \pm 52,48$ & $2,69 \pm 1,5$ & 0.08 & $13,85 \pm 10,54$ \\
\hline & & 20 & & $1,93 \pm 0,90$ & $2,07 \pm 2,27$ & $19,25 \pm 15,1$ & $3,59 \pm 3,12$ & $0,15 \pm 0,15$ & $11,14 \pm 10,03$ \\
\hline & & 50 & & $1,75 \pm 1,39$ & $1,23 \pm 1,89$ & $29,22 \pm 37,96$ & $2,06 \pm 1,44$ & $0,09 \pm 0,14$ & $12,61 \pm 5,57$ \\
\hline & & 100 & & $2,26 \pm 1,93$ & $2,06 \pm 2,16$ & $67,73 \pm 36,75$ & $2,31 \pm 1,24$ & $0,08 \pm 0,11$ & $38,93 \pm 19,65$ \\
\hline & & 150 & & $2,95 \pm 2,64$ & $3,35 \pm 2,59$ & $88,59 \pm 38,22$ & $1,19 \pm 0,66$ & $0,07 \pm 0,11$ & $65,75 \pm 27,34$ \\
\hline \multirow[t]{5}{*}{ CAMES } & Reflorestamento & 10 & Latossolo & $2,20 \pm 1,19$ & $2,98 \pm 3,29$ & $4,14 \pm 6,1$ & $1,74 \pm 1,08$ & $0,39 \pm 0,56$ & $12,39 \pm 19,6$ \\
\hline & & 20 & & $2,76 \pm 3,35$ & $4,10 \pm 3,08$ & $94,62 \pm 151,1$ & $1,69 \pm 1,01$ & $0,35 \pm 0,3$ & $12,31 \pm 12,37$ \\
\hline & & 50 & & $1,88 \pm 1,72$ & $2,89 \pm 2,40$ & $23,42 \pm 28,06$ & $2,29 \pm 0,87$ & $0,29 \pm 0,30$ & $20,07 \pm 35,63$ \\
\hline & & 100 & & $1,80 \pm 1,00$ & $2,16 \pm 2,22$ & $34,54 \pm 95,3$ & $1,87 \pm 1,1$ & $0,25 \pm 0,27$ & $4,44 \pm 1,59$ \\
\hline & & 150 & & $1,85 \pm 1,09$ & $2,21 \pm 2,48$ & $66,21 \pm 147,8$ & $0,36 \pm 0,93$ & $0,28 \pm 0,3$ & $25,45 \pm 54,9$ \\
\hline
\end{tabular}


Anexo A. Concentrações médias e desvio padrão das frações de nitrogênio na solução do solo para os perídos seco e chuvoso

\begin{tabular}{|c|c|c|c|c|c|c|c|c|c|}
\hline Local & Vegetação & $\begin{array}{l}\text { Prof. } \\
(\mathrm{cm})\end{array}$ & Solo & \multicolumn{2}{|c|}{ Período Chuvoso [ $\mu \mathrm{M}]$} & $\mathrm{NO}_{3}^{-}$ & $\mathbf{N H}_{4}^{+}$ & $\begin{array}{c}\mathrm{NO}_{2}^{-} \\
\text {Período Seco [ }\end{array}$ & $\mathrm{NO}_{3}^{-}$ \\
\hline \multirow[t]{5}{*}{ CAMES } & Fl. Secundária & 10 & Latossolo & $2,52 \pm 1,42$ & $3,03 \pm 2,39$ & $221,31 \pm 287,24$ & 0.00 & $0,31 \pm 0,29$ & $427,75 \pm 134$ \\
\hline & & 20 & & $2,19 \pm 3,02$ & $3,36 \pm 2,46$ & $260,81 \pm 273,9$ & $1,99 \pm 0,65$ & $0,23 \pm 0,24$ & $257,80 \pm 147,7$ \\
\hline & & 50 & & $1,77 \pm 1,53$ & $2,90 \pm 2,61$ & $161,31 \pm 79,73$ & $1,56 \pm 0,29$ & $0,37 \pm 0,26$ & $75,76 \pm 47,9$ \\
\hline & & 100 & & $1,69 \pm 1,33$ & $3,21 \pm 2,62$ & $77,02 \pm 62,30$ & $0,17 \pm 0,57$ & $0,41 \pm 0,34$ & $37,66 \pm 21,88$ \\
\hline & & 150 & & $2,21 \pm 2,27$ & $2,32 \pm 2,23$ & $23,13 \pm 16,45$ & $1,81 \pm 0,53$ & $0,32 \pm 0,33$ & $35,10 \pm 61,55$ \\
\hline \multirow[t]{5}{*}{ P. Figueiredo } & A. Degradada ${ }^{\text {A }}$ & 10 & Latossolo & $2,63 \pm 2,55$ & $00,06 \pm 0,08$ & $3,94 \pm 4,80$ & $4,57 \pm 2,77$ & $0,044 \pm 0,03$ & $0,18 \pm 0,02$ \\
\hline & & 20 & & 17.70 & 0.00 & 1.94 & $4,98 \pm 3,66$ & $0,06 \pm 0,07$ & $3,98 \pm 5,00$ \\
\hline & & 50 & & $2,19 \pm 1,68$ & $2,96 \pm 2,51$ & $0,75 \pm 0,79$ & $2,18 \pm 1,05$ & 0.00 & $0,04 \pm 0,05$ \\
\hline & & 100 & & $1,98 \pm 1,27$ & $4,05 \pm 1,92$ & $1,47 \pm 1,47$ & $2,21 \pm 1,77$ & 0.03 & $0,08 \pm 0,003$ \\
\hline & & 150 & & $1,81 \pm 1,10$ & $3,34 \pm 2,53$ & $2,23 \pm 2,15$ & $3,44 \pm 2,73$ & 0.00 & $0,45 \pm 0,49$ \\
\hline \multirow[t]{4}{*}{ P. Figueiredo } & A. Degradada ${ }^{\text {B }}$ & 10 & Latossolo & $0,61 \pm 1,21$ & $1,13 \pm 1,92$ & $4,55 \pm 7,65$ & * & * & $*$ \\
\hline & & 50 & & $0,05 \pm 0,10$ & $0,19 \pm 0,23$ & $42,80 \pm 64,55$ & $2,43 \pm 3,95$ & $0,24 \pm 0,02$ & $0,43 \pm 0,34$ \\
\hline & & 100 & & $1,25 \pm 2,19$ & $0,32 \pm 0,19$ & $35,77 \pm 81,23$ & $0,10 \pm 0,25$ & $0,23 \pm 0,02$ & $0,79 \pm 1,13$ \\
\hline & & 150 & & $0,45 \pm 1,04$ & $0,32 \pm 0,15$ & $25,32 \pm 45,14$ & 0.00 & $0,23 \pm 0,01$ & $0,17 \pm 0,03$ \\
\hline
\end{tabular}

Obs: Os valores que não apresentam desvio padrão é devido $\mathrm{n}=1 ;{ }^{*} \mathrm{n}=0 ;{ }^{\mathrm{A}}=$ maior grau de degradação ; ${ }^{\mathrm{B}}=$ área coberta por gramíneas 
Anexo B. Concentrações médias e desvio padrão dos cátions $\left(\mathrm{Na}^{+}, \mathrm{K}^{+}, \mathrm{Ca}^{+2}\right.$ e $\left.\mathrm{Mg}^{+2}\right)$ na solução do solo para os perídos seco e chuvoso

\begin{tabular}{|c|c|c|c|c|c|c|c|c|c|c|c|}
\hline \multirow[t]{2}{*}{ Local } & Vegetação & Prof. & Solo & $\mathrm{Cl}^{-}$ & $\left(\mathrm{SO}_{4}\right)^{-2}$ & $\left(\mathrm{PO}_{4}\right)^{-3}$ & $\mathrm{HCO}_{3}^{-}+\mathrm{CO}_{3}^{-}$ & $\mathrm{Cl}^{-}$ & $\left(\mathrm{SO}_{4}\right)^{-2}$ & $\left(\mathrm{PO}_{4}\right)^{-3}$ & $\mathrm{HCO}_{3}^{-}+\mathrm{CO}_{3}^{-}$ \\
\hline & & $(\mathrm{cm})$ & & \multicolumn{4}{|c|}{ Período Chuvoso [pM] } & \multicolumn{4}{|c|}{ Período Seco $[\mu \mathrm{M}]$} \\
\hline \multirow[t]{5}{*}{ ZF 2} & Fl. Primária & 10 & Latossolo & $32,80 \pm 27,02$ & $49,36 \pm 9,82$ & $0,36 \pm 0,26$ & $33,86 \pm 9,24$ & $21,87 \pm 12,88$ & $33,17 \pm 12,22$ & $0,60 \pm 0,6$ & $19,85 \pm 1,67$ \\
\hline & & 20 & & $23,54 \pm 2,65$ & $63,52 \pm 13,31$ & $0,02 \pm 0,05$ & $132,73 \pm 105,24$ & $14,00 \pm 3,15$ & $17,25 \pm 23,09$ & $0,27 \pm 0,38$ & $20,01 \pm 1,38$ \\
\hline & & 50 & & $33,47 \pm 17,01$ & $14,42 \pm 12,24$ & $0,46 \pm 0,39$ & $398,01 \pm 321,63$ & $37,81 \pm 1,33$ & $4,68 \pm 1,23$ & $0,15 \pm 0,04$ & $*$ \\
\hline & & 100 & & $37,49 \pm 19,08$ & $3,64 \pm 3,42$ & $1,10 \pm 1,46$ & $223,41 \pm 161,96$ & $23,94 \pm 12,55$ & $5,27 \pm 9,48$ & $0,25 \pm 0,19$ & $30,47 \pm 7,84$ \\
\hline & & 150 & & $35,93 \pm 24,44$ & $1,92 \pm 2,09$ & $0,19 \pm 0,13$ & $41,89 \pm 11,58$ & $18,52 \pm 7,89$ & $2,40 \pm 3,04$ & $0,99 \pm 0,64$ & $25,93 \pm 8,49$ \\
\hline \multirow[t]{5}{*}{ ZF 2} & Fl. Primária & 10 & Argissolo & $18,13 \pm 7,16$ & $2,07 \pm 1,37$ & $0,93 \pm 1,59$ & $39,57 \pm 10,25$ & $15,36 \pm 7,21$ & $2,98 \pm 3,7$ & $0,45 \pm 0,55$ & $31,81 \pm 11,81$ \\
\hline & & 20 & & $15,32 \pm 7,74$ & $1,52 \pm 1,42$ & $0,64 \pm 0,45$ & $41,16 \pm 15,33$ & $11,21 \pm 6,56$ & $2,76 \pm 4,24$ & $0,33 \pm 0,48$ & $24,36 \pm 6,80$ \\
\hline & & 50 & & $15,84 \pm 8,70$ & $3,54 \pm 2,40$ & $*$ & $*$ & $23,62 \pm 11,45$ & $2,22 \pm 0,81$ & $0,19 \pm 0,22$ & $22,28 \pm 3,62$ \\
\hline & & 100 & & $17,56 \pm 8,57$ & $2,43 \pm 1,23$ & $0,16 \pm 0,14$ & $33,20 \pm 11,18$ & $14,29 \pm 7,06$ & $2,23 \pm 2,10$ & $0,45 \pm 0,55$ & $20,03 \pm 1,26$ \\
\hline & & 150 & & $19,26 \pm 8,08$ & $0,96 \pm 0,85$ & $0,21 \pm 0,13$ & $41,36 \pm 16,93$ & $14,40 \pm 2,39$ & $4,52 \pm 4,72$ & $0,42 \pm 0,73$ & $32,60 \pm 13,13$ \\
\hline \multirow[t]{5}{*}{ ZF 2} & Fl. Primária & 10 & Espodossolo & $27,18 \pm 12,3$ & $1,78 \pm 1,75$ & $1,81 \pm 2,31$ & & $30,69 \pm 25,43$ & $7,02 \pm 15,6$ & $0,35 \pm 0,2$ & $*$ \\
\hline & & 20 & & $28,88 \pm 13,32$ & $3,82 \pm 4,72$ & $1,97 \pm 2,43$ & $29,70 \pm 6,09$ & $62,39 \pm 27,73$ & $5,02 \pm 5,25$ & $1,06 \pm 1,14$ & 19.71 \\
\hline & & 50 & & 28.77 & 22.17 & 1.61 & 22.90 & $35,62 \pm 21,17$ & $13,94 \pm 9,06$ & $1,12 \pm 0,67$ & * \\
\hline & & 100 & & $20,73 \pm 15,62$ & $6,98 \pm 4,69$ & $2,95 \pm 3,29$ & $46,15 \pm 34,79$ & $23,35 \pm 12,44$ & $7,08 \pm 5,08$ & $1,15 \pm 0,73$ & $22,42 \pm 2,96$ \\
\hline & & 150 & & $26,90 \pm 10,00$ & $12,77 \pm 14,78$ & $1,29 \pm 1,71$ & $40,54 \pm 33,32$ & $12,93 \pm 6,35$ & $18,14 \pm 17,6$ & $1,09 \pm 0,58$ & $21,87 \pm 2,00$ \\
\hline \multirow[t]{5}{*}{ P. Figueiredo } & Fl. Primária & 10 & Latossolo & $16,76 \pm 12,58$ & $5,25 \pm 5,19$ & $0,19 \pm 0,11$ & $27,90 \pm 5,24$ & $14,53 \pm 7,28$ & $4,76 \pm 3,10$ & $0,53 \pm 0,66$ & $34,80 \pm 15,89$ \\
\hline & & 20 & & $15,32 \pm 10,55$ & $4,62 \pm 3,17$ & $0,25 \pm 0,33$ & $33,23 \pm 10,87$ & $14,92 \pm 7,32$ & $2,45 \pm 1,24$ & $0,70 \pm 0,69$ & $24,81 \pm 3,43$ \\
\hline & & 50 & & $12,58 \pm 6,18$ & $1,05 \pm 2,04$ & $0,19 \pm 0,2$ & $32,72 \pm 7,99$ & $8,49 \pm 5,24$ & $0,44 \pm 0,38$ & $0,32 \pm 0,47$ & $28,20 \pm 6,40$ \\
\hline & & 100 & & $12,98 \pm 5,49$ & $0,32 \pm 0,39$ & $0,21 \pm 0,25$ & $31,40 \pm 8,44$ & $15,02 \pm 9,29$ & $0,521 \pm 0,61$ & $0,65 \pm 0,49$ & $24,74 \pm 6,08$ \\
\hline & & 150 & & $12,02 \pm 4,34$ & $0,56 \pm 0,67$ & $0,25 \pm 0,24$ & $30,35 \pm 7,20$ & $10,13 \pm 5,2$ & $0,11 \pm 0,05$ & $0,29 \pm 0,15$ & $20,26 \pm 2,09$ \\
\hline \multirow[t]{5}{*}{ CAMES } & Reflorestamento & 10 & Latossolo & $22,02 \pm 19,21$ & $6,26 \pm 8,11$ & $0,30 \pm 0,33$ & $43,11 \pm 8,3$ & $9,90 \pm 8,43$ & $4,05 \pm 5,17$ & $0,41 \pm 0,56$ & 78.14 \\
\hline & & 20 & & $29,13 \pm 19,86$ & $7,26 \pm 4,55$ & $0,36 \pm 0,22$ & $41,99 \pm 12,7$ & $12,47 \pm 8,69$ & $14,98 \pm 8,24$ & $0,52 \pm 0,44$ & 35.29 \\
\hline & & 50 & & $11,81 \pm 6,27$ & $11,76 \pm 3,76$ & $0,42 \pm 0,28$ & $39,30 \pm 15,55$ & $10,43 \pm 3,12$ & $15,96 \pm 1,88$ & $0,17 \pm 0,02$ & $27,75 \pm 5,02$ \\
\hline & & 100 & & $11,40 \pm 7,29$ & $18,09 \pm 4,44$ & $0,51 \pm 0,51$ & $41,04 \pm 11,57$ & $5,19 \pm 1,58$ & $25,27 \pm 10,39$ & $0,16 \pm 0,1$ & $39,32 \pm 3,01$ \\
\hline & & 150 & & $12,78 \pm 13,1$ & $28,30 \pm 15,71$ & $0,24 \pm 0,23$ & $47,79 \pm 15,65$ & $8,68 \pm 9,94$ & $26,10 \pm 15,94$ & $0,71 \pm 0,84$ & $33,18 \pm 14,82$ \\
\hline
\end{tabular}


Anexo B. Concentrações médias e desvio padrão dos cátions $\left(\mathrm{Na}^{+}, \mathrm{K}^{+}, \mathrm{Ca}^{+2}\right.$ e $\left.\mathrm{Mg}^{+2}\right)$ na solução do solo para os perídos seco e chuvoso

\begin{tabular}{|c|c|c|c|c|c|c|c|c|c|c|c|}
\hline \multirow[t]{2}{*}{ Local } & \multirow[t]{2}{*}{ Vegetação } & Prof. & Solo & $\mathrm{Cl}^{-}$ & $\left(\mathrm{SO}_{4}\right)^{-2}$ & $\left(\mathrm{PO}_{4}\right)^{-3}$ & $\mathrm{HCO}_{3}{ }^{-}+\mathrm{CO}_{3}^{-}$ & $\mathrm{Cl}^{-}$ & $\left(\mathrm{SO}_{4}\right)^{-2}$ & $\left(\mathrm{PO}_{4}\right)$ & $\mathrm{HCO}_{3}{ }^{-}+\mathrm{CO}_{3}$ \\
\hline & & \multicolumn{2}{|l|}{$(\mathrm{cm})$} & \multicolumn{4}{|c|}{ Período Chuvoso $[\mu \mathrm{M}]$} & \multicolumn{4}{|c|}{ Período Seco $[\mu \mathrm{M}]$} \\
\hline \multirow[t]{5}{*}{ CAMES } & Fl. Secundária & 10 & Latossolo & $29,23 \pm 23,4$ & $3,28 \pm 1,83$ & $0,45 \pm 0,41$ & $30,25 \pm 6,70$ & $27,5 \pm 7,19$ & $2,27 \pm 0,82$ & $0,35 \pm 0,39$ & 18.54 \\
\hline & & 20 & & $30,93 \pm 12,85$ & $2,54 \pm 3,53$ & $0,29 \pm 0,18$ & $28,36 \pm 6,27$ & $19,17 \pm 3,78$ & $2,53 \pm 1,91$ & $0,47 \pm 0,41$ & $18,09 \pm 0,43$ \\
\hline & & 50 & & $22,98 \pm 3,20$ & $5,45 \pm 1,60$ & $0,39 \pm 0,29$ & $31,62 \pm 8,03$ & $21,85 \pm 11,83$ & $7,47 \pm 1,56$ & $0,42 \pm 0,41$ & $52,25 \pm 48,29$ \\
\hline & & 100 & & $20,16 \pm 2,69$ & $5,75 \pm 1,26$ & $0,34 \pm 0,28$ & $33,86 \pm 11,34$ & $21,03 \pm 5,66$ & $9,60 \pm 1,91$ & $0,23 \pm 0,07$ & * \\
\hline & & 150 & & $18,55 \pm 5,29$ & $7,32 \pm 1,87$ & $0,26 \pm 0,23$ & $32,07 \pm 9,77$ & $18,32 \pm 7,83$ & $9,04 \pm 6,32$ & $0,56 \pm 0,46$ & $*$ \\
\hline \multirow[t]{5}{*}{ P. Figueiredo } & A. Degradada ${ }^{\text {A }}$ & 10 & Latossolo & $35,90 \pm 27,07$ & $20,12 \pm 1,20$ & 0.00 & $39,73 \pm 0,93$ & $16,06 \pm 6,10$ & $14,62 \pm 12,19$ & $0,77 \pm 1,03$ & $36,30 \pm 19,07$ \\
\hline & & 20 & & 27.08 & 9.47 & 0.00 & 34.07 & $32,7 \pm 6,34$ & $30,94 \pm 19,71$ & 0.117 & $40,52 \pm 7,33$ \\
\hline & & 50 & & $36,47 \pm 9,49$ & $3,32 \pm 2,28$ & $0,78 \pm 1,10$ & $34,14 \pm 7,09$ & $32,86 \pm 4,80$ & $1,05 \pm 0,69$ & 0.049 & $39,06 \pm 13,91$ \\
\hline & & 100 & & $37,86 \pm 5,28$ & $1,77 \pm 1,24$ & $0,61 \pm 0,43$ & $30,07 \pm 6,09$ & $31,87 \pm 5,06$ & $1,14 \pm 0,83$ & $1,14 \pm 0,5$ & $33,99 \pm 9,91$ \\
\hline & & 150 & & $30,68 \pm 7,63$ & $1,83 \pm 0,75$ & $0,46 \pm 0,37$ & $31,71 \pm 6,59$ & $20,38 \pm 12,1$ & $2,12 \pm 1,08$ & $0,80 \pm 1,02$ & $30,94 \pm 12,81$ \\
\hline \multirow[t]{4}{*}{ P. Figueiredo } & A. Degradada ${ }^{\text {B }}$ & 10 & Latossolo & $13,08 \pm 12,12$ & $4,65 \pm 4,79$ & $0,04 \pm 0,1$ & $53,15 \pm 16,03$ & $*$ & * & * & $*$ \\
\hline & & 50 & & $10,96 \pm 3,28$ & $32,23 \pm 1,13$ & $0,19 \pm 0,03$ & $57,20 \pm 16,68$ & $3,04 \pm 1,26$ & $13,05 \pm 5,30$ & $0,15 \pm 0,04$ & $*$ \\
\hline & & 100 & & $25,77 \pm 28,34$ & $5,06 \pm 0,80$ & $0,07 \pm 0,02$ & $60,09 \pm 24,57$ & $9,93 \pm 5,20$ & $5,05 \pm 5,44$ & $0,14 \pm 0,04$ & * \\
\hline & & 150 & & $22,29 \pm 20,1$ & $4,10 \pm 3,77$ & $0,05 \pm 0,05$ & $98,69 \pm 45,67$ & $7,61 \pm 1,19$ & $1,61 \pm 0,12$ & $0,14 \pm 0,04$ & $*$ \\
\hline
\end{tabular}

Obs: Os valores que não apresentam desvio padrão é devido $\mathrm{n}=1 ;{ }^{*} \mathrm{n}=0 ;{ }^{\mathrm{A}}=$ maior grau de degradação ${ }^{\mathrm{B}}=$ área coberta por gramíneas 
Anexo C. Concentrações médias e desvio padrão dos cátions $\left(\mathrm{HCO}_{3}^{-}+\mathrm{CO}_{3}{ }^{-}, \mathrm{Cl}^{-}, \mathrm{SO}_{4}{ }^{-}\right)$na solução do solo para os perídos seco e chuvoso

\begin{tabular}{|c|c|c|c|c|c|c|c|c|c|c|c|}
\hline \multirow[t]{2}{*}{ Local } & Vegetação & Prof. & Solo & $\mathrm{Na}^{+}$ & $\mathbf{K}^{+}$ & $\mathbf{M g}^{++}$ & $\mathrm{Ca}^{++}$ & $\mathrm{Na}^{+}$ & $\mathbf{K}^{+}$ & $\mathbf{M g}^{++}$ & $\mathbf{C a}^{++}$ \\
\hline & & $(\mathrm{cm})$ & & \multicolumn{4}{|c|}{ Período Chuvoso [ $\mu \mathrm{M}]$} & \multicolumn{4}{|c|}{ Período Seco $[\mu \mathrm{M}]$} \\
\hline \multirow[t]{5}{*}{ ZF2 } & Fl. Primária & 10 & Latossolo & $29,44 \pm 27,21$ & $4,95 \pm 6,70$ & $10,94 \pm 7,6$ & $25,17 \pm 24,30$ & $21,76 \pm 20,66$ & $3,13 \pm 3,05$ & $4,79 \pm 2,61$ & $14,44 \pm 10,15$ \\
\hline & & 20 & & $11,75 \pm 3,90$ & $1,66 \pm 0,75$ & $26,45 \pm 10,87$ & $100,33 \pm 39,04$ & $26,42 \pm 26,73$ & $2,89 \pm 2,72$ & $4,81 \pm 5,76$ & $12,99 \pm 20,58$ \\
\hline & & 50 & & $11,79 \pm 6,99$ & $3,22 \pm 4,68$ & $6,08 \pm 12,3$ & $52,95 \pm 134,14$ & $28,46 \pm 27,32$ & $3,15 \pm 3,9$ & $1,21 \pm 1,16$ & $5,54 \pm 3,36$ \\
\hline & & 100 & & $32,08 \pm 31,56$ & $3,75 \pm 2,56$ & $12,34 \pm 9,36$ & $56,84 \pm 56,76$ & $23,38 \pm 26,07$ & $2,39 \pm 2,09$ & $3,29 \pm 2,18$ & $8,29 \pm 9,03$ \\
\hline & & 150 & & $33,42 \pm 25,95$ & $6,63 \pm 4,92$ & $6,08 \pm 2,72$ & $17,30 \pm 14,69$ & $28,66 \pm 8,09$ & $2,31 \pm 2,16$ & $1,56 \pm 1,04$ & $4,03 \pm 1,92$ \\
\hline \multirow[t]{5}{*}{ ZF2 } & Fl. Primária & 10 & Argissolo & $27,30 \pm 14,72$ & $2,85 \pm 3,93$ & $3,87 \pm 3,17$ & $9,46 \pm 9,21$ & $30,66 \pm 17,99$ & $2,75 \pm 2,80$ & $6,65 \pm 7,09$ & $7,11 \pm 11,96$ \\
\hline & & 20 & & $15,93 \pm 10,34$ & $2,04 \pm 1,5$ & $5,31 \pm 4,17$ & $9,07 \pm 7,17$ & $27,69 \pm 13,55$ & $3,18 \pm 1,91$ & $3,41 \pm 2,68$ & $9,03 \pm 11,95$ \\
\hline & & 50 & & $38,22 \pm 24,14$ & & & & $36,67 \pm 16,17$ & $3,73 \pm 2,38$ & $4,55 \pm 3,22$ & $6,40 \pm 5,75$ \\
\hline & & 100 & & $39,89 \pm 19,34$ & $2,28 \pm 1,55$ & $2,05 \pm 2,40$ & $3,51 \pm 2,77$ & $39,34 \pm 20,07$ & $4,12 \pm 2,62$ & $2,99 \pm 2,28$ & $9,66 \pm 8,38$ \\
\hline & & 150 & & $31,04 \pm 17,55$ & $1,54 \pm 4,53$ & $2,76 \pm 7,49$ & $2,80 \pm 1,52$ & $23,41 \pm 21,06$ & $2,57 \pm 2,44$ & $2,14 \pm 2,56$ & $5,24 \pm 4,93$ \\
\hline \multirow[t]{5}{*}{ ZF2 } & Fl. Primária & 10 & Espodossolo & $37,73 \pm 20,10$ & $5,55 \pm 4,24$ & $2,99 \pm 2,92$ & $11,06 \pm 15,92$ & $51,90 \pm 65,15$ & $6,45 \pm 7,68$ & $18,80 \pm 36,3$ & $40,65 \pm 68,7$ \\
\hline & & 20 & & $31,51 \pm 15,89$ & $6,93 \pm 4,28$ & $4,83 \pm 2,74$ & $18,63 \pm 12,47$ & $30,49 \pm 34,17$ & $13,48 \pm 17,99$ & $16,81 \pm 20,33$ & $39,27 \pm 39,85$ \\
\hline & & 50 & & 52.02 & 20.17 & 12.18 & 17.35 & $17,27 \pm 10,84$ & $24,53 \pm 26,1$ & $65,65 \pm 69,26$ & $198,05 \pm 167,49$ \\
\hline & & 100 & & $24,16 \pm 8,49$ & $14,40 \pm 20,7$ & $14,24 \pm 9,46$ & $48,91 \pm 32,42$ & $25,35 \pm 13,61$ & $14,82 \pm 14,6$ & $13,19 \pm 5,94$ & $25,92 \pm 25,1$ \\
\hline & & 150 & & $26,98 \pm 12,53$ & $9,76 \pm 10,3$ & $14,77 \pm 9,29$ & $64,14 \pm 60,61$ & $16,37 \pm 11,4$ & $3,87 \pm 2,52$ & $9,46 \pm 13,52$ & $51,29 \pm 72,3$ \\
\hline \multirow[t]{5}{*}{ P. Figueiredo } & Fl. Primária & 10 & Latossolo & $14,32 \pm 12,85$ & $1,70 \pm 1,08$ & $2,08 \pm 3,12$ & $8,07 \pm 13,06$ & $23,12 \pm 31,12$ & $3,33 \pm 3,37$ & $0,65 \pm 0,43$ & $3,36 \pm 1,08$ \\
\hline & & 20 & & $26,72 \pm 17,89$ & $2,24 \pm 1,42$ & $0,98 \pm 0,54$ & $2,86 \pm 1,98$ & $23,59 \pm 20,17$ & $3,09 \pm 2,53$ & $1,37 \pm 0,8$ & $4,49 \pm 2,34$ \\
\hline & & 50 & & $17,98 \pm 20,29$ & $3,16 \pm 4,07$ & $1,42 \pm 1,57$ & $4,20 \pm 7,30$ & $25,31 \pm 29,7$ & $3,69 \pm 4,44$ & $2,05 \pm 6,06$ & $7,08 \pm 9,9$ \\
\hline & & 100 & & 15.61 & $1,41 \pm 1,07$ & $0,67 \pm 0,31$ & $3,00 \pm 0,96$ & $23,15 \pm 32,49$ & $2,49 \pm 2,21$ & $1,47 \pm 1,07$ & $6,04 \pm 3,35$ \\
\hline & & 150 & & 21.65 & $2,16 \pm 1,34$ & $1,62 \pm 0,66$ & $4,90 \pm 2,16$ & $15,56 \pm 17,49$ & $2,02 \pm 2,49$ & $2,28 \pm 1,10$ & $6,31 \pm 4,7$ \\
\hline \multirow[t]{5}{*}{ CAMES } & Reflorestamento & 10 & Latossolo & $17,42 \pm 12,14$ & $3,14 \pm 2,77$ & $2,57 \pm 1,96$ & $16,26 \pm 12,74$ & $13,74 \pm 15,97$ & $1,35 \pm 1,26$ & $3,83 \pm 6,71$ & $11,38 \pm 4,61$ \\
\hline & & 20 & & $16,37 \pm 8,64$ & $2,47 \pm 3,18$ & $3,29 \pm 3,19$ & $26,72 \pm 21,56$ & $20,29 \pm 12,76$ & $2,32 \pm 1,61$ & $1,76 \pm 1,6$ & $11,58 \pm 4,79$ \\
\hline & & 50 & & $15,80 \pm 11,55$ & $2,17 \pm 1,29$ & $2,40 \pm 1,13$ & $16,43 \pm 4,43$ & $13,08 \pm 16,03$ & $1,17 \pm 1,02$ & $1,32 \pm 0,73$ & $9,44 \pm 3,17$ \\
\hline & & 100 & & $12,18 \pm 4,96$ & $2,29 \pm 1,53$ & $2,70 \pm 1,19$ & $20,93 \pm 10,62$ & $7,73 \pm 4,90$ & $1,87 \pm 2,61$ & $1,59 \pm 0,73$ & $10,96 \pm 5,34$ \\
\hline & & 150 & & $12,33 \pm 5,99$ & $1,73 \pm 0,71$ & $3,36 \pm 1,14$ & $23,80 \pm 6,19$ & $14,38 \pm 25,9$ & $0,87 \pm 0,58$ & $3,68 \pm 5,91$ & $13,36 \pm 7,61$ \\
\hline
\end{tabular}


Anexo C. Concentrações médias e desvio padrão dos cátions $\left(\mathrm{HCO}_{3}{ }^{-}+\mathrm{CO}_{3}{ }^{-}, \mathrm{Cl}^{-}, \mathrm{SO}_{4}{ }^{-}\right)$na solução do solo para os perídos seco e chuvoso

\begin{tabular}{|c|c|c|c|c|c|c|c|c|c|c|c|}
\hline \multirow[t]{2}{*}{ Local } & \multirow[t]{2}{*}{ Vegetação } & Prof. & \multirow[t]{2}{*}{ Solo } & $\mathrm{Na}^{+}$ & $\mathbf{K}^{+}$ & $\mathbf{M g}^{++}$ & $\mathbf{C a}^{++}$ & $\mathrm{Na}^{+}$ & $\mathbf{K}^{+}$ & $\mathbf{M g}^{++}$ & $\mathbf{C a}^{++}$ \\
\hline & & $(\mathbf{c m})$ & & \multicolumn{4}{|c|}{ Período Chuvoso $[\mu \mathrm{M}]$} & \multicolumn{4}{|c|}{ Período Seco $[\mu \mathrm{M}]$} \\
\hline \multirow[t]{5}{*}{ CAMES } & Fl. Secundária & 10 & Latossolo & $12 \pm 6,94$ & $3,86 \pm 2,77$ & $7,15 \pm 5,61$ & $5,97 \pm 3,89$ & $4,13 \pm 1,96$ & $2,5 \pm 2,68$ & $3,89 \pm 1,85$ & $5,98 \pm 3,52$ \\
\hline & & 20 & & $15,34 \pm 19,33$ & $2,86 \pm 2,45$ & $8,89 \pm 9,56$ & $8,16 \pm 4,44$ & $9,64 \pm 21,28$ & $2,17 \pm 2,18$ & $3,87 \pm 2,29$ & $6,08 \pm 4,52$ \\
\hline & & 50 & & $8,46 \pm 6,24$ & $2,01 \pm 1,05$ & $4,23 \pm 2,70$ & $6,07 \pm 3,17$ & $4,93 \pm 4,69$ & $1,85 \pm 2,3$ & $2,31 \pm 1,99$ & $6,45 \pm 4,18$ \\
\hline & & 100 & & $11,19 \pm 10,88$ & $2,06 \pm 2,47$ & $2,47 \pm 2,5$ & $4,07 \pm 2,73$ & $5,28 \pm 7,43$ & $0,96 \pm 0,97$ & $1,80 \pm 1,06$ & $3,40 \pm 1,63$ \\
\hline & & 150 & & $12,14 \pm 8,85$ & $1,72 \pm 1,49$ & $1,39 \pm 0,73$ & $3,44 \pm 2,18$ & $6,02 \pm 4,00$ & $2,66 \pm 1,85$ & $1,66 \pm 1,32$ & $3,72 \pm 1,76$ \\
\hline \multirow[t]{5}{*}{ P. Figueiredo } & A. Degradada ${ }^{A}$ & 10 & Latossolo & $35,14 \pm 25,97$ & $17,51 \pm 9,76$ & $7,57 \pm 1,73$ & $7,67 \pm 1,65$ & $29,03 \pm 22,70$ & $8,58 \pm 5,67$ & $6,40 \pm 4,61$ & $5,12 \pm 3,74$ \\
\hline & & 20 & & 30.63 & 10.31 & 5.50 & 12.78 & $34,50 \pm 31,75$ & $8,70 \pm 6,24$ & $3,97 \pm 2,25$ & $8,22 \pm 7,87$ \\
\hline & & 50 & & $18,79 \pm 10,57$ & $6,96 \pm 3,11$ & $3,45 \pm 1,41$ & $4,41 \pm 1,39$ & $25,85 \pm 6,02$ & $9,72 \pm 6,24$ & $1,90 \pm 1,03$ & $2,83 \pm 1,86$ \\
\hline & & 100 & & $15,85 \pm 5,53$ & $8,50 \pm 4,86$ & $2,05 \pm 0,74$ & $3,06 \pm 1,28$ & $19,22 \pm 16,39$ & $5,49 \pm 4,95$ & $2,14 \pm 1,28$ & $2,85 \pm 1,54$ \\
\hline & & 150 & & $20,05 \pm 7,78$ & $4,59 \pm 5,2$ & $2,15 \pm 2,22$ & $2,16 \pm 0,71$ & $36,00 \pm 34,44$ & $5,03 \pm 3,87$ & $2,12 \pm 1,56$ & $6,15 \pm 5,09$ \\
\hline \multirow[t]{4}{*}{ P. Figueiredo } & A. Degradada ${ }^{\text {B }}$ & 10 & Latossolo & $10,73 \pm 8,74$ & $1,47 \pm 0,27$ & $2,88 \pm 3,40$ & $4,62 \pm 4,83$ & * & * & * & $*$ \\
\hline & & 50 & & $6,99 \pm 9,78$ & $1,24 \pm 0,43$ & $5,48 \pm 5,17$ & $10,62 \pm 4,95$ & $14,84 \pm 12,57$ & $5,93 \pm 7,13$ & $8,15 \pm 9,46$ & $4,62 \pm 0,46$ \\
\hline & & 100 & & $9,64 \pm 11,9$ & $2,00 \pm 2,21$ & $4,57 \pm 3,70$ & $11,57 \pm 4,98$ & $12,71 \pm 15,44$ & $1,89 \pm 2$ & $0,85 \pm 0,42$ & $6,29 \pm 4,05$ \\
\hline & & 150 & & $11,15 \pm 12,63$ & $1,78 \pm 1,03$ & $3,76 \pm 3,76$ & $8,57 \pm 3,59$ & $2,48 \pm 2,00$ & $0,62 \pm 0,33$ & $1,37 \pm 1,08$ & $7,21 \pm 1,97$ \\
\hline
\end{tabular}

Obs: Os valores que não apresentam desvio padrão é devido $n=1 ;{ }^{*} \mathrm{n}=0 ;{ }^{\mathrm{A}}=$ maior grau de degradação ; ${ }^{\mathrm{B}}=$ área coberta por gramíneas 


\section{REFERÊNCIAS BIBLIOGRÁFICAS}

AROCENA, J.M. Cations in solution from forest soils subjected to forest floor removal and compaction treatments. Forest Ecology and Management, v.133, n.1/2, p.7180, 2000.

ARZHANOVA, V.S.; VERTEL, Y.F. Trace elements and soluble organic matter in lysimeter water. Sovietic Soil Science, v. 13, p.72-78, 1981.

BATJES, N.H.; DIJKSHOORN, J.A. Carbon and nitrogen stocks in the soils of the Amazon Region. Geoderma, v.89, n.3/4, p.273-286, 1999.

BERNER, E.K.; BERNER, R.A._The Global Water Cycle. New Jersey: Prentice-Hall, 1987. $397 \mathrm{p}$.

BIGELOW, S.W.; EWEL, J.J.; HAGGAR, J.P. Enhancing nutrient retention in tropical tree plantations: No short cuts. Ecological Applications, v.14, n.1, p.28-46, 2004.

BOULET, R.; LUCAS, Y.; CHAUVEL, A.; RANZINI, G. SCATOLINI, F. Transição Latossolos-Espodossols sobre a Formação Barreiras na Região de Manaus, Amazônia. Revista Brasileira de Ciência do Solo, v.8, p.325-335, 1984.

BRADY, N.C.; WEIL, R.R. The nature and properties of soil. New Jersey: PrenticeHall. 1999. 881 p.

BRASIL. Ministério das Minas e Energia. Folha S. A. 20, 1978. In: Projeto RADAMBRASIL. Levantamento dos Recursos Naturais. Manuas. Manaus, 1978. 
BRAVARD, S.; RIGHI, D. Characteristics of Clays in an Oxisol - Spodosol Toposequence in Amazonia (Brazil). Clay Minerals, v.23, n.3, p.279-289, 1988.

BRINKMANN, W.L.F. Ground water in water resources planning. In: INTERNATIONAL SYMPOSIUM FOR PROGRAME INTERNATIONAL HYDROLOGICAL. Federal Republic of Germany: Koblenz, 1983. p.67-83.

BRINKMANN, W.L.F.; NASCIMENTO, J.C de. The effect of slash and burn agriculture on plant nutrients in the Tertiary region of central Amazonia. Turrialba, v.21, n.4 p. 459-465, 1973.

BRINKMANN, W.L.F.; SANTOS, A. Natural Waters in Amazonia. Acta Amazonica, v.3, p.33-40, 1973.

BRUENING, E.F. Conservation and management of tropical rainforest. Wallingford, Oxon, UK: CAB International,1996. 339p.

BUSCHBACLER, R.J. Deforestation for sovereignty over remote frontiers. In: (Ed.). Amazonian Rain Forests Ecosystem Disturbance and Recovery. New York: Springer Verlang. Deforestation for Sovereignty Over Remote Frontiers, 1987, p.130.

CAMPO, J.; MAASS, J.M.; JARAMILLO, V.J.; YRIZAR, A.M. Calcium, potassium, and magnesium cycling in a Mexican tropical dry forest ecosystem. Biogeochemistry, v.49, n.1, p.21-36, 2000.

CAPUTO, M.V. Stratigraphy, tectonics, paleoclimatology paleogeography of northern basins of Brazil. California, 1984. 583p. Thesis (Ph.D.) - University of California.

CAPUTO, M.V.; RODRIGUES, R.; VASCONCELOS, D.N.N. Nomenclatura estratigráfica da bacia do Rio Amazonas. In: CONGRESSO BRASILEIRO DE GEOLOGIA, 26., Belém, 1972. Anais. Belém: SBG, 1972. p.35-46. 
CARNEIRO, V. M. C. Composição florística e análise estrutural da floresta primária de terra firme na bacia do Rio Cuieiras, Manaus-AM. Manaus, 2004. 67p. Dissertação (Mestrado) - Universidade Federal do Amazonas.

CAROZZI, A.V.; PAMPLONA, H.R.P.; CASTRO, J.C.; CONTREIRAS, C.J.A. Ambientes deposicionais e evolução tectono-sedimentar da seção clástica paleozóica da bacia do médio Amazonas. In: CONGRESSO BRASILEIRO DE GEOLOGIA, 27., São Paulo, 1973. Anais. Rio de Janeiro: SBG, 1973.p 279-314.

CERRI, C.C. Dinâmica da matéria orgânica do solo no agroecossistema cana-de-açúcar. Piracicaba, 1986. 197p. Tese (Livre Docência) - Escola Superior de Agricultura "Luiz de Queiroz", Universidade de São Paulo.

CERRI, C.E.P. Variabilidade espacial e temporal do carbono do solo na conversão de floresta em pastagens na Amazônia Ocidental - Rondônia. Piracicaba, 2003. 159p. Tese (Doutorado) - Centro de Energia Nuclear na Agricultura, Universidade de São Paulo.

CHAUVEL, A. Contribuição para o estudo dos latossolos amarelos, distróficos, argilosos na borda do platô, na região de Manaus: mecanismos de gibbsitização. Acta Amazônica, v.11, p.227-245, 1981.

CHAUVEL, A. Os latossolos amarelos, álicos, argilosos dentro dos ecossistemas das bacias experimentais do INPA e da região vizinha. Acta Amazônica, v.12, Supl., p.47-60, 1982.

CHRIST, M.J., DAVID, M.B. Dynamics of extractable organic carbon in spodosol forest floors. Soil Biology \& Biochemistry, v.28, p.1171-1179, 1996.

CHRISTENSEN, B.T. Physical fractionation of soil organic matter in primary particle size and density separates. Advances Soil Science, v.20, p.1-90, 1992. 
CUNHA, P.R.C.; CONZAGA, F.G.; COUTINHO, L.F.C.; FEIJÓ, F.J. Bacia do Amazonas. Boletin de Geoiências, v. 8, n.1, p.47-55, 1994.

DAEMON, R.F. Contribuição a datação da Formação Alter do Chão, Bacia do Amazonas. Revista Brasileira Geociências, v. 5, n.2, p.78-84, 1975

DAWSON, H.J.; HRUTFIORD, B.F.; ZASOSKI, R.J.; UGOLINI, F.C. The MolecularWeight and Origin of Yellow Organic-Acids. Soil Science, v.132, n.3, p.191-199, 1981.

DREVER, J.I. The Geochemistry of natural waters: surface and groundwater environments. New Jersey: Prentice Hall, 1997. 436p.

DUXBURY, J.M.; SMITH, M.S.; DORAN J.W. Soil organic matter as a source and a sink of plant nutrients. In: COLEMAN, D.C. (Ed) Dynamics of soil organic matter in tropical ecosystems. Honolulu: Niftal Project, 1989. p.33-67.

EMPRESA BRASILEIRA DE PESQUISA AGROPECUÁRIA. Manual de métodos de análises de solo. Rio de Janeiro: CNPS, 1979. 212 p.

EMPRESA BRASILEIRA DE PESQUISA AGROPECUÁRIA. Sistema brasileiro de classificação de solos. Brasília: SPI, 1999. 370 p

FEIGL, B.J.; MELILLO, J.; CERRI, C.C. Changes in the origin and quality of soil organic-matter after pasture introduction in Rondonia (Brazil). Plant and Soil, v.175, n.1, p.21-29, 1995.

FERREIRA, S. J. F. Ciclo hidrológico e de nutrientes em uma área de manejo florestal em floresta de terra firme na Amazônia Central. São Carlos, 1999. 181p. Tese (Doutorado) - Escola de Engenharia de São Carlos, Universidade de São Paulo.

FERREIRA, S.J.F.; FERRAZ, J.B.; KOBAYASHI, M.; HIRAI, K.; TAKAHASHI, M.; SILVA, C.E.M. Processos de degradação e recuperação de ecossistemas florestais na 
Amazônia Central: Alterações no armazenamento de água nos solos. In: Projeto jacarandá - fase 2: pesquisas florestais na Amazônia Central. Manaus: INPA, 2003. p.169-178.

FIEDLER, S.; KALBITZ, K. Concentrations and properties of dissolved organic matter in forest soils as affected by the redox regime. Soil Science, v.168, n.11, Nov, p.793801, 2003.

FILOSO, S.; WILLIAMS, M. R.; MELACK, J.M. Composition and deposition of throughfall in a flooded forest archipelago (Negro River, Brazil). Biogeochemistry, v.45, n.2, p.169-195, 1999.

GARCIA-MONTIEL, D.C.; STEUDLER, P.A.; PICCOLO, M.C.; MELILLO, J.M.; NEILL, C.; CERRI, C.C. Controls on soil nitrogen oxide emissions from forest and pastures in the Brazilian Amazon. Global Biogeochemical Cycles, v.15, n.4, p.1021-1030, 2001.

GRAHN, Y. Revision of Silurian and Devonian strata of Brazil. Palinology, v.16, p.3561, 1992.

GRIMALDI, C.; GRIMALDI, M.; MILLET, A.; BARIAC, T.; BOULEGUE, J. Behaviour of chemical solutes during a storm in a rainforested Headwater catchment. Hydrological Processes, v.18, n.1, p.93-106, 2004.

GUGGENBERGER, G. ZECH, W. Dissolved organic carbon controls in acid forest soils of the Fichtelgebirge (Germany) as revealed by distribution patterns and structural composition analyses. Geoderma, v.59, p.109-129, 1993.

HEDIN, L.O.; VITOUSEK, P.M.; MATSON, P.A. Nutrient losses over four million years of tropical forest development. Ecology, v.84, n.9, p.2231-2255, 2003. 
HINTON, M.J.; SCHIFF, S.L.; ENGLISH, M.C. Sources and flowpaths of dissolved organic carbon during storms in two forested watersheds of the Precambrian Shield. Biogeochemistry, v.41, n.2, p.175-197, 1998.

HOLDRIDGE, L.R. Ecologia basada en zonas de vida. San Jose: IICA, 1978. 216p.

INSTITUTO DE PESQUISAS ECOLÓGICAS DA AMAZÔNIA. Os solos da área Manaus - Itacoatiara. Manaus, IPEAM, 1969. 177p.

INSTITUTO NACIONAL DE METEOROLOGIA. Normais climatológicas (19611990). Brasília, 1992. 84p.

INSTITUTO NACIONAL DE PESQUISAS ESPACIAIS. Monitoramento da floresta amazônica brasileira por satélite: 2000-2001. São José dos Campos: http://www.obt.inpe.br/prodes/prodes_2000_2001. htm (25 maio 2004).

JANZEN, D.H. Tropical black-water rivers, animals, and mast fruiting by the Dipterocapaceae. Biotropicu, v.6, p.69-103, 1974.

JORDAN, C F. Nutrient cycling in tropical ecosystems: principales and their application in management and conservation. New York: John Wily, 1985. 190p.

JORDAN, C.F. Amazonia rain forest ecosystem: disturbance and recovery. New York: Spring Verlag, 1987. 130p.

JUNK, W.J. The central Amazon floodplain. Berlin: Springer-Verlag. 1997. 525p.

KALBITZ, K. Properties of organic matter in soil solution in a German fen area as dependent on land use and depth. Geoderma, v.104, n.3/4, p.203-214, 2001.

KALBITZ, K.; GEYER, S.; GEYER, W. A comparative characterization of dissolved organic matter by means of original aqueous samples and isolated humic substances. Chemosphere, v.40, n.12, p.1305-1312, 2000. 
KAUFFMAN, J.B.; CUMMINGS, D.L.; WARD, D.E. Fire in the brazilian Amazon 2. biomass, nutrient pools and losses in cattle pastures. Oecologia, v.113, n.3, p.415427, 1998.

KAUFFMAN, J.B.; CUMMINGS, D.L.; WARD, D.E.; BABBITT, R. Fire in the brazilian Amazon .1. biomass, nutrient pools, and losses in slashed primary forests. Oecologia, v.104, n.4, p.397-408, 1995.

KÖPPEN, W. Climatologia; non un estudio de los climas de la tierra. México: Fondo de Cultura Econômica, 1948. 463p.

LAURANCE, W.F.; FEARNSIDE, P.M.; LAURANCE, S.G.; DELAMONICA, P.; LOVEJOY, T.E.; RANKIN-DE MERONA, J.; CHAMBERS, J.Q.; GASCON, C. Relationship between soils and Amazon forest biomass: A landscape-scale study. Forest Ecology and Management, v.118, n.1-3, 14, p.127-138, 1999.

LEENLEER, J.A. Origin and nature of humic substances in the waters of the Amazon River Basin. Acta Amazônica, v.10, p.513-526, 1980.

LEMOS, R.C. Manual de descrição e coleta de solo no campo. Campinas: Sociedade Brasileira de Ciência do Solo, 1996. 84 p.

LIKENS, G.E.; BORMANN, F.H. Nutrienty cycles. Biogeochemistry of a forested ecosystem. New York: Springer-Verlag, 1977. 159 p.

LUCHESE, E.B.; FAVERO, L.O.B.; LENZI, E. Fundamentos da química do solo. Rio de Janeiro: Freitas Bastos, 2001. 182p.

LUIZÃO, F.J. Litter production and mineral element imput tho the forest foor in a central Amazonian forest. Geojournal, v.19, p.407-417,1989. 
MARRS, R.H.; THOMPSON, J.; SCOTT, D.; PROCTOR, J. Nitrogen mineralization and nitrification in terra-firme forest and savanna soils on Ilha-De-Maraca, Roraima, Brazil. Journal of Tropical Ecology, v.7, p.123-137, 1991.

MCCLAIN, M.E.; RICHEY, J.E.; BRANDES, J.A.; PIMENTEL, T.P. Dissolved organic matter and terrestrial-lotic linkages in the central Amazon basin of Brazil. Global Biogeochemical Cycles, v.11, n.3, p.295-311, 1997.

MCDOWELL, W.H.; WOOD, T. Podzolization - soil processes control dissolved organic-carbon concentrations in stream water. Soil Science, v.137, n.1, p.23-32, 1984.

MCGRATH, D.A.; SMITH, C.K.; GHOLZ, H.L.; OLIVEIRA, F.D. Effects of land-use change on soil nutrient dynamics in Amazonia. Ecosystems, v.4, n.7, p.625-645, 2001.

MCKNIGHT, D.M.; BENCALA, K.E.; ZELLWEGER, G.W.; AIKEN, G.R.; FEDER, G.L.; THORN, K.A. Sorption of dissolved organic-carbon by hydrous aluminum and iron-oxides occurring at the confluence of deer creek with the snake river, summit County, Colorado. Environmental Science \& Technology, v.26, n.7, p.1388-1396, 1992.

MELLO, A.W.F. Avaliação do estoque e composição isotópica do carbono do solo no Acre. Piracicaba, 2003. 74p. Dissertação (Mestrado) - Escola Superior de Agricultura “Luiz de Queiroz” - Universidade de São Paulo.

MEYER, J.L.; TATE, C.M. The effects of watershed disturbance on dissolved organiccarbon dynamics of a stream. Ecology, v.64, n.1, p.33-44, 1983.

MORTATTI, J. Erosão na Amazonia: processos, modelos e balanco. Piracicaba, 1995. 127p - Tese (Livre-Docencia) - Escola Superior de Agricultura “Luiz de Queiroz”, Universidade de São Paulo. 
NEILL, C.; MELILLO, J.M.; STEUDLER, P.A.; CERRI, C.C.; MORAES, J.F.L.; PICCOLO, M.C.; BRITO, M. Soil carbon and nitrogen stocks following forest chearing for pasture in the southwestern Brazilian Amazon. Ecological Applications, v.7, n.4, p.1216-1225, 1997.

NELSON, P.N.; BALDOCK, J.A.; OADES, J.M. Concentration and composition of dissolved organic carbon in streams in relation to catchment soil properties. Biogeochemistry, v.19, p.27-50, 1993.

NEPSTAD, D.C.; DECARVALHO, C.R.; DAVIDSON, E.A.; JIPP, P.H.; LEFEBVRE, P.A.; NEGREIROS, G.H.; DASILVA, E.D.; STONE, T.A.; TRUMBORE, S.E.; VIEIRA, S. The role of deep roots in the hydrological and carbon cycles of Amazonian forests and pastures. Nature, v.372, n.6507, p.666-669, 1994.

NOGUEIRA, A.C.R. Depósitos costeiros neoproterozóicos da formação Prosperança, Município de Presidente Figueiredo - Estado do Amazonas. In: SIMPÓSIO DE GEOlogiA DA AMAZÔniA, 6., Manaus, 1999. Anais. Manaus: SBG, 1999. p.412.

NOGUEIRA, A.C.R.; SOUZA, V.; SOARES, E.A.A.. Contribuição à tectônica cenozóica da região de Presidente Figueiredo, norte de Manaus -AM. In: SIMPÓSIO NACIONAL DE ESTUDOS TECTÔNICOS, 6., Pirinópolis, 1997. Anais. Pirinópolis: SBG, 1997. p.123-125.

NOVAIS, R.F.; SMYTH, T.J. Fósforo em solo e planta em condições tropicais. Viçosa: UFV - DPS, 1999. 399p.

ODUM, E.P. Fundamentals of Ecology. México: Interamericana, 1972. 639 p.

ONUSKA, F.I. Techniques and procedures for preparation of aquatic samples for chromatographic analyses. Journal of High Resolution Choromatografy, v.12, p.4-11, 1989. 
PARTON, W.J.; SCHIMEL, D.S.; COLE, C V.; OJIMA, D.S. Analysis of factors controlling soil organic-matter levels in great-plains grasslands. Soil Science Society of America Journal, v.51, n.5, p.1173-1179, 1987.

PARTON, W.J.; SCURLOCK, J.M.O.; OJIMA, D.S.; GILMANOV, T.G.; SCHOLES, R.J.; SCHIMEL, D.S.; KIRCHNER, T.; MENAUT, J,C.; SEASTEDT, T.; MOYA, E.G.; KAMNALRUT, A.; KINYAMARIO, J.I. Observations and modeling of biomass and soil organic-matter dynamics for the grassland biome worldwide. Global Biogeochemical Cycles, v.7, n.4, p.785-809, 1993.

POELS, R.L.H. Soils, water and nutrients in a forest ecosystem in Suriname. Suriname: Wageningen, 1987. $252 \mathrm{p}$.

POST, W.M.; PASTOR, J.; ZINKE, P.J.; STANGENBERGER, A.G. Global patterns of soil-nitrogen storage. Nature, v.317, n.6038, p.613-616, 1985.

RANZINI, G. Identificação e caracterização de alguns solos da estação de silvicultura tropical do INPA. Acta Amazônica, v.10, p.7-41, 1980.

SANTOS, A.; RIBEIRO, M.N. Nitrogênio na água do solo do ecossistema Campina Amazônica. Acta Amazônica, v.5, p.173-182, 1975.

SANTOS, G.A.; CAMARGO, F.A.O. Fundamentos da matéria orgânica do solo: ecossistemas tropicais e subtropicais. Porto Alegre: Gênesis, 1999. 508 p.

SCHIMEL, D.S. Terrestrial ecosystems and the carbon-cycle. Global Change Biology, v.1, n.1, p.77-91, 1995.

SCHIMEL, D.S.; BRASWELL, B.H.; HOLLAND, E.A.; MCKEOWN, R.; OJIMA, D.S.; PAINTER, T.H.; PARTON, W.J.; TOWNSEND, A.R. Climatic, edaphic, and biotic controls over storage and turnover of carbon in soils. Global Biogeochemical Cycles, v.8, n.3, p.279-293, 1994. 
SCHINDLER, D.W.; BAYLEY, S.E.; CURTIS, P.J; PARKER, B.R.; STAINTON, M.P.; KELLY, C.A. Natural and man-caused factor affecting the abundance and cycling of dissolved organic substances in precambrian shield lakes. Hidrobiologia, v.229, p.1-21, 1992.

SCHROTH, G.; SEIXAS, R.; SILVA, L.F.; TEIXEIRA, W.G.; ZECH, W. Nutrient concentrations and acidity in ferralitic soil under perennial cropping, fallow and primary forest in central Amazonia. European Journal of Soil Science, v.51, n.2, p.219-231, 2000.

SCHROTH, G.; ELIAS, M.E.A.; UGUEN, K.; SEIXAS, R.; ZECH, W. Nutrient fluxes in rainfall, throughfall and stemflow in tree-based land use systems and spontaneous tree vegetation of central Amazonia. Agriculture Ecosystems \& Environment, v.87, n.1, p.37-49, 2001.

SCHWESIG, D.; KALBITZ, K.; MATZNER, E. Mineralization of dissolved organic carbon in mineral soil solution of two forest soils. Journal of Plant Nutrition and Soil Science-Zeitschrift Fur Pflanzenernahrung Und Bodenkunde, v.166, n.5, p.585-593, 2003.

SILVER, W.L.; NEFF, J.; MCGRODDY, M.; VELDKAMP, E.; KELLER, M.; COSME, R. Effects of soil texture on belowground carbon and nutrient storage in a lowland Amazonian forest ecosystem. Ecosystems, v.3, n.2, p.193-209, 2000.

SIOLI, H. The Amazon: limnology and landscape ecology of a mighty tropical river and its basin. Boston: Kluwer Academic, 1984. 763 p.

SMETHURST, P.J. Soil solution and other soil analyses as indicators of nutrient supply: a review. Forest Ecology and Management, v.138, n.1/3, p.397-411, 2000.

SOARES, E.A.A. Análise faciológica-estratigráfica da formação Nhamundá, grupo trombetas, siluriano da Bacia do Amazonas, região de Presidente Figueiredo - AM. 
Pará, 1998. 98p. Dissertação (Mestrado) - Centro de Geociências, Universidade Federal do Pará.

SOLINGER, S.; KALBITZ, K.; MATZNER, E. Controls on the dynamics of dissolved organic carbon and nitrogen in a central European deciduous forest. Biogeochemistry, v.55, n.3, p.327-349, 2001.

SPANGENBERG, A.; BREDEMEIER, M. Application of spectral analysis to meteorological and soil solution chemistry data. Chemosphere, v.39, n.10, p.16511665, 1999.

STALLARD, R.F.; EDMOND, J.M. Geochemistry of the Amazon. 1. Precipitation chemistry and the marine contribution to the dissolved-load at the time of peak discharge. Journal Of Geophysical Research-Oceans And Atmospheres, v.86, n.10, p.9844-9858, 1981.

TELLES, E. C. C. Dinâmica do carbono no solo influenciado pela textura, drenagem, mineralogia e carvões em florestas primárias na região centro-oriental da Amazônia. Piracicaba, 2002. 92p. Tese (Doutorado) - Centro de Energia Nuclear na Agricultura, Universidade de São Paulo.

TELLES, E.D.C.; CAMARGO, P.B.; MARTINELLI, L.A.; TRUMBORE, S.E.; COSTA, E. S.; SANTOS, J.; HIGUCHI, N.; OLIVEIRA, R. C. Influence of soil texture on carbon dynamics and storage potential in tropical forest soils of Amazonia. Global Biogeochemical Cycles, v.17, n.2, 2003.

THURMAN, E.M. Organic geochemistry of natural waters. Dordrecht: Martinus Nijhoff, 1985. v.2, 497 p.

TRAVASSOS, W.A.S.; BARBOSA FILHO, C.M. Tectonismo terciário na área do rio Tapajós, bacia do Amazonas. Boletin Geociências, v. 4, n.3, p.221-340, 1990. 
VAN RAIJ B. ANDRADE J.C. CANTARELLA H. QUAGGIO J.A. Análise química para avaliação da fertilidade de solos tropicais. Campinas: Instituto Agronômico, 2001. 285p.

VELDKAMP, E. Organic-carbon turnover in 3 tropical soils under pasture after deforestation. Soil Science Society of America Journal, v.58, n.1, p.175-180, 1994.

VIEIRA, S.A. Mudanças globais e taxa de crescimento arbóreo na Amazônia. Piracicaba, 2003. 103p. Tese (Doutorado) - Centro de Energia Nuclear na Agricultura, Universidade Estadual de São Paulo.

VITOUSEK, P.M.; MATSON, P.A. Matson. Nitrogen transformations in a range of tropical forest soils. Soil Biology \& Biochemistry, v.20, n.3, p.361-367, 1988. 